Old Dominion University

ODU Digital Commons

Winter 2013

\title{
The Effect of Emotionally Arousing Negative Images on Judgments About News Stories
}

\author{
Martin Daniel Smith-Rodden \\ Old Dominion University
}

Follow this and additional works at: https://digitalcommons.odu.edu/psychology_etds

Part of the Cognitive Psychology Commons, Experimental Analysis of Behavior Commons, and the Mass Communication Commons

\section{Recommended Citation}

Smith-Rodden, Martin D.. "The Effect of Emotionally Arousing Negative Images on Judgments About News Stories" (2013). Doctor of Philosophy (PhD), Dissertation, Psychology, Old Dominion University, DOI: $10.25777 /$ rjtq-be87

https://digitalcommons.odu.edu/psychology_etds/170

This Dissertation is brought to you for free and open access by the Psychology at ODU Digital Commons. It has been accepted for inclusion in Psychology Theses \& Dissertations by an authorized administrator of ODU Digital Commons. For more information, please contact digitalcommons@odu.edu. 


\title{
THE EFFECT OF EMOTIONALLY AROUSING NEGATIVE \\ IMAGES ON JUDGMENTS ABOUT NEWS STORIES
}

\author{
by
}

\author{
Martin Daniel Smith-Rodden \\ M.S. December 2010, Old Dominion University
}

A Thesis Submitted to the Faculty of

Old Dominion University in Partial Fulfillment of the

Requirements for the Degree of

DOCTOR OF PHILOSOPHY

APPLIED EXPERIMENTAL PSYCHOLOGY

OLD DOMINION UNIVERSITY

December 2013

Approved by:

Ivan K. Ash (Director)

Barbara Winstead (Member)

Joe Cósco (Member) 


\title{
ABSTRACT \\ THE EFFECT OF EMOTIONALLY AROUSING NEGATIVE IMAGES ON JUDGMENTS ABOUT NEWS STORIES
}

\author{
Martin Daniel Smith-Rodden \\ Old Dominion University, 2013 \\ Director: Dr. Ivan K. Ash
}

Two experiments investigated the effects of the presentations of photographic images (highly emotionally arousing/low arousal /no image) on people's attitudes after reading a news story. Experiment 1 presented a story and images about U.S. involvement in the Afghanistan War. Experiment 2 replicated the design with a story and images about African famine relief efforts. Consistent with predictions of the affect heuristic model of judgment formation, the addition of emotionally arousing pictures had an effect on people's support for the war in Afghanistan and their support for famine aid. Additionally, effects were observed in broader attitudes concerning participant's support of a militaristic national policy. These results are discussed regarding their implications for theories of judgment formation and journalistic practice. 
This thesis is dedicated to Pam, Wilson and Katherine.

...with love to my amazing family - a dedication such as this is not nearly enough to celebrate what a blessing you are and how much you have supported me throughout this long journey.

And to the memory of my parents, Bernie and Katherine Rodden, who taught that accomplishment is always in my reach and who travel every moment with me, in my heart. 


\section{ACKNOWLEDGMENTS}

An acknowledgements section should not begin without offering appreciation to my committee members Drs. Barbara Winstead, Joe Cosco and chaired by Dr. Ivan K. Ash, my advisor. Special gratitude goes to Dr. Ash, whose patient guidance, mentoring and stewardship played a pivotal role in moving this work from an idea to reality.

This research couldn't have happened without support from my undergraduate assistants, who helped develop and deliver these experiments to hundreds of participants: Jessica Stinnette, my terrific lead assistant, as well as Ben Frey, Thomas Passarelli, my primary assistants, as well as Patrick Graessle, Sheila Gray, Chelsea Katz, and Colin McDowell. Special thanks to masters graduate student and lab partner Kimberley Lee and also Pamela Smith-Rodden for proofing and feedback on the manuscript.

My colleagues among The Virginian-Pilot's Photo Leadership team also played a large role in supporting this research, Randall Greenwell, Director, Bill Kelley, and The' Pham, my fellow photo editors. Special appreciation also goes to the rest of the photographers on the staggeringly brilliant photo staff: Brian Clark, Vicki Cronis-Nohe, Steve Earley, Rich Joseph Facun, Preston Gannaway, Stephen M. Katz, Hyunsoo Léo Kim, Amanda Lucier, The' Pham, L. Todd Spencer, Ross Taylor, and Bill Tiernan. I should extend my appreciation to the leadership of The Virginian-Pilot, who assisted not only with moral support but also with tuition assistance. Many thanks to Senior Editor Michele Vernon-Chesley, Managing Editor Maria Carrillo, Editor Denis Finley, and Publisher David Mele. Denis Finley also offered valuable consultation for my conclusions, which added focus and depth to the "implications for practitioners" section. 
University's College of Media \& Communication, and also his advisee, Natalia Mielczarek, a doctoral student and mass communications scholar at the University of Iowa, for an ongoing discussion concerning iconic imagery and the power of news photos. Thanks to Dr. Renee Martin-Kratzer for our early email discussions about the power of news imagery, as well as the measures for use in determining the emotional load of images. Also to venerable psychologist and decision researcher Dr. Paul Slovic, professor of psychology at the University of Oregon and the president of Decision Research: Dr. Slovic very kindly offered clarifying thoughts about the Affect Heuristic, as well as feedback, suggestions, and future directions.

Thanks to Ross Taylor, of the Pilot staff, for his photo, used in the Experiment 1 image pilot study. Also, grateful appreciation to my colleague Teresa Annas, for the loan of Goldberg's book "The Power of Photography." Many thanks also to Jim Collins, who consulted as a photo editor with the Associated Press, and submitted several images for consideration as use in visual stimuli early in the development of this research.

Heartfelt thanks to Peggy Kinard, Mary P. Boswell, and Linda D. Forchas of the in the office of the Old Dominion University psychology department for the countless assists all along the way - and also to Dr. Bryan Porter, the department's graduate program chair, for his mentorship and support throughout my time as a graduate student. Finally, so much appreciation for my mentors from Virginia Wesleyan College: Drs. Bill Gibson, Margaret Zimmerman, and the late Neil Ramsey - all of whom seemed to think I could pull off grad school, and helped convinced me to take the first steps on this lengthy journey. 
$\begin{array}{lll}2 & \text { Page }\end{array}$

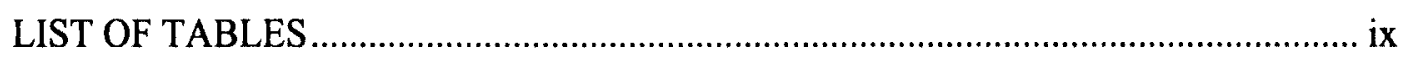

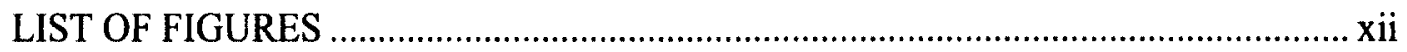

CHAPTER

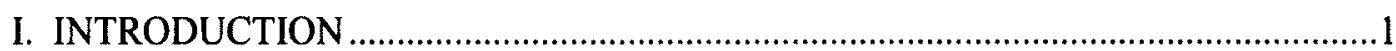

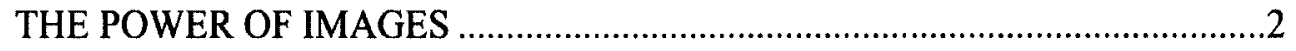

MAPPING THE PSYCHOLOGICAL EFFECTS OF NEWS IMAGES ................4

OVERVIEW OF EXPERIMENTAL MATERIALS AND DESIGN ..................10

PILOTS FOR EXPERIMENT 1: WAR IN AFGHANISTAN MATERIALS ......12

METHOD: PRESCREENING SURVEY FOR EXPERIMENT …......................12

METHOD: AFGHANISTAN IMAGES PILOT TESTING.................................25

METHOD: AFGHANISTAN TEXT PILOT TESTING .....................................37

II. EXPERIMENT 1: EFFECTS OF EMOTIONALLY AROUSING NEWS PICTURES

ON ATTITUDES ABOUT THE AFGHANISTAN WAR …......................................45

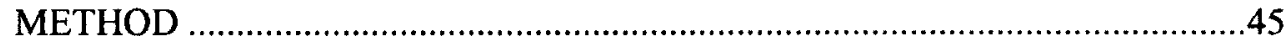

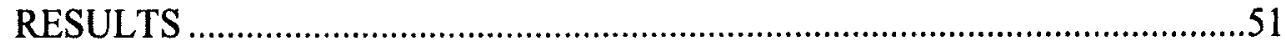

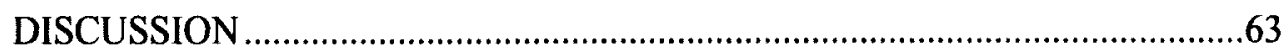

PILOTS FOR EXPERIMENT 2: AFRICAN FAMINE MATERIALS .................66

METHOD: FAMINE IMAGES PILOT TESTING...........................................66

METHOD: FAMINE TEXT PILOT TESTING ............................................. 74

METHOD: PRE-SCREENING SURVEY FOR EXPERIMENT 2 ....................76

III. EXPERIMENT 2: EFFECTS OF EMOTIONALLY AROUSING NEWS PICTURES ON ATTITUDES ABOUT THE AFRICAN FAMINE. ............................89

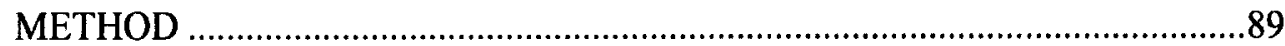

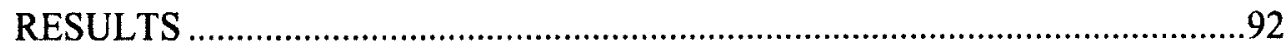

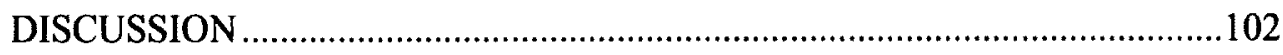

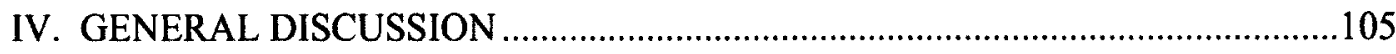

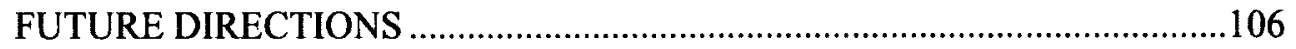

IMPLICATIONS FOR PRACTITIONERS AND GATEKEEPERS .................108

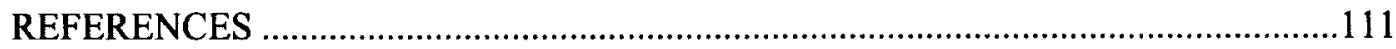

APPENDICES

A. RECRUITMENT TO THE PRE-SCREENING SURVEY .........................124

B. UNIVERSITY HUMAN SUBJECTS COMMITTEE ..................................125

C. THE RIGHT WING AUTHORITARIAN SCALE .....................................126 
D. SOCIAL DOMINANCE ORIENTATION SCALE .....................................128

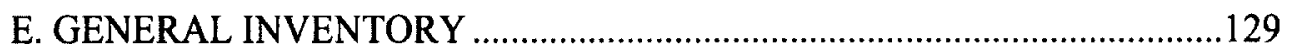

F. INFORMED CONSENT NOTIFICATION ................................................133

G. FINAL SURVEY PAGE AND ONLINE DEBRIEFING ...............................135

H. RECRUITMENT TO THE EXPERIMENT 1 PILOT STUDY ………............136

I. TRAINING VIDEO FOR PILOT TESTING ................................................137

J. STIMULI SET FOR THE PILOT STUDY: AFGHANISTAN IMAGES .......138

K. OLD DOMINION UNIVERSITY AGREEMENT TO PARTICPATE..........139

L. STUDY RECRUITMENT FOR TEXT PILOT .............................................141

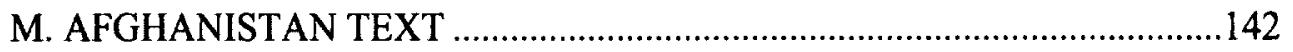

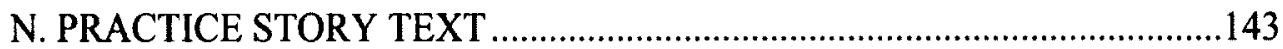

O. STUDY RECRUITMENT FOR EXPERIMENT 1 …………......................144

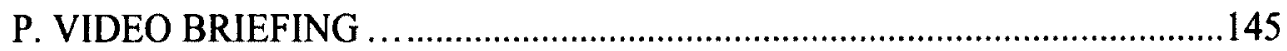

Q. GENERAL MILITARISTIC ATTITUDES ………………………….......146

R. OLD DOMINION UNIVERSITY AGREEMENT TO PARTICPATE..........147

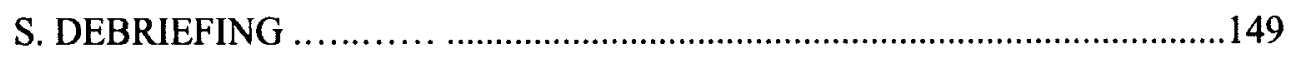

T. RECRUITMENT TO THE EXPERIMENT 2 PILOT STUDY........................150

U. STIMULI SET FOR THE FAMINE IMAGE PILOT STUDY .......................151

V. FAMINE RELIEF: AMERICANS FACE DIFFICULT CHOICES ...............152

W. RECRUITMENT TO EXPERIMENT 2 ………………………………......153

$X$. SCREEN INTERFACES FOR EXPERIMENT 2 PRE-SCREENING ...........154

Y. TRAINING VIDEO FOR PRESCREENING PROCEDURE …….................155

Z. ATTITUDES TOWARD CHARITABLE ORGANIZATIONS........................156

AA. ATTITUDES TOWARD HELPING OTHERS...........................................157

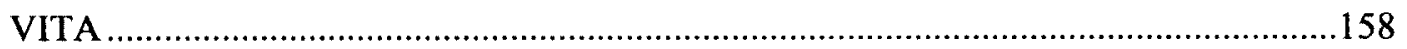




\section{LIST OF TABLES}

Table

Page

1. Prescreening Study for Experiment 1: Demographics on participants who completed the online procedure 13

2. Prescreen study Prescreening Study for Experiment 1: Frequency distribution of participants who completed pre-screening study by age

3. Prescreening Study for Experiment 1: Demographics on participants in prescreening who were invited to participate in experiment.

4. Prescreening Study for Experiment 1: Frequency distribution of participants invited to experiment by age. 20

5. Prescreen study: Frequency distribution of invitees to Experiment 1 by religion.

6. Prescreen study: Frequency distribution of participants invited to Experiment 1 by "How active are you in the practice of your religion?" 21

7. Prescreen study: Frequency distribution of invitees to Experiment 1 by political affiliation. 22

8. Descriptive Statistics of Dependent Variables in the General Inventory $(N=260)$.

9. Summary of correlations for Inventories in the Pre-screening study. .25

10. Summary of descriptive statistics for Afghanistan Pilot Image 1: Two amputee servicemen exercising. (AP Photo) 33

11. Summary of descriptive statistics for Afghanistan Pilot Image 2: Lightly wounded servicemen looking on inside helicopter (AP Photo).

12. Summary of descriptive statistics for Afghanistan Pilot Image 3: Soldiers and medics carrying a wounded serviceman in a field (AP Photo). 34

13. Summary of descriptive statistics for Afghanistan Pilot Image 3: Soldiers and medics carrying a wounded serviceman in a field (AP Photo). 34

14. Summary of descriptive statistics for Afghanistan Pilot Image 4: Group of servicemen amputees at a ceremony (AP Photo). 
15. Summary of descriptive statistics for Afghanistan Pilot Image 6: Badly wounded

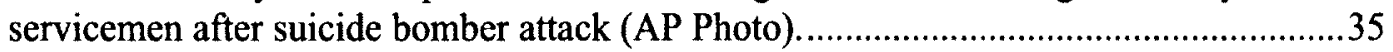

16. Summary of descriptive statistics for Afghanistan Pilot Image 7: Critically wounded servicemen in hospital with Purple Heart on chest (AP Photo) .........................36

17. Summary of descriptive statistics for participant responses in the text pilot for the Afghanistan "news story." 44

18. Summary of correlations for Pre-screening Inventories with DVs in Experiment 1. .53

19. Summary of descriptive statistics for participant responses Experiment 1 . .53

20. Summary of descriptive statistics for African Famine Pilot Image 1: Image of tents in a Somalia refugee camp during famine in late 2011. (AP Photo)......................68

21. Summary of descriptive statistics for African Famine Pilot Image 2: People gathered within a shelter in a Somalia refugee camp during famine in late 2011. (AP Photo)...

22. Summary of descriptive statistics for African Famine Pilot Image 3: Hundreds gathered and sitting outside in a Somalia refugee camp during famine in late 2011. (AP)

23. Summary of descriptive statistics for African Famine Pilot Image 4: Hundreds gathered outside in food lines in a Somalia refugee camp during famine in late 2011. (AP) .70

24. Summary of descriptive statistics for African Famine Pilot Image 5: Emaciated, crying baby held in a clinic at Somalia refugee camp during famine in late 2011. (AP).

25. Summary of descriptive statistics for African Famine Pilot Image 6: Emaciated, starving baby held in a clinic at Somalia refugee camp during famine in late 2011. (AP)

26. Summary of descriptive statistics for African Famine Pilot Image 7: Emaciated, starving baby staring into camera in a clinic at Somalia refugee camp during 2011 famine. (AP). .71

27. Summary of descriptive statistics for participant responses in the text pilot for the African Famine text. .76

28. Prescreening Study for Experiment 2: Demographics on participants who completed the pre-screening procedure. .78 
29. Prescreen study Prescreening Study for Experiment 2: Frequency distribution of participants who completed pre-screening study by age. .78

30. Prescreening Study for Experiment 2: Demographics on participants in prescreening who were retained for Experiment 2.

82

31. Prescreening Study for Experiment 2: Frequency distribution of participants who were retained for Experiment 2 .

32. Prescreen study for Experiment 2: Frequency distribution of participants who were retained for Experiment 2, by religion. .83

33. Prescreen study for Experiment 2: Frequency distribution by "How active are you in the practice of your religion?"

34. Prescreen study for Experiment 2: Frequency distribution of participants who were retained for Experiment 2, by political affiliation. .84

35. Prescreen study for Experiment 2: Descriptive Statistics of items in the General Inventory addressing topic of interest $(\mathrm{N}=151)$.

36. Summary of correlations for Inventories in the Pre-screening study for Experiment 2 . .88

37. Summary of correlations comparing possible covariates with DV's for

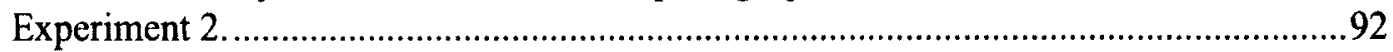

38. Summary of descriptive statistics for participant responses Experiment 2........93 


\section{LIST OF FIGURES}

Figure

Page

1. Blast Wall mural, Camp Spearhead, Kuwait, 2005.

.1

2. Distribution of Right Wing Authoritarianism scores among participants in the Prescreening study who were invited to participate in Experiment 1 .

3. Distribution of Social Dominance Orientation scores among participants in the Pre-screening study who were invited to participate in Experiment 1.

4. "The Self-Assessment Manikin (SAM) used to rate the affective dimensions of valence (top panel), arousal (middle panel), and dominance (bottom panel)"

5. Photo showing the mouse interface, with the response bar, layered on top of the SAM's Valence dimension. .28

6. Photo showing an example of image display showing the response bar, layered on top of a Likert scale continuum.

7. Example of display showing response bar with opposing responses. .30

8. Directions of mean emotional valence measures for images in Afghanistan pilot study, showing t-test results. 38

9. Directions of mean emotional arousal measures for images in Afghanistan pilot study.

10. Object Rotation directions. .42

11. Object Rotation task screen. .42

12. Experiment 1 paradigm. 46

13. Distribution of scores among participants Experiment 1 for dependent variables (all groups): Index for support of Afghanistan War. .56

14. Distribution of scores among participants Experiment 1 for dependent variable in all groups for General Militaristic Attitudes inventory. .57

15. Distribution of scores among participants by group for the index for support of Afghanistan War, the first dependent variable in Experiment 1. 
16. Distribution of scores of Experiment 1 participants by group for General Militaristic Attitudes inventory, the second dependent variable. ....................................58

17. Adjusted means for dependent variables in Experiment 1

18. Directions of mean emotional valence measures for images in African Famine

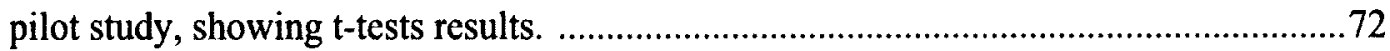

19. Means of emotional arousal for images in African Famine pilot study................73

20. Distribution of Right Wing Authoritarianism (RWA) scores from the Experiment

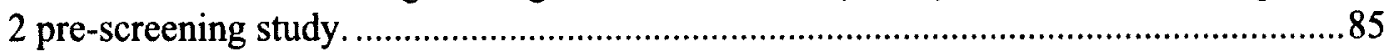

21. Distribution of Social Dominance Orientation (SDO) from the Experiment 2 prescreening study. .85

22. Distribution of scores from the Attitude toward Charitable Organizations (ACO), in the Experiment 2 pre-screening study. .86

23. Distribution of scores from the Support for Famine Aid Pretest (SFAP), in the Experiment 2 pre-screening study. .86

24. Score distribution in Experiment 2 for Index of Support for African Famine Aid. 96

25. Score distribution for Attitudes toward Helping Others. .96

26. Distribution of the Index of support for African Famine Aid scores by group for Experiment 2 .

27. Distribution of the Attitudes toward Helping Others, or AHO (DV2) scores by group for Experiment 2

28. Adjusted means for dependent variables in Experiment 2. 100 


\section{CHAPTER I}

\section{INTRODUCTION}

The horrific and well-documented spectacle from the terrorist attacks of

September 11,2001 played a significant role in altering the societal and political culture of the United States, with lasting changes in public perceptions of safety, security, and terror threats, (Breckenridge \& Zimbardo, 2007; Woods, 2011a) as well as shifts in national policy and strategy on civil liberties, and military priorities (Kellner, 2004). The news imagery from the " $9 / 11$ " attacks took on symbolic meanings (Figure 1), and played an important role in how the United States, both nationally and internationally, defined itself during its "war on terror" (Silberstein, 2002), now waged for more than a decade. The psychological effect and lasting memories of these iconic images on the national

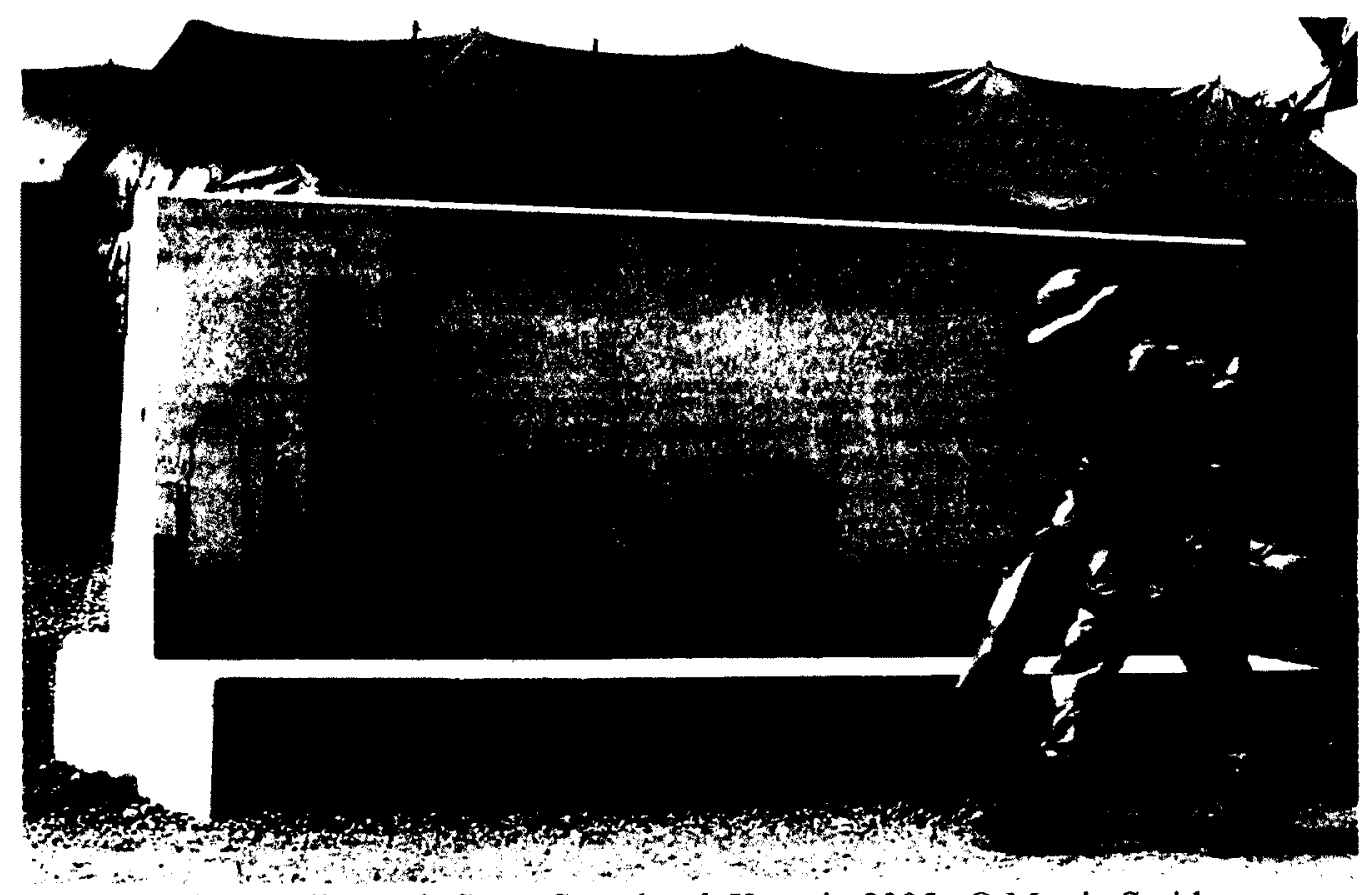

Figure 1: Blast Wall mural, Camp Spearhead, Kuwait, 2005. (C) Martin SmithRodden / The Virginian-Pilot

Journal of Applied Psychology was used as the journal model for this manuscript. 
psyche is said to motivate the political narrative, which helped define and motivate a historic shift of culture and policy (Hill \& Helmers, 2004; Zelizer, 2002). It is among the most recent - if not most dramatic - examples of such a media effect, driven in part by the influence of powerful news imagery on human decision-making. The purpose of these studies is to begin a line of empirical research to examine the influence of news images on human judgment formation.

\section{The Power of Images}

Psychologists define power as "the capacity to influence others, even when they try to resist this influence," (VandenBos, 2007, p. 718). It's often discussed and theorized among scholars in many fields that some news photos wield a certain "power." Historically, iconic images have been said to possess a quality of visual determinism, which has the power to sway the masses, change opinion and form policy - especially if these photographs constitute singularly vivid and emotionally-laden imagery that depict human struggles, suffering, death, or tragedy (Perlmutter, 1998). In The Republic, Plato warned of the effects of paintings (along with poems) on the political culture of ancient Greece, citing their ability to affect people's demeanors, opinions, and perceptions of reality and have the "power to corrupt all but a few very good people" (Plato \& Reeve, 2004, p. 310; see also: Domke, et al., 2002; Perlmutter, 1998, 2005). In her treatise entitled "Regarding the Suffering of Others," popular writer and cultural critic Susan Sontag says that "the iconography of suffering has a long pedigree," (Sontag, 2003, p. 40), observing that the early Christian art works that depicted the passion of Christ and grisly executions of Christian martyrs were classical examples of visual communication, with clear aims to inform, inspire, arouse or excite the masses (Sontag, 2003). 
Photographic war imagery dates back to the Crimean War and the American Civil War - a long history of images with the aim of bringing the horrors of war to those who have not experienced it (Perlmutter, 2001; Sontag, 2003). The imagery themes often depict gallant sacrifice and heroism of commanders and comrades who have gone to war, especially in the face of losses or mortality (Perlmutter, 2001). The experience of a "living room war" (Perlmutter, 2001, p. 175), literally brings home and familiarizes the readers or viewers with the sensations of war, while not placing them in harm's way. In 1861, Alexander Gardner, a photographer working for the Matthew Brady studio, captured stark images of sprawling bodies across the pastoral fields at Antietam, and thus introduced war's grim realities to far-off civilians in ways they were likely unequipped to imagine (Goldberg, 1991; Perlmutter, 2001). Newspaper images, etched from photographs of emaciated Union troops imprisoned in Andersonville, enraged the public and the ensuing outcry motivated the government to prosecute the prison official as a war criminal, sending a Confederate officer to the gallows (Goldberg, 1991). In addition to the earlier $9 / 11$ example, still images in modern times have been suggested as playing a role in facilitating a responsive public. Holocaust images helped sustain support of Allied efforts in World War 2 (Zelizer, 2002). News photography was said to play a part in swaying public opinion against the Vietnam War (Goldberg, 1991; Perlmutter, 1998, 2001) and U.S. military activity in Somalia, (Perlmutter, 1998, 2001), as well as motivating PR-conscious military leaders to hasten the close of the first Gulf War (Perlmutter, 2001, 2005). Recent presidential administrations even imposed strict prohibitions on news photos of flag-draped caskets, fearing that reminders of the costs of war would negatively impact public support for the war (Mueller, 2005). The vicarious 
experiences of a living-room war are said to play an important role in the decisionmaking of the voting public and policy makers, although the direct influence or "power" of such imagery is complex and difficult to conceptualize and measure, and may even be over-stated in some cases (Perlmutter, 2001).

Surprisingly, scholarly examinations of "powerful photos," with a few exceptions, have largely bypassed empirical researchers in psychology (Smith-Rodden \& Ash, 2012). Most discussions of the power of images tend to be macro-level and qualitative in their scope, as mass communication research in recent decades has edged toward qualitative research as the institutional methodology (Jensen \& Jankowski, 1991; Lindlof \& Taylor, 2011). Despite the considerable academic and political conjecture on the power of news images, the "conventional wisdom" and general presumptions that photos manifest some sort of influential power outweigh the empirical evidence (Domke, Perlmutter, \& Spratt, 2002). Whether influencing the masses of voting citizens, or only a handful of key policy makers, the effects of imagery on human judgment formation, decision-making and behavior are foundational to any understanding of broader media effects.

Applied experimental psychology can fill the empirical gaps by showing the ways that news images can influence human judgment formation and behaviors. Quantitative methods are uniquely able - and necessary - to inform the largely qualitative research and dialogue (Smith-Rodden \& Ash, 2012).

\section{Mapping the Psychological Effects of News Images}

If we are to track the cognitive process of influence following exposure to a news image, then the theoretical focus should be on human information processing: from perception to behavior and the decision-making processes in between. Roughly half of 
the human neo-cortex is involved in one way or another during visual processing, and as such, vision is considered a vitally important sense that engages resource-intensive mental processes (de Gelder, 2000; Hoffman, 1998; Sereno, et al., 1995). Since the visual system is a vigorous information processor, with strong connections to emotional and rational thought (Hoffman, 1998), it follows that exposure to news imagery as visual stimuli should have important roles and effects in human information processing. Information processing is a conceptual framework that outlines how information and mental representations (see Wyer, 2007) are modified within the brain, ultimately resulting in observable action in some manner of behavior, (Massaro \& Cowan, 1993). The components can be broken down, step by step, to very basic stages that are not unlike a computer: input mechanisms, central processing mechanisms (includes memory, conscious and unconscious processing, as well as judgment formation and decisionmaking), and the output, which can take the form of implicit and explicit judgments, decisions and actions (Broadbent, 1982). Of interest is how mental representations are handled within the attentional processes and working memory (WM) stores, nested in the central processing mechanisms (Cowan, 1988, 2010; Massaro \& Cowan, 1993). As a dedicated, highly adaptable and limited capacity system for the handling of information, the functions, abilities and capacity of WM are vital components to higher-order cognitive processes such as reasoning, comprehension, problem solving and judgment formation, as well as having broad implications to intelligence and development across a lifespan (Baddeley, 1992, 2003; Baddeley \& Andrade, 2000; Baddeley \& Hitch, 1974; Cowan, 2010; Engle, 2002; Kane, Poole, Tuholski, \& Engle, 2006; Michel-Kerjan \& 
Slovic, 2010). These finite central-processing mechanisms - and the decision-making strategies found within - are of interest to the research.

Decision-making strategies. Decision-making strategies handle mental representations during memory and attentional processing. For six decades, a robust and continually-developing line of research and theory shows scholars how judgment and decision making might operate in specific situations (Gilovich \& Griffin, 2010). Some of these recently developed decision-making models provide useful frameworks to view the effects of news images on judgment and decision-making outcomes.

The bounds of reason. The information processing system is described as a limited capacity system (Cowan, 2010). While humans do employ reason, human rationality has finite limits and boundaries. Simon (1955) coined the phrase "bounded rationality" to describe how humans make decisions (Gilovich \& Griffin, 2010; MichelKerjan \& Slovic, 2010; Simon, 1955, 1978). Because the theorized human information processing system is a limited system, there are confining bounds for the human attention and memory processing mechanisms. Therefore, whatever decision-making strategy the human mind uses within this limited space needs to operate efficiently, nimbly, and rapidly.

From early on, economics influenced descriptions of human decision-making. Microeconomic theorists and behavioral economists formed psychology's initial explanations of human behavior, describing sometimes elaborate and detailed mental processes, such as cost-benefit analysis, as models of human thought. Cost-benefit theorizes that humans engage in a thorough and comprehensive process to assess all or most costs and benefits in such a way as to maximize the former and minimize the later 
in a largely rational choice (Friedman, 1953; Gilovich \& Griffin, 2010; Larrick, Morgan, \& Nisbett, 1990; Larrick, Nisbett, \& Morgan, 1993; Michel-Kerjan \& Slovic, 2010; Simon, 1955, 1978).

Given the limited nature of human information processing, cost-benefit reasoning as a decision-making strategy seems an unlikely way to model human opinion and judgment formation. Humans are wholly incapable of the computational demands, knowledge of probabilities, and even the motivation to execute the calculations such strategies would require (Gilovich \& Griffin, 2010; Kahneman, 2003a, 2003b; MichelKerjan \& Slovic, 2010; Simon, 1955, 1978; Wargo, 2012). However, the cost-benefit model persistently enjoys some popularity and support in explanations of people's decision-making. One example is the public's support for war.

At the time of this research, the United States military faced an increasingly volatile situation in Afghanistan, during the 2012 election year. The risks in continued U.S. involvement versus withdrawal was the topic for much discussion and debate. Since the Vietnam War, cost-benefit models have been used to describe people's support for war as they respond to news about the conflict, especially concerning casualties (Althaus, et al., 2008; Eichenberg, 2005; Gartner, 2008; Larson \& Rand Corporation., 1996; Larson \& Savych, 2005; Mueller, 1971, 1973, 2005). Scholars have used cost-benefit to explain a stable statistical relationship between ebbing-support for war and increasing casualties. Specifically, they describe initial popular and euphoric support for the war - a "Rally around the flag" phenomenon - followed by a sense of disillusionment as the war's casualties rise (Mueller, 2005). 
If speculations like the cost-benefit models are problematic and implausible theories of human reasoning, then it invites the question of what is a more plausible decision model - especially when it comes to understanding how news imagery may influence levels of support for military action.

The Affect Heuristic. Heuristics have been presented as a strategy to describe how a human mind makes fast and frugal decisions (Gigerenzer \& Goldstein, 1996; Gigerenzer \& Todd, 1999; Gigerenzer, Todd, \& ABC Research Group., 1999; Kahneman, 2003a; Tversky \& Kahneman, 1992). Well known among psychologists, heuristic models describe mental rules and shortcuts, which often lead to sound decisions, yet can also contribute to errors and biases due to faulty processing of information (Gilovich \& Griffin, 2010; Tversky \& Kahneman, 1992).

With regard to the previously-mentioned question about public support for war, the affect heuristic (Loewenstein, Weber, Hsee, \& Welch, 2001; Slovic, Finucane, Peters, \& MacGregor, 2002; Slovic \& Peters, 2006; Slovic \& Västfjäll, 2010) may present a more probable explanation for a parsimonious decision process. The affect heuristic involves a reliance on the subjective and immediate good/bad (or approach/avoidance) feelings (Loewenstein, et al., 2001; Slovic, et al., 2002; Slovic \& Västfjäll, 2010) with regard to emotionally activating stimuli. Ultimately these emotional responses drive various judgments, decisions, and valuation, leading people into either approach or avoidance responses. In a relatively short time, there has been a substantial line of research on the affect heuristic, where it has been especially useful in theorizing about human risk perception (Finucane, Alhakami, Slovic, \& Johnson, 2000; Slovic, 2004). For instance, research has implicated the affect heuristic as a mechanism for people's 
negative attitudes about nuclear power, concern over electro-magnetic field hazards, (Siegrist, Keller, \& Cousin, 2006), attraction toward small wagering (Bateman, Dent, Peters, Slovic, \& Starmer, 2007), attitudes about air pollution via wood burning (Hine, Marks, Nachreiner, Gifford, \& Heath, 2007) and toxicology (Slovic, 2004). Although little research ties this specific heuristic to feelings about war, this relatively recently developed construct has been tied to perceptions and responses to terrorist threats (Breckenridge \& Zimbardo, 2007; Breckenridge, Zimbardo, \& Sweeton, 2010; Mandel, 2011; Woods, 2011b). Furthermore, the previously described patterns of diminishing public support concerning war as casualties mount appear to be consistent with the fundamental assumptions of the affect heuristic.

With regard to emotion and news imagery, the influential effects of emotionallypowerful and "iconic" photos has received a great deal of scholarly attention and discussion, especially among visual communication theorists (Perlmutter, 1998, 2001). Perlmutter (1998) coined the term "icons of outrage" - the influential news images that were attention grabbing, evocative, repeatedly viewed, well-recognized, and highlypublished. Visual communication scholars consider such news photos to be a rare set of ubiquitous images, which enjoy some "fame" and achieve a certain level of ascribed power regarding their ability to sway or influence people (Perlmutter, 1998).

Several diverse characteristics surface when discussing what defines an iconic image, ranging from familiarity, to frequency of publication, perceived-importance of subject matter, striking composition, among other factors (Perlmutter, 1998). Such a complex array of factors makes it difficult to operationally define an iconic news photo with any firm conceptual validity, which is necessary for a strong empirical study on 
what gives iconic images their "power." Yet, a foundational assumption is that "powerful" iconic images contain some type of striking and emotionally-stirring content (Perlmutter, 1998). As a highly plausible, yet still developing, cognitive construct for understanding judgment formation, the affect heuristic may provide a useful framework to examine the influence of news imagery, stirring the mind's emotions in such a way as to make a photo somehow powerful.

\section{Overview of Experimental Materials and Design}

This research began as an examination of influential or "powerful" news images, and also the role that the affect heuristic might play. As a timely and politically important topic in current news content, public support for the war in Afghanistan served as a useful subject area to begin this examination.

Even though the media is currently focused on the Afghanistan War, a meaningful line of empirical research into the effects of news images should not be confined to this single domain. It's important for science to generalize across circumstances and situations. Accordingly, another domain where powerful images of human tragedy may influence people, the news coverage of famine, was chosen (Dogra, 2007; Plewes \& Stuart, 2007; Radley \& Kennedy, 1997). At the time of this research, the Horn of Africa was suffering a deadly famine for a second consecutive year, with agencies describing the situation and continuing pathos as "grave" and a "deepening emergency," in which the world's developed nations are said to have under-responded (AP, 2012; OXFAM, 2012;

UNICEF, 2012). So, influencing effects of news imagery of famine provided a timely and useful topic of study for the second experiment. 
A number of research questions were put forward for empirical testing. The first and obvious question: Do news photos influence judgment? Participants were exposed to images, with an accompanying text in a format consistent with print and online journalism mediums. The independent variable (IV) was the image presentations, manipulated by the level of emotional arousal of the image (high and low), while using a third no-photo control group. After exposure to the "news material," any between-groups differences in relevant judgments were observed, as our dependent variable (DV).

Based on the affect heuristic model, it was first hypothesized $\left(\mathrm{H}_{1}\right)$ that participants who were exposed to news images in a conventional media presentation (i.e., a combination of a story with a photo) would show a change in judgments regarding content-relevant topics when compared to those who were not exposed to news images decreased support for the war and increased support for famine aid. Secondly, it was expected these effects of influence were driven by the degree of emotional arousal, resulting from the content of the news images. Therefore, after seeing highly emotionally arousing images, we predicted $\left(\mathrm{H}_{2}\right)$ higher levels of influence in post-exposure measures of judgment, following the same pattern predicted in $\mathrm{H}_{1}$ (i.e., decreased support for the war and increased support for famine aid), when compared to exposure to low-arousal images (high-arousal>low-arousal), and $\left(\mathrm{H}_{3}\right)$ also for no image groups (high-arousal>no image).

Certain exploratory measures were administered as part of these experiments. Items were included to explore the participant's perceptions of slant or bias in the "news stories" that they read, as well as self-report items on whether they felt influenced by the text. An open memory inventory also was used to examine the amount of material 
recalled by the participants to look for differences across groups in story comprehension. No hypotheses were put forward for any of the exploratory measures.

\section{Pilots for Experiment 1: War in Afghanistan Materials}

Experiment 1 focused on judgment effects following exposure to images of the Afghanistan War. Some preliminary work "set the stage" for this experiment. First, we will present the methods and results from a pre-screening survey that was conducted to measure participants pre-existing attitudes about the war in Afghanistan and test potential covariates. Second, we will present methods and results from a pilot study designed to measure and select emotionally arousing war images for use in the main experiment. Third, we will present the methods and results of a pilot study designed to develop and test the influence of the base news story text on participant's attitudes. Fourth, we will present the methods and results from Experiment 1.

\section{Method: Prescreening Survey for Experiment 1}

A well-focused analysis of judgment effects should control unwanted variables, confounds and "noise." So, an important issue for any study of decision-making effects is to identify and control for appropriate individual differences among participants, (Bröder, 2002). Inventories were administered to participants in pre-experimental sessions for consideration as covariates. Additionally, in these pre-experimental sessions, researchers have an opportunity to screen participants who experienced direct personal involvement

or loss with regard to the war in Afghanistan, to avoid the possibility of emotional trauma during the experiment (e.g., Afghanistan War vets and widows will not be exposed to graphic imagery depicting war casualties). 
Participants. Participants were recruited to the pre-screening survey (see Appendix A) from the pool of undergraduate students at Old Dominion University $(N=$ 483). Volunteers were at least 18 years old (demographics in Tables 1 and 2), restricted to U.S. citizens, and received class credit in exchange for online research participation. The ethical guidelines of the American Psychological Association (A.P.A., 2002) were followed throughout these procedures. This research received exemption from the university's College of Science Human Subjects Committee (Appendix B).

Table 1

Prescreening Study for Experiment 1: Demographics on participants who completed the online procedure.

\begin{tabular}{lcccccc}
\hline & \multicolumn{2}{c}{ Gender } & & \multicolumn{3}{c}{ Age } \\
\cline { 2 - 3 } \cline { 5 - 7 } & $N$ & $\%$ & & $M$ & $S D$ & Min/Max \\
\hline Male & 155 & 32.1 & 21.63 & 5.72 & $18 / 50$ \\
Female & 328 & 67.9 & 21.50 & 5.62 & $18 / 57$ \\
& 483 & & & 21.50 & 5.65 & $18 / 57$
\end{tabular}


Table 2

Prescreen study Prescreening Study for Experiment 1: Frequency distribution of participants who completed pre-

screening study by age

\begin{tabular}{|c|c|c|}
\hline & Frequency & Percent \\
\hline 18 & 112 & 23.2 \\
\hline 19 & 89 & 18.4 \\
\hline 20 & 81 & 16.8 \\
\hline 21 & 65 & 13.5 \\
\hline 22 & 49 & 10.1 \\
\hline 23 & 19 & 3.9 \\
\hline 24 & 12 & 2.5 \\
\hline 25 & 4 & .8 \\
\hline 26 & 4 & .8 \\
\hline 27 & 8 & 1.7 \\
\hline 28 & 6 & 1.2 \\
\hline 29 & 4 & .8 \\
\hline 30 & 1 & .2 \\
\hline 31 & 4 & .8 \\
\hline 32 & 3 & .6 \\
\hline 33 & 1 & .2 \\
\hline 34 & 2 & .4 \\
\hline 35 & 1 & .2 \\
\hline 36 & 1 & .2 \\
\hline 37 & 1 & .2 \\
\hline 40 & 1 & .2 \\
\hline 41 & 1 & .2 \\
\hline 42 & 1 & .2 \\
\hline 43 & 2 & .4 \\
\hline 45 & 2 & .4 \\
\hline 46 & 1 & .2 \\
\hline 47 & 2 & .4 \\
\hline 48 & 1 & .2 \\
\hline 49 & 2 & .4 \\
\hline 50 & 1 & .2 \\
\hline 54 & 1 & .2 \\
\hline \multirow[t]{2}{*}{57} & 1 & .2 \\
\hline & 483 & 100 \\
\hline
\end{tabular}


Materials. The pre-screening survey was built and administered on a university website, using Inquisite ${ }^{\top M}$ survey building software (Version 9).

Right Wing Authoritarianism. Regarding an individual's support for war, scholars have identified two contemporary inventories that show high predictive validity across years of study: Right Wing Authoritarianism (RWA) and also the Social Dominance Orientation (SDO) (Altemeyer, 1998; Crowson, 2009a, 2009b; Heaven, Organ, Supavadeeprasit, \& Leeson, 2006; Pratto, Sidanius, Stallworth, \& Malle, 1994). The RWA (see Appendix C) is a measure of individual differences with a focus on conventionality and nationalism, as well as the observance of and devotion to societal norms, administered in a 20 item inventory (Altemeyer, 1998). The RWO offers respondents 22 questions. The first two questions are table-setters or warm up items to help familiarize the respondent with the topic and the -4 to +4 Likert format, and are not scored (Altemeyer, 1998, 2006). The inventory polls the respondents' level of agreement in 9-point Likert scale responses to certain statements of dogmatic belief (e.g., "God's laws about abortion, pornography, and marriage must be strictly followed before it is too late, and those who break them must be strongly punished;" "The 'old-fashioned ways' and 'old-fashioned values' still show the best way to live"). Ten items are reverse-scored statements of broadmindedness (e.g., "There is no 'ONE right way' to live life; everybody has to create their own way"; "There is absolutely nothing wrong with nudist camps.”). The RWA has seen robust use since its inception in 1981 and its most recent revision (Altemeyer, 2006), and has been generally considered reliable as a measure, with Cronbach's alpha reported at .92 (Altemeyer, 1998). During analysis for this research, the 
Cronbach's alpha for RWA among the full sample of pre-screening respondents showed was .90 .

Convergent validity for RWA is also strongly correlated with other constructs, such as indices measuring conformity $(r=.40)$, traditionalism $(r=.51)$, religious fundamentalism ( $r=.77)$, feelings of a dangerous world $(r=.49)$, self-righteousness $(r=$ $.63)$, and a composite index of prejudiced and patriotic attitudes $(r=.51)$, (Altemeyer, 1998). Most importantly, the RWA has been shown to strongly correlate with $(r=66)$ and predict $(\beta=.64, p<.01)$ attitudes supportive of the restrictions of civil liberties and human rights in pursuit of the war on terror, as well as military action in Iraq (Crowson, 2009b; Crowson, DeBacker, \& Thoma, 2005). Crowson also found that the RWA accounted for $28 \%$ of the variance for people's support for the Iraq War (Crowson, et al,, 2005). Researchers also linked the RWA with support for Anti-Arab Aggression $(r=.32)$ which included military action in Afghanistan and aggressive pursuit of the war on terror (Henry, Sidanius, Levin, \& Pratto, 2005).

Social Dominance Orientation. The SDO (Appendix D) is a 16-item inventory measuring beliefs of ingroup dominance and the protection of stratified social systems. Respondents are measured using 7-point Likert items regarding their positive or negative feelings to statements following a theme concerning social hierarchies (e.g., "Some groups of people are simply not the equals of others"; "To get ahead in life, it is sometimes necessary to step on others") and also with six other items of egalitarian statements being reversed scored (e.g., "In an ideal world, all nations would be equal"; "Increased economic equality"). The SDO has been a frequently used socialpsychological measure of individual differences (Altemeyer, 1998). In the prescreening 
study, the reliability analysis using the full sample exceeded those expectations, with Cronbach's alpha for the items at .95 , indicating very high reliability.

The SDO also shows convergent validity as it is strongly correlated with other related constructs including indices measuring power $(r=.43)$, ethnocentrism $(r=.58)$, as well as a composite index of prejudiced and patriotic attitudes $(r=.59$, Altemeyer, 1998). The SDO also strongly correlates with attitudes of support regarding the war on terror $(r=.38)$ (Crowson, 2009b). It was expected that use of the SDO as a covariate would be an effective way to reduce unwanted variance.

General inventory and judgment-domain questions. The final section of the prescreening procedure was a general inventory (Appendix E), which contained items to establish baseline tendencies among participants. Subjects responded to items pertaining to the dependent variables using a 9-point Likert format. A reliable (Cronbach's alpha $=$ 92) pre-test war support index was created by averaging the responses to the two items measuring explicit support and (reverse-coded) opposition to the war (e.g., I support the current war in Afghanistan; I am against the current war in Afghanistan).

Exclusionary screening questions. Several other questions on the final survey page served as exclusionary screening items. Five items on the final survey page were designed to screen-out participants who have had unusual personal experiences, or have suffered personal loss related to the judgment domain of interest (e.g., "Are you now or have you previously served in the Armed Forces?"; "Have you lost a family member, spouse or very close friend in the war in Afghanistan?"). Participants who answered "yes" were excluded from further study in light of ethical concerns of not causing them emotional trauma during the procedure. 
In the interest of ethical recruitment into the first experiment, pre-screening participants also had an opportunity to "opt out" of being invited into the laboratory study. A single item on the online survey was a check box labeled: "Yes, l'm interested in receiving invitations through the SONA system to upcoming on-site studies for Project Reactions." Participants who left the box unchecked were neither invited into the image pilot study, nor Experiment 1.

Two items were intended as screening devices for inattentive or unreliable respondents (e.g., "I am paying attention to the questions on this survey," "Please select 'Moderately Agree' for this item.”). Eight distracter items were also intermixed among the screening questions (e.g.: "I am optimistic about the state of the world"; "One year after the fall of Hosni Mubarak, Egypt is better off."). These items were not intended for analysis in this study, yet followed the general themes found among the items in the survey.

Finally, given that the experimental procedures include the presentation of full color (RGB) images, one last exclusionary item inquired if the participant is diagnosed as or had reason to believe that they are colorblind. Those who self-reported as being colorblind were excluded, as they would not experience the visual stimuli as would most people.

Procedure. In an online survey accessed through the university student participant system, participants viewed a page notifying the volunteers of their informed consent (Appendix F). After consenting to the terms, they proceeded to the survey's webpages. First, they responded to a short list of basic demographic questions (e.g., gender, age, experience with English, religion and political affiliation). Then, they moved 
on to respond to the separate inventories. The three inventories were the RWA, the SDO, and the general inventory. After responding to all pages of the inventories and screening items, they were debriefed in a final webpage (Appendix G).

Results. The exclusionary items were examined to make a determination of who among the 483 participants that completed the study would be invited to the first experiment. Of those respondents, 12 participants (2\%) self-reported as colorblind. After that, 59 participants $(12 \%)$ who responded to "Please select 'Moderately agree' for this item" did not choose "moderately agree." Eleven participants (2\%) responded either neutrally or negatively to the statement "I am paying attention to the questions in this survey." Thirty-nine participants (8\%) were excluded from Experiment 1, when they responded to "Are you now or have you previously served in the armed forces?" - with 34 responding "yes" and five leaving missing data on that item. Nineteen respondents (4\%) were excluded because they had either lost a family member, loved one or close friend in Afghanistan. Seven participants (1\%) were excluded from recruitment into the lab study because they reported losing a family member, loved one or close friend in the attacks of September 11, 2001, or in the "War on Terror." Seventy-two participants (15\%) opted out of being contacted, by un-checking the box that gave permission to be contacted and invited into the later experiments. Finally, 4 participants $(1 \%)$ left either incorrect SONA numbers or left the numbers missing on the survey.

In summary, of the original 483 participants who completed the survey, 223 participants $(46 \%)$ were screened from being invited to the first experiment, which left 260 participants to be invited to the primary experiments. The remaining discussion of the pre-screening results will address this sample $(N=260$, demographics in Tables 3-7). 
Table 3

Prescreening Study for Experiment 1: Demographics on participants in prescreening who were invited to participate in experiment.

\begin{tabular}{lcccccc}
\hline & \multicolumn{2}{c}{ Gender } & & \multicolumn{3}{c}{ Age } \\
\cline { 2 - 3 } \cline { 5 - 7 } & $N$ & $\%$ & & $M$ & $S D$ & Min/Max \\
\hline Male & 76 & 29.2 & 20.63 & 4.08 & $18 / 49$ \\
Female & 184 & 70.8 & 20.84 & 4.30 & $18 / 47$ \\
Total & 260 & 100 & 20.78 & 4.23 & $18 / 49$
\end{tabular}

Table 4

Prescreening Study for Experiment 1: Frequency distribution of participants invited to experiment by age

\begin{tabular}{rrr}
\hline & Frequency & Percent \\
\hline 18 & 65 & 25 \\
19 & 51 & 19.6 \\
20 & 45 & 17.3 \\
21 & 32 & 12.3 \\
22 & 33 & 12.7 \\
23 & 12 & 4.6 \\
24 & 3 & 1.2 \\
25 & 3 & 1.2 \\
26 & 2 & .8 \\
27 & 1 & .4 \\
28 & 2 & .8 \\
29 & 3 & 1.2 \\
30 & 1 & .4 \\
32 & 2 & .8 \\
42 & 1 & .4 \\
43 & 1 & .4 \\
45 & 1 & .4 \\
47 & 1 & .4 \\
49 & 1 & .4 \\
& 260 & 100
\end{tabular}


Table 5

Prescreen study: Frequency distribution of invitees to Experiment I by religion.

\begin{tabular}{|c|c|c|}
\hline & Frequency & Percent \\
\hline Protestant & 60 & 23.1 \\
\hline Catholic & 47 & 18.1 \\
\hline Jewish & 2 & .8 \\
\hline Mormon / LDS & 1 & .4 \\
\hline Islam & 1 & .4 \\
\hline Hindu & 1 & .4 \\
\hline Other & 80 & 30.8 \\
\hline $\begin{array}{l}\text { No preference / No religious } \\
\text { affiliation }\end{array}$ & 53 & 20.4 \\
\hline Would rather not say & 15 & 5.8 \\
\hline Total & 260 & 100.0 \\
\hline
\end{tabular}

Table 6

Prescreen study: Frequency distribution of participants invited to Experiment 1 by "How active are you in the practice of your religion?"

\begin{tabular}{lll}
\hline & Frequency & Percent \\
\hline Very active & 48 & 18.5 \\
Somewhat active & 92 & 35.4 \\
Not very active & 48 & 18.5 \\
Not active & 29 & 11.2 \\
Does not apply & 38 & 14.6 \\
Would prefer not to say & 5 & 1.9 \\
Total & 260 & 100.0
\end{tabular}


Table 7

Prescreen study: Frequency distribution of invitees to Experiment I by political affiliation.

\begin{tabular}{lll}
\hline & Frequency & Percent \\
\hline Conservative & 50 & 19.2 \\
Independent & 36 & 13.8 \\
Liberal & 84 & 32.3 \\
Libertarian & 12 & 4.6 \\
Moderate & 30 & 11.5 \\
Tea Party & 1 & .4 \\
None of the above & 46 & 17.7 \\
No response/missing data & 1 & .4 \\
& 260 & 100
\end{tabular}

$\boldsymbol{R} \boldsymbol{W} \boldsymbol{A}$ and SDO. Both the RWA and the SDO produced summed index scores.

Scores from each item of the 9-point Likert scale responses on the RWA (ranging from 1 to 9) were totaled. The range of the RWA is between 20 and 180, with higher scores indicating higher levels of authoritarian traits. Respondents who were invited to Experiment 1 trended toward neutrality in their responses, and a normal distribution was observed $(M=81.78, S D=25.07$, histogram in Figure 2).

Similarly, the SDO is scored by totaling the responses from the 7-point Likert scale items (ranging 1 to 7 ) to create an index score that has a range of 14 to 98 , with higher scores indicating a greater level of the social dominance trait (Altemeyer, 1998; Pratto, et al., 1994). Respondents indicated an overall neutral pattern in their responses, $(M=34.04, S D=13.10$, histogram in Figure 3). 


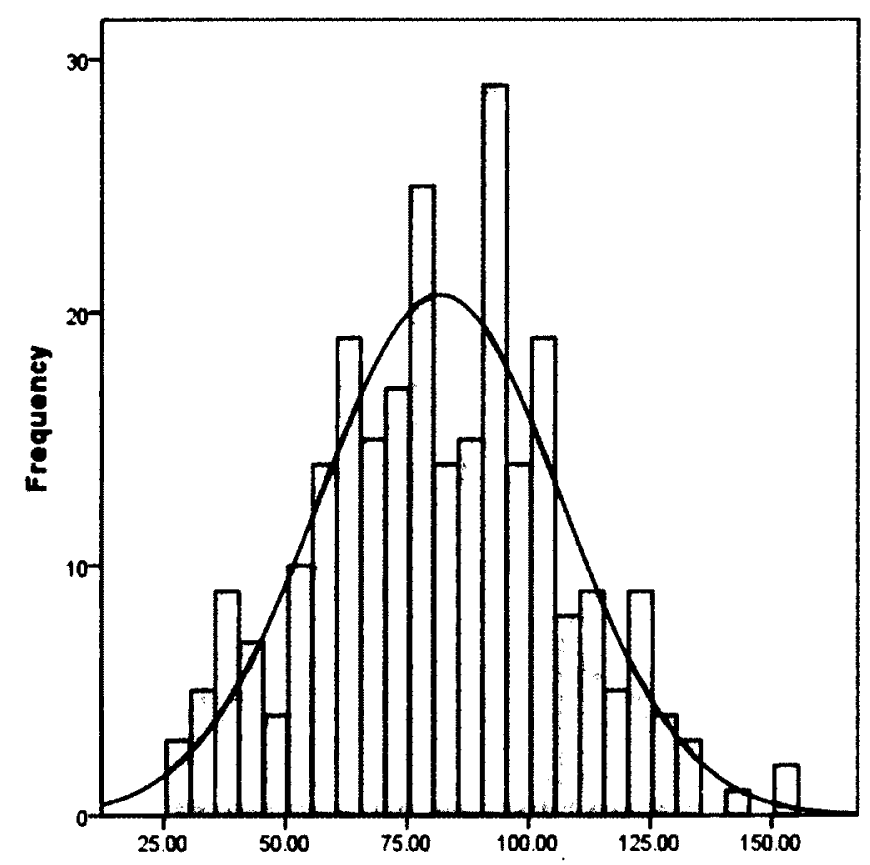

Figure 2. Distribution of Right Wing Authoritarianism scores among participants in the Pre-screening study who were invited to participate in Experiment 1.

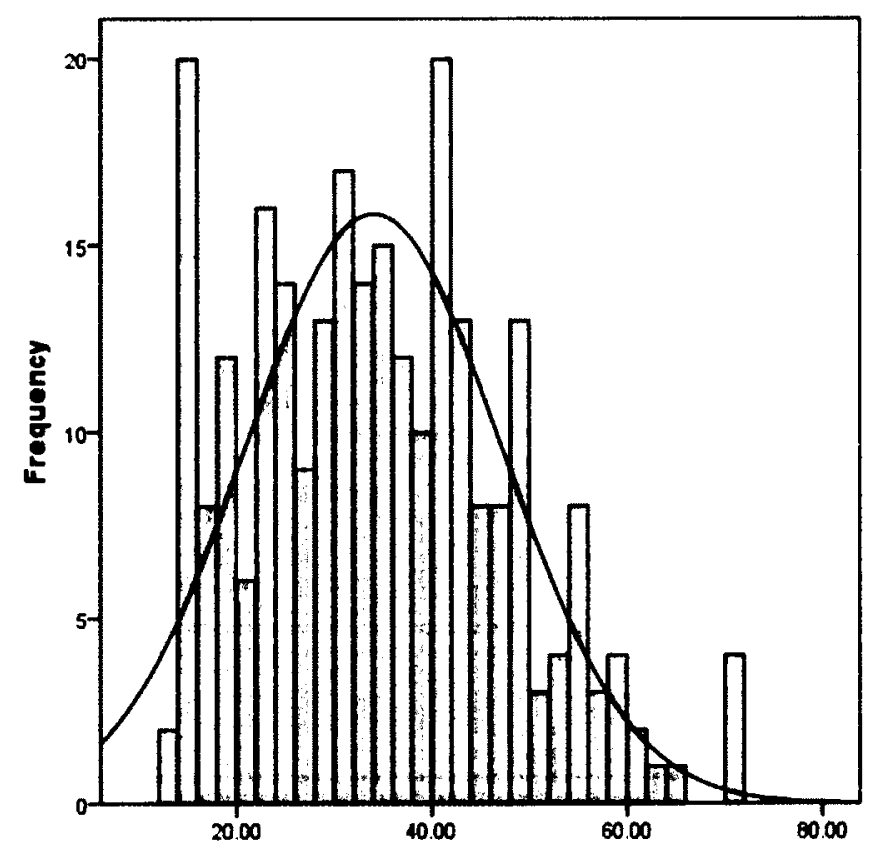

Figure 3. Distribution of Social Dominance Orientation scores among participants in the Pre-screening study who were invited to participate in Experiment 1. 
General Inventory. Responses to general inventory items addressing the variables of interest (i.e., support of U.S. involvement in the Afghanistan War) were tabulated for the pre-screening participants eligible for study invitations, with the narrow and broad support indexes calculated as previously discussed. The data showed strong central tendencies, acceptable levels of kurtosis, minimal skewness, and good reliability measures (see descriptive statistics in Table 8). Support for the war was very strongly correlated with both the RWA and SDO inventories for these participants, with all $p$ 's $<$ .01 (Table 9). The results suggest that the RWA and the SDO might be good choices for use as covariates in the analysis.

Table 8

Descriptive Statistics of Dependent Variables in the General Inventory $(N=260)$.

\begin{tabular}{|c|c|c|c|c|}
\hline & $M$ & $S D$ & Kurtosis & Skew \\
\hline $\begin{array}{l}\text { "I support the current war in } \\
\text { Afghanistan." }\end{array}$ & 3.87 & 1.98 & -.30 & .41 \\
\hline $\begin{array}{l}\text { "I am against the current war in } \\
\text { Afghanistan." (Reverse coded) } \\
\text { "America should send more troops }\end{array}$ & 4.19 & 2.03 & -.05 & -.50 \\
\hline $\begin{array}{l}\text { to Afghanistan in order to defeat the } \\
\text { terrorists." }\end{array}$ & 3.43 & 1.70 & -.43 & .27 \\
\hline $\begin{array}{l}\text { "America should hasten to remove } \\
\text { troops from Afghanistan." } \\
\text { (Reverse coded) }\end{array}$ & 4.19 & 1.56 & 1.05 & -.56 \\
\hline $\begin{array}{l}\text { General Support of Afghanistan } \\
\text { War (centered, 2-item index) }\end{array}$ & -0.97 & 1.86 & -.15 & .34 \\
\hline
\end{tabular}


Table 9

Summary of correlations for Inventories in the Pre-screening study.

\begin{tabular}{|c|c|c|c|c|}
\hline Measure & 1 & 2 & 3 & 4 \\
\hline 1. RWA & -- & $.38^{* *}$ & $.16^{* *}$ & $.15^{* *}$ \\
\hline 2. SDO & & $\cdots$ & $.30 * *$ & $.28 * *$ \\
\hline $\begin{array}{l}\text { 3. General Support of } \\
\text { Afghanistan War } 1 \\
\text { (centered narrow index) }\end{array}$ & & & -- & $.98^{* *}$ \\
\hline $\begin{array}{l}\text { 4. General Support of } \\
\text { Afghanistan War } 2 \\
\text { (centered, broad index) }\end{array}$ & & & & --- \\
\hline \multicolumn{5}{|c|}{$\begin{array}{l}\text { Note. } N=260 . \text { RWA }=\text { Right Wing Inventory; } \mathrm{SDO}=\text { Social Dominance Orientation; General } \\
\text { Support of Afghanistan War } 1=2 \text { item index; General Support of Afghanistan War } 2=4 \text { item } \\
\text { broader index. } \\
* * p<.01\end{array}$} \\
\hline
\end{tabular}

\section{Method: Afghanistan Images Pilot Testing}

It was important to use images that were good examples of negative images of both high and low emotional arousal. Pre-experimental pilot tests measured the direction of valence and degree of emotional arousal from the images to be used in the procedure.

Participants. Volunteers $(N=15)$ who completed the pre-screening procedure were recruited to the pilot study through invitations via the SONA Research participation system, (Appendix H), volunteering in exchange for class research credit. Participants who answered affirmatively to exclusionary screening questions in the pre-screening procedure were excluded. Two of the participants were male and 13 were female. Their ages ranged from 18 to 47 , with eight participants (53.3\%) between 18 and 20 , six participants (40\%) between 21 and 28, and one 47 year-old participant (6.7\%). All spoke English as their first language.

Materials. The procedure used a computer-administered experimental program. An interactive procedure with presentations of image and text, response logging as well 
as any additional questionnaires was created using E-Prime experimental programming software (Schneider, Eschman, \& Zuccolotto, 2002a, 2002b) and was administered using a series of computers (PCs) within a university computer lab.

Training video. A short video, (running time: 5:49), was produced to professional standards, using Final Cut Pro software and a Canon EOS 7D camera system, to introduce participants to the various unique interfaces used in the procedure, e.g., the response bar, scales of emotional measurement, and the object rotation task (see Appendix I for an online link to this video, and screengrabs).
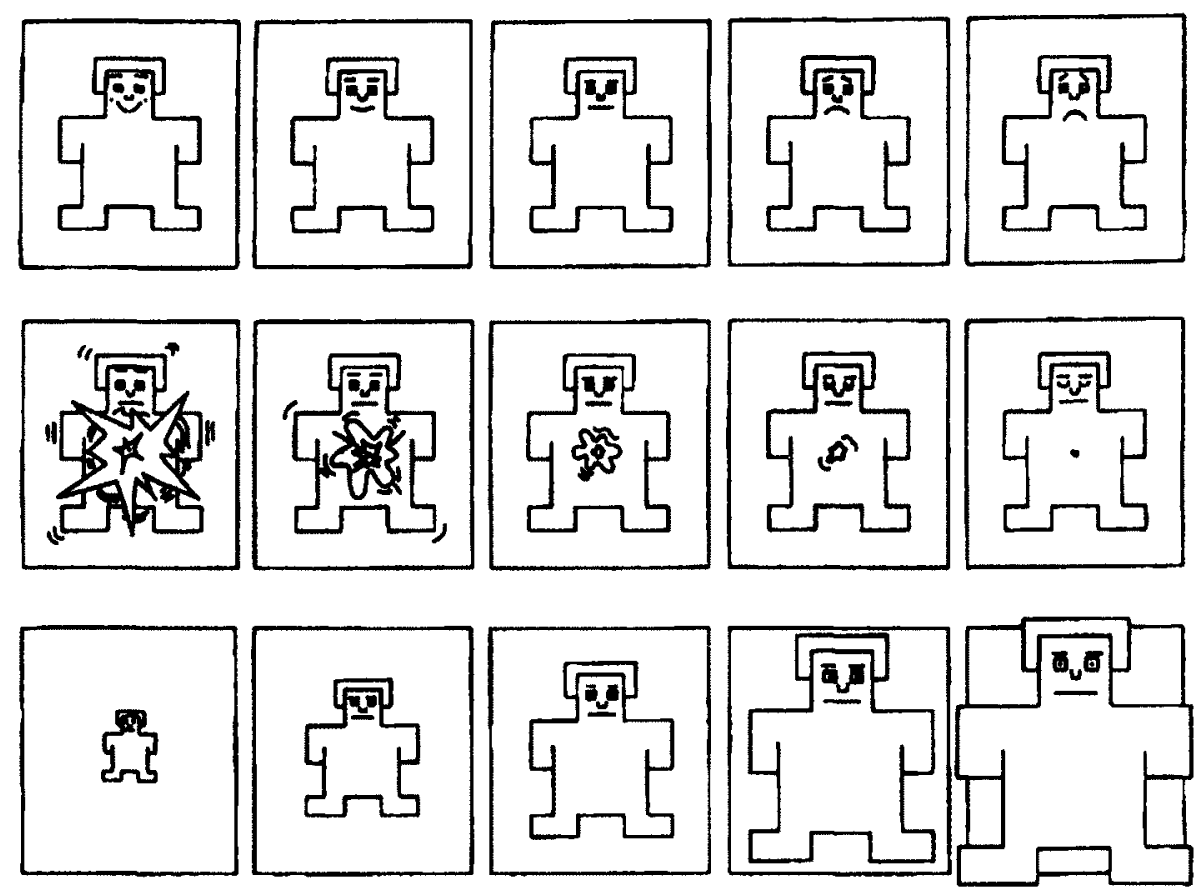

Figure 4. "The Self-Assessment Manikin (SAM) used to rate the affective dimensions of valence (top panel), arousal (middle panel), and dominance (bottom panel)," (Bradley \& Lang, 1994, p. 51).

The Self-Assessment Manikin (SAM). To help establish the degree of emotional arousal associated with the images, the experimental procedure paired the presentation of 
images and texts with the Self-Assessment Manikin, or SAM (Bradley \& Lang, 1994). The SAM is a pictorially based self-reporting tool that collects an individual's affective responses in experimental procedures. The SAM allows a participant to quickly select a graphical illustration that depicts the closest description of their affective mental state. The participant responds to three panels, each representing a different dimension of an emotional measure. Each panel consists of five illustrations (Figure 4). The first dimension is valence (range from extremely pleasant to extremely unpleasant); the second dimension is arousal (from feeling extremely aroused to extremely calm); and the last dimension in the SAM is dominance (from feeling totally controlled to feeling totally in-control). Valence and arousal are the two specific constructs of interest to this research with regard to the affect heuristic. Bradley and Lang (1994) demonstrated that the SAM showed substantial convergent validity with other self-report measures of affect, such as the Semantic Differential Scale (Mehrabian \& Russell, 1974), for measures of valence ( $r$ $=>.96)$, and arousal $(r \Rightarrow>94)$, with correlations addressing dominance failing to reach significance in that comparison (Bradley \& Lang, 1994).

News photos. News photos (Appendix J) were selected to depict a range of arousal levels from the Associated Press and The Virginian-Pilot newspaper image archives. The set contained seven images of United States military casualties as a result of the war in Afghanistan.

Procedure. In a university computer lab, participants were welcomed, sat down at a PC, and given informed consent documents to read (Appendix K), with an opportunity to ask questions or discuss concerns. After signing the agreement to volunteer in the 
research, and answering a brief series of demographic questions, participants were instructed to hit a key on the keyboard to launch the experimental procedure on the PC.

Training Phase for the response bar. The initial phase for all of the pilot and experimental procedures in this research was a Training Phase. This included a short briefing video viewed on a large screen in front of the room. The participants were shown that their responses would be recorded by using their mouse to click on a response bar, located at the bottom of the screen, and positioned under each item, question, selection of text, or image on the screen (Figure 5).

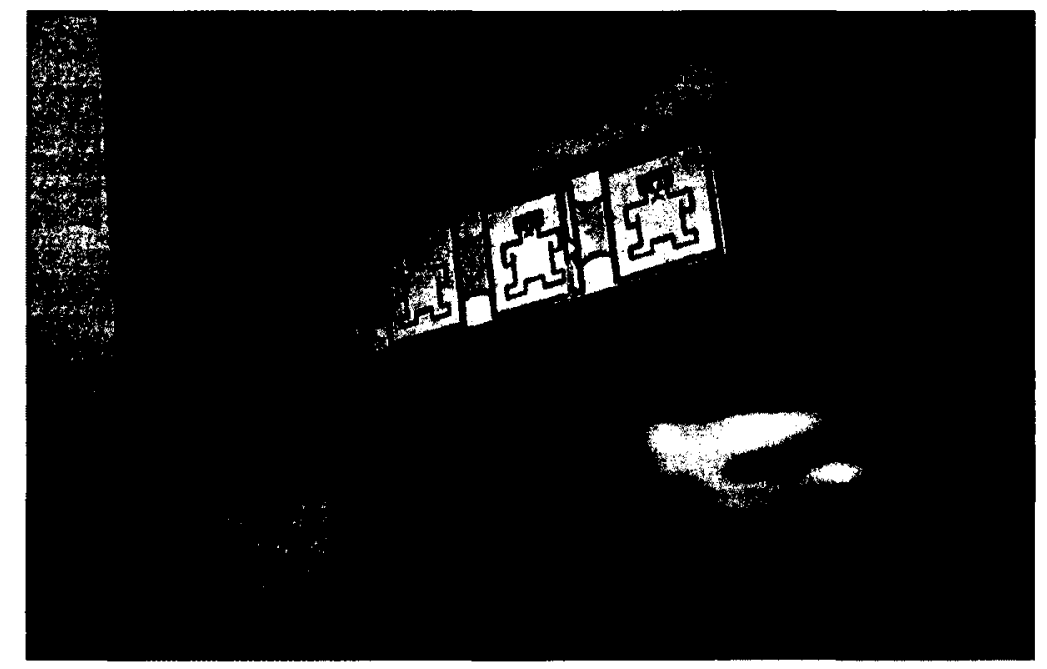

Figure 5. Photo showing the mouse interface, with the response bar, layered on top of the SAM's Valence dimension.

The response bar is a long horizontal rectangular area, layered on top of a target image on the screen, and sliced into 81 invisible, narrow, vertical sections. In essence, the underlying target image is the only visible part of the response bar. When a participant clicks anywhere on the target image, a narrow, vertical section where the cursor is positioned will "light up" in bright yellow for one second to indicate where they clicked, 
and then the screen immediately moves to the next item. Depending on where the participant clicked, the program's data logging will record an assigned numerical value, ranging from -40 at the far left, to +40 at far right, with a centered 0 -point.

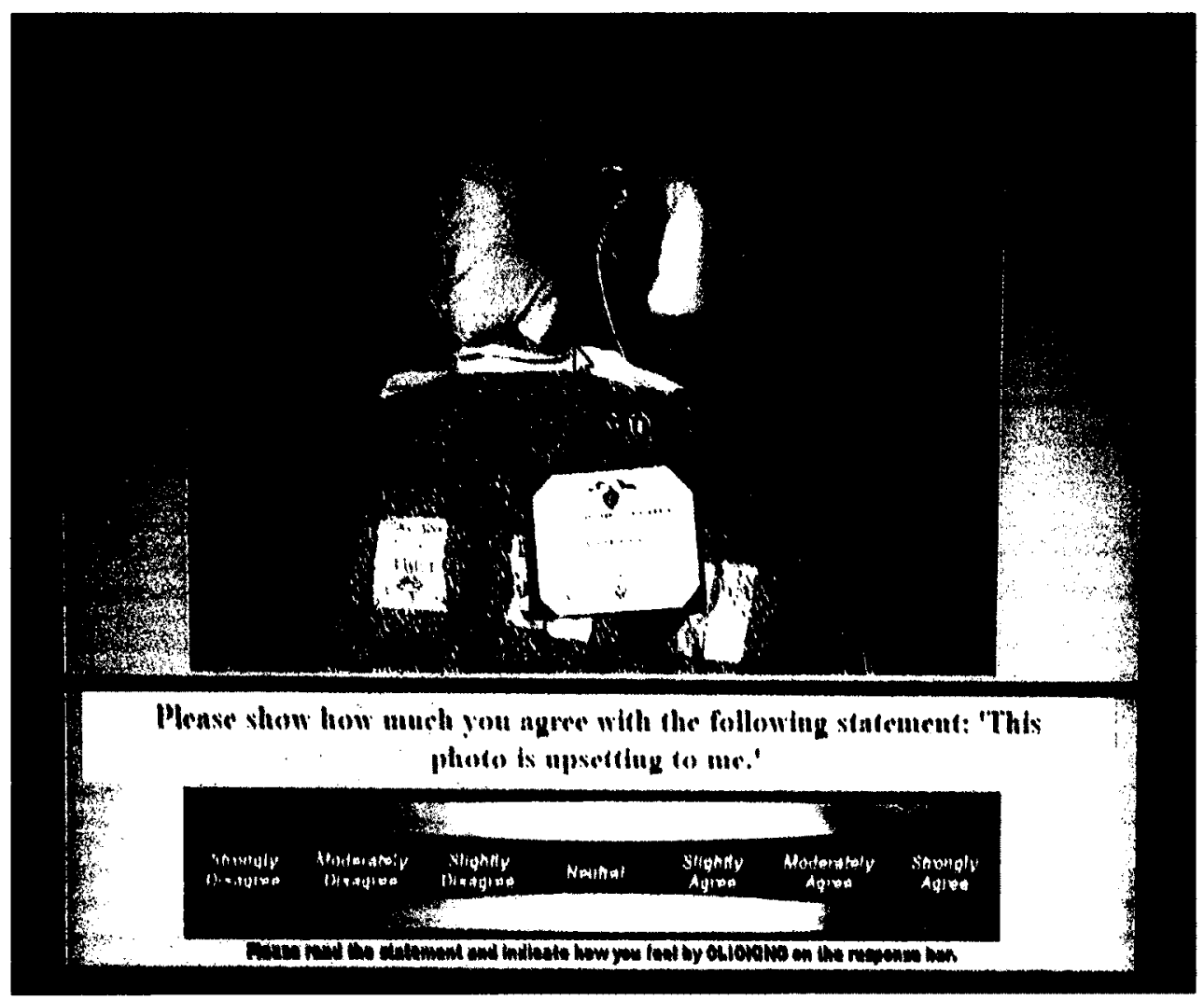

Figure 6. Photo showing an example of image display showing the response bar, layered on top of a Likert scale continuum.

The target images "beneath" the response bar can vary: from the SAM valence and arousal dimensions; to a 7-point Likert scale guide, e.g., a bi-directional continuum incrementally labeled with "very strongly disagree" at far left to "very strongly agree" at right, (Figure 6); to various versions of opposing choice "slider" responses (see the opposing choice response bar in Figure 7). 


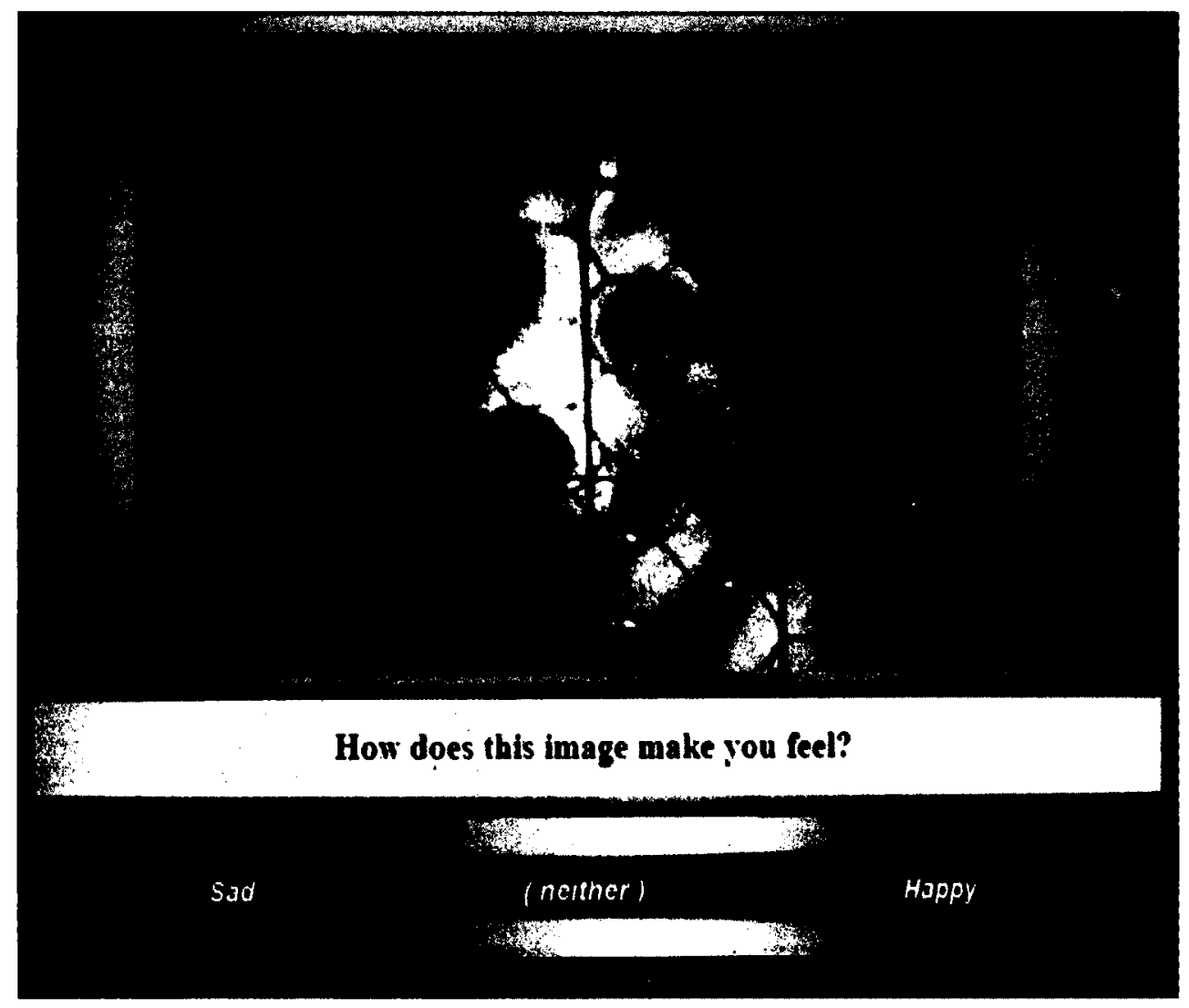

Figure 7. Example of display showing response bar with opposing responses.

In effect, the response bar as a computer interface gives researchers an opportunity to obtain participant responses and ratings in a continuous scale, and a range of 81 points, from a wide variety of questions and items. For instance, in responding to items using the SAM dimensions, participants would see the SAM's pictographs for the valence dimension presented at the bottom of the screen under an image paired with a question, such as "How does this image make you feel: pleasant or unpleasant?" Participants would respond by simply clicking somewhere along the strip of SAM figures, to indicate how they are feeling at that moment, then see their responses recorded 
with a slice of the image briefly flashing yellow where they had clicked. Immediately afterward, the screen advances to the next item to record their next response (i.e., onto the SAM arousal dimension and another questions). The briefing video instructed the participants that their choices would be recorded when they clicked the mouse, and urged them to "please be careful and sure of where [they] are clicking."

After stepping the participants through the dimensions and the computer's interface, the participants were given a series of practice items consisting of SAM dimensions, Likert-format practice items (e.g., I always eat my vegetables, I usually remember my dreams, I dislike it when it rains, etc.). Participants finished the training part of the trial by responding to practice items for the valence and arousal dimensions of the SAM, by simply indicating how they were feeling at that moment.

Image assessment phase. After Training Phase, participants moved on to the second phase of the pilot, where they were exposed to the news photos being considered for the experiment. Participants recorded their feelings and reactions to seven images showing injured servicemen from the Afghanistan War, as well as indicating any previous level of familiarity with the pictures. The images were presented in counterbalanced blocks, to control for order and presentation effects. Images were uniformly sized and presented on the screen to be as large as possible (1200 wide by 600 pixels high) at the top of the screen. Response bars showing the SAM dimensions (first, the valence dimension, followed by arousal) were presented at the bottom of the screen, paired with a prompting question (e.g., "How does this image make you feel? Do you feel 'pleasant' or do you feel 'unpleasant'?"; "How does this image make you feel? Do you feel 'excited or agitated' or do you feel 'calm'?'). 
After responding to the SAM items, participants moved on to items about their general impressions of the image, (e.g., "How does this image make you feel?"; "I find this photo upsetting to me"; "I feel an emotional reaction when I look at this photo"). Participants also responded to exploratory items inquiring to their level of familiarity with the image (e.g., "I have seen this specific photo before"; "This photo seems familiar to me"; "I have seen photos similar to this before"). For the item "How does this image make you feel?" the response bar was an opposing response continuum, designed to record responses to opposing choice items, such as to whether a sentence in a text supports one idea or another. Two choices were presented on each end of the response bar: "Unpleasant" at the left end and "Pleasant" at the right. For the remaining items, respondents indicated their agreement to these items using the 81-point Likert-formatted response bar, ranging from "Very Strongly Disagree," to "Very Strongly Agree," as described earlier.

Completing these items concluded the procedure. The participants were debriefed, given opportunities to ask questions about the procedure, and excused.

Analysis. The objective of this pilot study for the images was to determine which two news photos had the highest and lowest emotional arousal, with both of those images indicating negative emotional valence. Response scores for all items were tabulated for each image (see Tables 10 through 16, for full descriptive statistics). 
Table 10

Summary of descriptive statistics for Afghanistan Pilot Image 1: Two amputee servicemen exercising. (AP Photo).

\begin{tabular}{|c|c|c|c|c|}
\hline & $M$ & $S D$ & Kurt & Skew \\
\hline 1. SAM Valence dimension & -17.53 & 14.40 & -0.65 & 0.00 \\
\hline 2. SAM Arousal dimension & -1.27 & 22.23 & -1.55 & 0.21 \\
\hline $\begin{array}{l}\text { 3. "How does this image make you feel?" (Unpleasant } \\
\text { Pleasant) }\end{array}$ & -15.07 & 14.63 & -1.37 & 0.12 \\
\hline 4. "This photo is upsetting to me.". & 5.33 & 22.84 & -0.33 & -0.68 \\
\hline 5. Averaged Valence Measures & -16.30 & 13.71 & -0.95 & 0.05 \\
\hline 6. Averaged Arousal Measures & 9.58 & 15.89 & -0.71 & 0.64 \\
\hline $\begin{array}{l}\text { 7. "I feel an emotional reaction from looking at this } \\
\text { photo." }\end{array}$ & 24.67 & 11.04 & -1.07 & -0.41 \\
\hline 8. "I have seen this photo before." & -29.93 & 12.53 & 2.18 & 1.73 \\
\hline 9. "This photo seems familiar" & 18.60 & 19.70 & -1.23 & 0.66 \\
\hline 10. "I have seen photos like this before." & 14.00 & 25.47 & 0.67 & -1.22 \\
\hline
\end{tabular}

Note. $N=15$. All variables are centered, a range of -40 to 40 . See Figure $\mathrm{J} 1$, Appendix $\mathrm{J}$.

Table 11

Summary of descriptive statistics for Afghanistan Pilot Image 2: Lightly wounded servicemen looking on inside helicopter (AP Photo).

\begin{tabular}{lcccc}
\hline & $M$ & $S D$ & Kurt & Skew \\
\hline 1. SAM Valence dimension & -10.13 & 9.57 & -0.71 & 0.64 \\
2. SAM Arousal dimension & -11.00 & 16.46 & -0.79 & -0.69 \\
3. "How does this image make you feel?" & -11.27 & 11.71 & -1.12 & -0.57 \\
(Unpleasant Pleasant) & 3.67 & 17.29 & 1.72 & -0.03 \\
4. "This photo is upsetting to me." & -10.70 & 9.92 & -0.71 & -0.64 \\
5. Averaged Valence Measures & 1.40 & 13.55 & 0.56 & 0.94 \\
6. Averaged Arousal Measures & 11.53 & 12.36 & 0.21 & 0.41 \\
7. "I feel an emotional reaction from looking & & & & \\
at this photo." & -28.33 & 14.74 & -0.18 & 1.22 \\
8. "I have seen this photo before." & -21.33 & 18.48 & -1.12 & 0.64 \\
9. "This photo seems familiar" & 4.07 & 26.39 & -0.94 & -0.32 \\
10. "I have seen photos like this before." & & &
\end{tabular}

Note. $N=15$. All variables are centered, a range of -40 to 40 . 
Table 12

Summary of descriptive statistics for Afghanistan Pilot Image 3: Soldiers and medics carrying a wounded serviceman in a field (AP Photo).

\begin{tabular}{lcccc}
\hline & $M$ & $S D$ & Kurt & Skew \\
\hline 1. SAM Valence dimension & -14.67 & 15.95 & -1.62 & 0.21 \\
2. SAM Arousal dimension & -4.00 & 19.34 & -1.28 & 0.47 \\
3. "How does this image make you feel?" (Unpleasant & -13.87 & 14.60 & -1.81 & -0.01 \\
Pleasant) & 12.00 & 18.34 & -0.70 & -0.41 \\
4. "This photo is upsetting to me." & -14.27 & 14.76 & -1.86 & 0.01 \\
5. Averaged Valence Measures & 9.16 & 15.96 & -1.69 & -0.19 \\
6. Averaged Arousal Measures & 19.47 & 14.31 & -1.40 & -0.31 \\
7. "I feel an emotional reaction from looking at this & -28.53 & 13.29 & 0.11 & 1.23 \\
photo." & -14.13 & 20.58 & -0.97 & 0.35 \\
8. "I have seen this photo before." & 12.40 & 23.66 & -0.26 & -0.60 \\
9. "This photo seems familiar" & & &
\end{tabular}

Note. $N=15$. All variables are centered, a range of -40 to 40 . See Figure J5, Appendix J.

\section{Table 13}

Summary of descriptive statistics for Afghanistan Pilot Image 4: Group of servicemen amputees at a ceremony (AP Photo).

\begin{tabular}{lcccc}
\hline & $M$ & $S D$ & Kurt & Skew \\
\hline 1. SAM Valence dimension & -16.20 & 21.51 & 0.09 & -0.95 \\
2. SAM Arousal dimension & 1.07 & 20.50 & -0.48 & -0.64 \\
3. "How does this image make you feel?" (Unpleasant & -15.27 & 20.18 & 0.69 & 1.09 \\
Pleasant) & 13.73 & 22.71 & 0.57 & -1.11 \\
4. "This photo is upsetting to me." & -15.73 & 21.59 & 0.43 & 1.04 \\
5. Averaged Valence Measures & 12.18 & 18.49 & 0.31 & -0.96 \\
6. Averaged Arousal Measures & 7.40 & 21.29 & 0.05 & -0.92 \\
7. "I feel an emotional reaction from looking at this & -26.80 & 14.31 & -1.00 & 0.89 \\
photo." & -18.60 & 18.15 & -1.07 & 0.49 \\
8. "I have seen this photo before." & -1.27 & 28.93 & -1.57 & -0.17 \\
9. "This photo seems familiar" & & &
\end{tabular}

Note. $N=15$. All variables are centered, a range of -40 to 40 . See Figure $\mathrm{J} 7$, Appendix $\mathrm{J}$. 
Table 14

Summary of descriptive statistics for Afghanistan Pilot Image 5: Badly wounded servicemen in helicopter (AP Photo).

\begin{tabular}{lcccc}
\hline & $M$ & $S D$ & Kurt & Skew \\
\hline 1. SAM Valence dimension & -30.07 & 7.43 & 3.89 & -1.61 \\
2. SAM Arousal dimension & 11.26 & 16.14 & 0.57 & 1.05 \\
3. "How does this image make you feel?" & -23.20 & 8.66 & 2.36 & 1.63 \\
(Unpleasant Pleasant) & 21.67 & 16.96 & 2.80 & -1.80 \\
4. "This photo is upsetting to me." & -26.63 & 7.54 & 1.89 & 1.43 \\
5. Averaged Valence Measures & 19.18 & 13.92 & -1.69 & 2.44 \\
6. Averaged Arousal Measures & 24.60 & 12.22 & 1.22 & -1.26 \\
7. "I feel an emotional reaction from looking at this & -29.47 & 11.88 & 1.45 & 1.47 \\
photo." & -19.40 & 19.31 & -1.22 & 0.60 \\
8. "I have seen this photo before." & 13.67 & 19.87 & 2.48 & -1.15 \\
9. "This photo seems familiar" & & 40.562 &
\end{tabular}

Note. $N=15$. All variables are centered, a range of -40 to 40 . See Figure J2, Appendix J.

\section{Table 15}

Summary of descriptive statistics for Afghanistan Pilot Image 6: Badly wounded servicemen after suicide bomber attack (AP Photo).

\begin{tabular}{lcccc}
\hline & $M$ & $S D$ & Kurt & Skew \\
\hline 1. SAM Valence dimension & -35.20 & 8.47 & 9.84 & 2.93 \\
2. SAM Arousal dimension & 19.67 & 17.93 & 4.36 & -1.82 \\
3. "How does this image make you feel?" (Unpleasant $~$ & -28.20 & 11.07 & 2.35 & 1.52 \\
Pleasant) & 26.80 & 15.99 & 4.65 & -2.04 \\
4. "This photo is upsetting to me." & -31.70 & 9.36 & 6.23 & 2.70 \\
5. Averaged Valence Measures & 25.58 & 15.68 & 7.42 & -2.52 \\
6. Averaged Arousal Measures & 30.27 & 14.99 & 10.24 & -3.04 \\
7. "I feel an emotional reaction from looking at this." & -29.80 & 11.27 & -1.01 & 0.95 \\
8. "I have seen this photo before." & -19.73 & 18.28 & -0.72 & 0.64 \\
9. "This photo seems familiar" & 1.60 & 27.21 & -1.50 & -0.04 \\
10. "I have seen photos like this before." & & &
\end{tabular}

Note. $N=15$. All variables are centered, a range of -40 to 40 . See Figure $\mathrm{J} 4$, Appendix $\mathrm{J}$. 
Table 16

Summary of descriptive statistics for Afghanistan Pilot Image 7: Critically wounded servicemen in hospital with Purple Heart on chest (AP Photo).

\begin{tabular}{lcccc}
\hline & $M$ & $S D$ & Kurt & Skew \\
\hline 1. SAM Valence dimension & -26.00 & 12.19 & -0.69 & 0.71 \\
2. SAM Arousal dimension & 9.07 & 18.49 & -0.92 & 0.43 \\
3. "How does this image make you feel?" (Unpleasant & -24.47 & 10.92 & -1.22 & 0.60 \\
Pleasant) & 21.07 & 16.14 & 0.31 & -0.94 \\
4. "This photo is upsetting to me." & -25.23 & 10.26 & -0.92 & 0.48 \\
5. Averaged Valence Measures & 18.78 & 14.26 & -0.54 & -0.59 \\
6. Averaged Arousal Measures & 26.20 & 12.13 & -0.95 & -0.46 \\
7. "I feel an emotional reaction from looking at this." & -28.13 & 14.97 & 0.28 & 1.31 \\
8. "I have seen this photo before." & -18.40 & 20.36 & -1.60 & 0.45 \\
9. "This photo seems familiar" & 0.67 & 29.05 & -1.52 & -0.14 \\
10. "I have seen photos like this before." & & & &
\end{tabular}

Note. $N=15$. All variables are centered, a range of -40 to 40 . See Figure J6, Appendix J.

The respondents expressed general unfamiliarity with the specific images. The valence was computed for each of the seven images. The direction of emotional valence for each image was established by creating an index using the mean of the SAM Valence dimension, with the item "How does this image make you feel?" ("Unpleasant" or “Pleasant"). The index had a range of -40 to 40 , with negative scores indicating negative valence. All images scored significantly below midpoint, indicating negative valence for each image used in the pilot study (Figure 8).

For measures of emotional arousal for each image, centered scores for the images were averaged for the SAM Arousal dimension with the items asking the respondent's level of agreement to the statements "I find this photo to be upsetting" and also "I feel an emotional reaction when I look at this photo" (Figure 9). This index had a range of -40 to 40, with negative scores indicating greater degrees of negative emotional arousal. An 
image of the immediate aftermath of a bloody suicide bombing (Figure J4, in Appendix J), which showed several gravely injured U.S. servicemen lying on the ground, was selected as the image with the highest emotional arousal for the respondents $(M=25.58$; $S D=15.68)$. An image of a young serviceman sitting in a helicopter, staring impassively with his arm in a sling (Figure $J 3$, in Appendix J), was chosen as the image with the lowest level of emotional arousal $(M=1.40 ; S D=13.55)$. These two images, which differed significantly in arousal, $t(14)=-5.72, p<.001, d=1.48,95 \%$ CI $[-33.24,-$ 15.12], were selected as those to be used as stimuli in the first experiment.

\section{Method: Afghanistan Text Pilot Testing}

It was necessary that the "news story" text be as neutral and balanced as possible to avoid introducing a biasing element to any observed effects. Furthermore, it is a widely known journalistic principle to pursue evenhandedness and impartiality in reporting, which often is accomplished by constructing a balanced story and presenting "all sides," in the interest of being fair (ASNE, 2006; SPJ, 1996). As such, a neutral and balanced story in the journalistic tradition would bolster the degree of external validity. This pilot study helped develop and balance such a text, which would be used across the conditions of the experiments.

Participants. Subjects $(N=32)$ were recruited to the pilot study via the SONA Research participation system (Appendix L), volunteering in exchange for class research credit. Seven participants were male and 25 were female. The participants ranged in age from 18 to 29 , with 23 participants $(71.9 \%)$ between 18 and 20 , with $9(28.1 \%)$ between 21 and 29. All were fluent in English.

Materials. As earlier, the pilot tests for text used a pre-programmed computer 


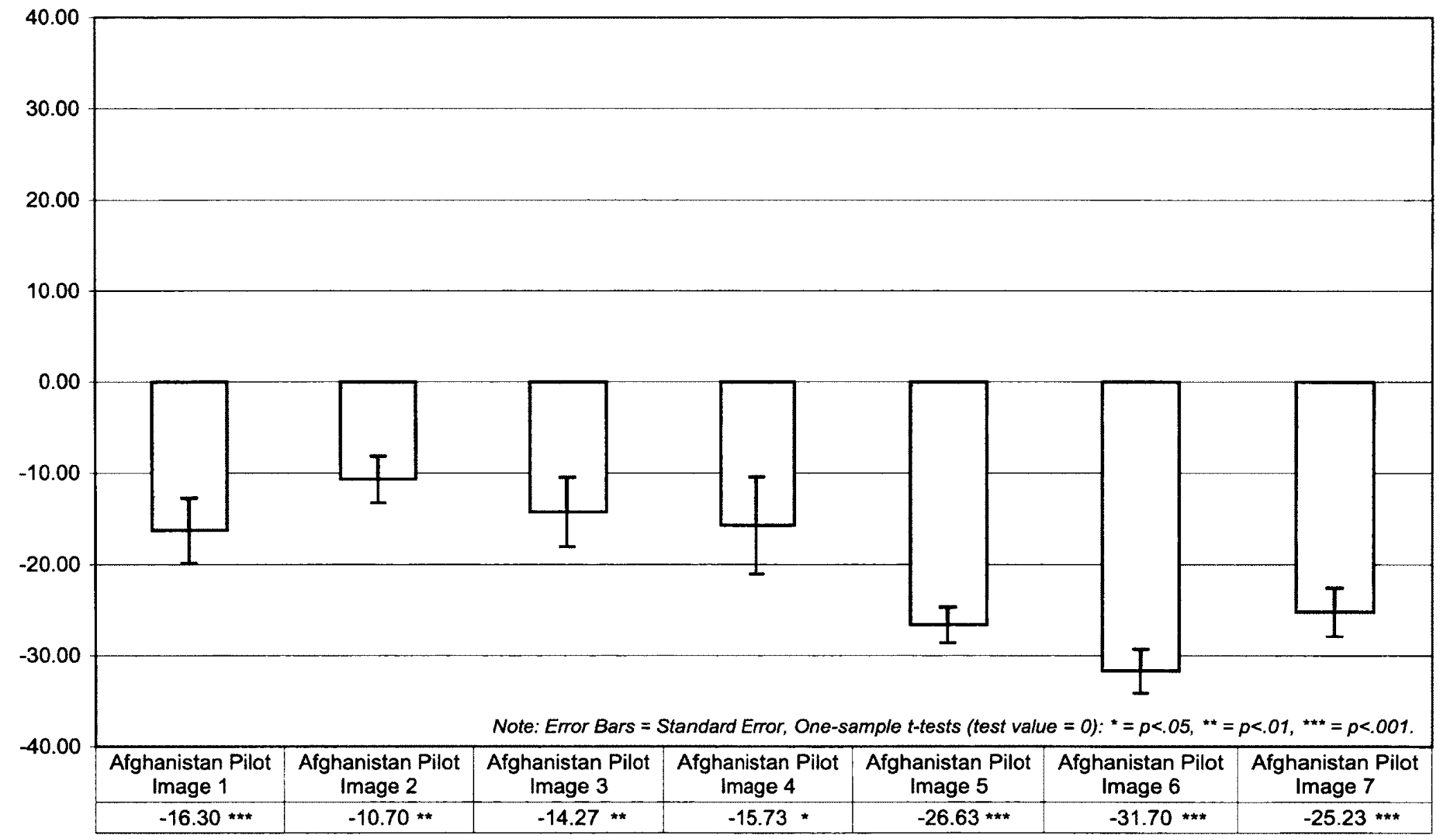

Figure 8. Directions of mean emotional valence measures for images in Afghanistan pilot study, showing $t$-test results. 


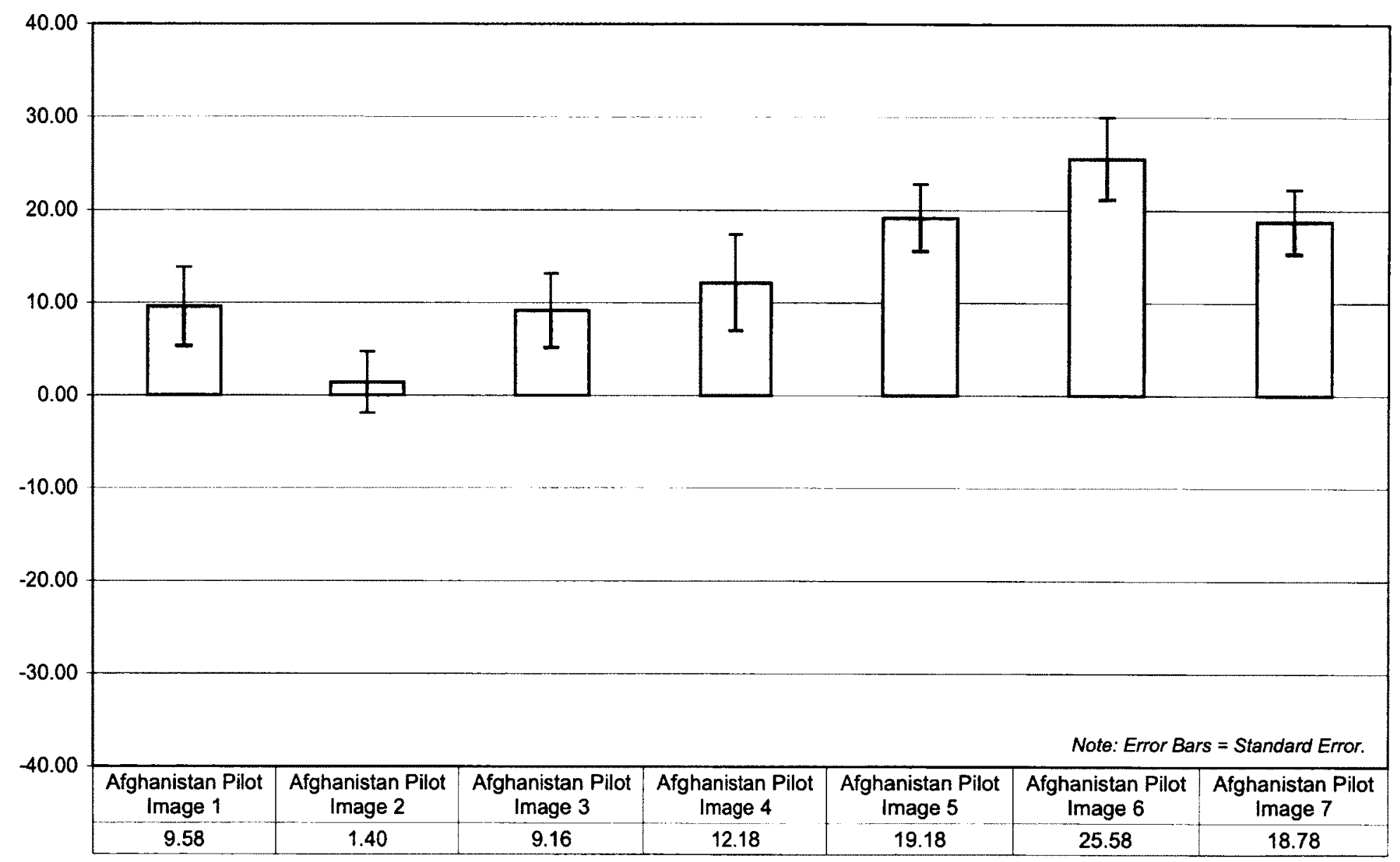

Figure 9. Directions of mean emotional arousal measures for images in Afghanistan pilot study. 
procedure. Interactive procedures with presentations of text, response logging, as well as any additional questionnaires were created using E-Prime and administered in a university computer lab.

Training video. The training video used in the previously described pilot was used to brief participants for this computer-based procedure.

Afghanistan text. A text was constructed addressing the question of continuing the U.S. military involvement in the Afghanistan War. Although written in the same style as national/international news stories, this text (Appendix $M$ ) was compiled from parts of stories from various news organizations, with the introductory and concluding parts written by the researcher. The 235 -word text was designed to emulate a very brief Afghanistan "news story," which discussed the difficult choices the U.S. faced in maintaining troops there. Quotes were inserted showing a difference of opinions, balancing pro and con statements, and designed to exert minimal influence on the reader.

Procedure. Participants were seated in a university computer lab, and after signing participation agreement forms, the computer procedure was launched as described in the earlier section. As with the image pilot, the first phase was the Training Phase, where after watching a short briefing video participants responded to practice items. The participants were told that even though they were practice items, they should answer truthfully regarding their own feelings and responses to each item. They were also informed that they might see questions or items rephrased or presented twice.

A central part of the Training Phase was the reading task, where a practice story was presented to read (see Appendix $N$ ), and then respond to items immediately afterward that addressed the text. The story was a short text about the "No Child Left 
Behind" (NCLB) educational initiative, titled, "The good and bad of No Child Left Behind" (Rhodebeck, 2012). Immediately following, participants responded to randomized items asking about the text, similar to what they would encounter later in the pilot study. They would use the response bar in both the Likert format to respond to these practice items (e.g., I think NCLB was a good idea [bad idea]; I felt this story covered the main points of the issue very well; I think this story influenced me regarding how I feel about the subject; I am interested in this topic; I felt I had a better understanding of the topic after reading the story; I felt this story was not helpful in my understanding of the topic, etc). Participants also practiced using the opposing response continuum to answer some items (e.g., I felt this story was slanted in favor of one of the sides of the argument: Slanted against [in favor of] No Child Left Behind).

After the practice session, the participants responded to a set of preliminary questions. These items were randomized questions (e.g. "I am interested in the news"; "I am more of a morning person than a night person"; "The United States is the greatest country on the Earth"; "One year after the fall of Hosni Mubarak, Egypt is better off") to offer further practice. Included were items related to the variables of interest (e.g., "I support the current war in Afghanistan," "I am against the war in Afghanistan"), which will also serve as a pre-test measure for measuring the degree of influence for the text samples.

Object rotation task. As a distracter procedure between the preliminary questions and those that would follow, an object rotation task was administered. Participants were informed that the task was "a test of [their] spatial processing and perception abilities." The 20 item task is a simplified version of commonly used mental rotation procedures 


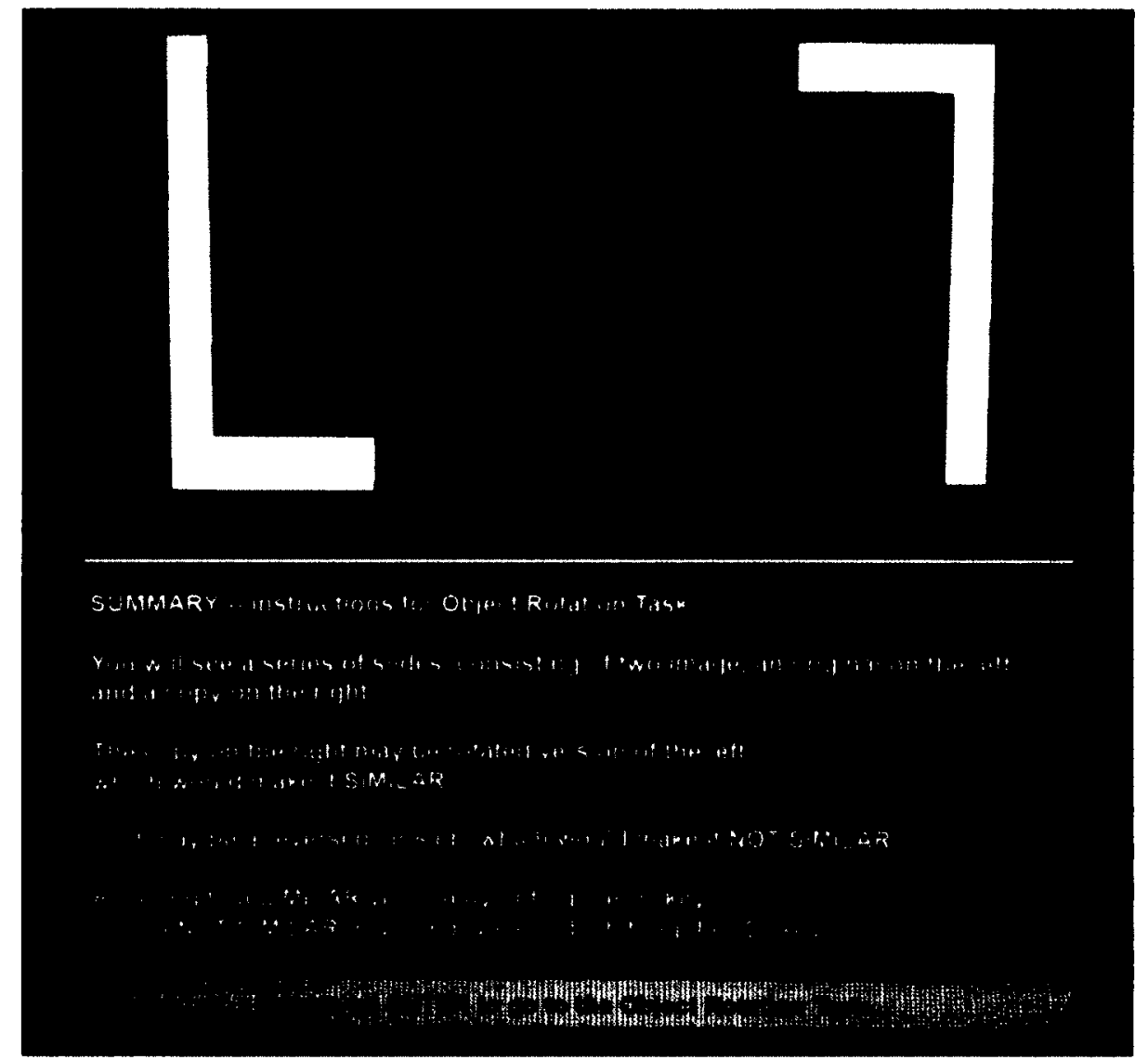

Figures 10. Object Rotation directions.

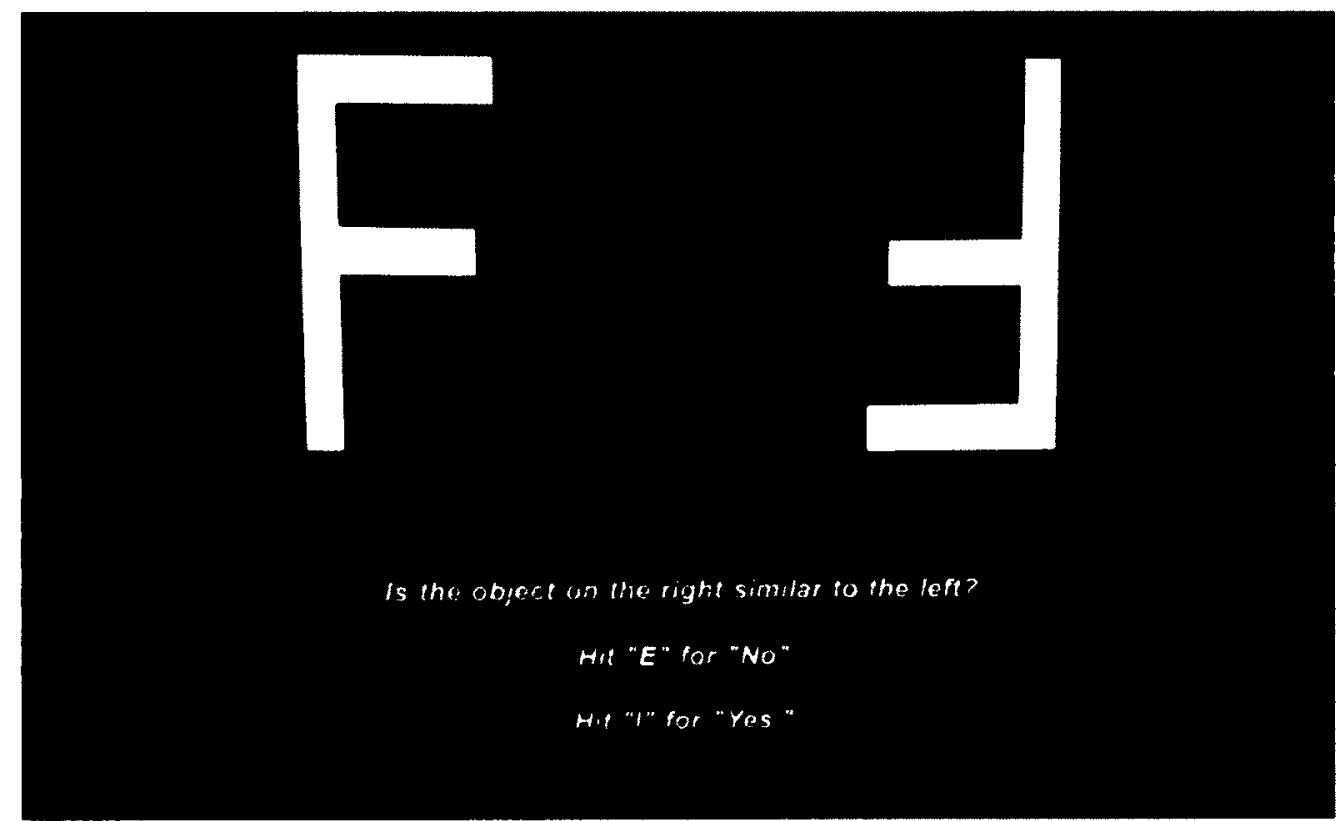

Figures 11. Object Rotation task screen. 
(Cooper \& Shepard, 1973; Shepard \& Metzler, 1971), where participants view pairs of letters presented with various degrees of rotation and attempt to recognize whether or not the letter on the right is a flipped version of that on the left (see Figures 10 and 11).

Text assessment procedure and phase. After completing the object rotation task, participants in the text-evaluation pilot sessions went on to read a short text which was the "news story" entitled, "Afghanistan: Americans face difficult choices." First participants read the entire text, presented in a single text block on the screen. Next, they responded to items using the Likert scale continuum, regarding the decisions of interest (e.g., "I support the current war in Afghanistan"; "I do not support the current war in Afghanistan"). This served as a post-test measure to determine the influence of the text. Next, they also recorded their perceptions of the general balance or editorial slant of the story (e.g., "I felt this story made a strong case for keeping the US troops in Afghanistan."; "I felt this story made a strong case for taking the US troops out of Afghanistan."; "I felt this story presented all sides in a balanced manner."; "I felt this story was slanted in favor of one of the sides of the argument").

Analysis. The purpose of the text pilot study was to determine if the text stimuli presented as balanced and non-influential "news stories" on the average. Response scores for all items were tabulated (descriptive statistics in Table 17). The respondents reported only slight agreement in feeling influenced by the story, and that it made a strong case for keeping U.S. troops in Afghanistan, and otherwise expressed central tendencies in the influence of the text. For an index of general support of the war, centered scores of war support were averaged with reversed scores of opposition to the war. The participant's general support of the current war in Afghanistan did not shift significantly after reading 
the text, $t(32)=-1.34, p=.190, d=0.23,95 \% \mathrm{CI}[-6.23,1.29]$. Results indicate that the text is largely neutral in its influence among participants, and was a good choice for the experiment.

\section{Table 17}

Summary of descriptive statistics for participant responses in the text pilot for the Afghanistan "news story."

\begin{tabular}{|c|c|c|c|c|}
\hline & $M$ & $S D$ & Kurt & Skew \\
\hline 1. "I support the current war in Afghanistan." (pre-test) & -11.03 & 20.77 & -0.29 & 0.55 \\
\hline $\begin{array}{l}\text { 2. "I am against the current war in Afghanistan." (pre- } \\
\text { test) }\end{array}$ & 12.22 & 20.79 & -0.70 & -0.56 \\
\hline 3. I support the current war in Afghanistan." (post-test) & -8.97 & 21.45 & -0.61 & 0.40 \\
\hline $\begin{array}{l}\text { 4. "I am against the current war in Afghanistan." (post- } \\
\text { test) }\end{array}$ & 9.16 & 21.89 & -0.54 & -0.45 \\
\hline $\begin{array}{l}\text { 5. "I felt this story made a strong case for keeping the } \\
\text { U.S. troops in Afghanistan." }\end{array}$ & -6.56 & 16.68 & -0.27 & 0.43 \\
\hline $\begin{array}{l}\text { 6. "I felt this story made a strong case for taking the U.S. } \\
\text { troops out of Afghanistan." }\end{array}$ & 0.44 & 17.76 & -0.77 & 0.03 \\
\hline $\begin{array}{l}\text { 7. "I think this story did not influence me regarding how } \\
\text { I feel about the subject." }\end{array}$ & 9.66 & 20.18 & -0.96 & -0.16 \\
\hline $\begin{array}{l}\text { 8. "I think this story may have influenced me regarding } \\
\text { how I feel about the subject." }\end{array}$ & -3.78 & 19.84 & -0.90 & -0.21 \\
\hline $\begin{array}{l}\text { 9. "I felt this story was slanted in favor of one of the } \\
\text { sides of the argument." }\end{array}$ & -1.31 & 12.43 & 1.57 & -0.47 \\
\hline $\begin{array}{l}\text { 10. General support of current war in Afghanistan. (pre- } \\
\text { test) }\end{array}$ & -10.63 & 19.97 & -0.44 & 0.55 \\
\hline $\begin{array}{l}\text { 11. General support of current war in Afghanistan. (post- } \\
\text { test) }\end{array}$ & -8.06 & 20.29 & -0.57 & 0.34 \\
\hline
\end{tabular}

Note. $N=32$. All variables are centered, a range of -40 to 40 . $=$ Likert format response bar: Negative scores indicates level of disagreement / positive is level of agreement; $*$ = Opposing choice response bar: Negative scores is "slanted against keeping troops in Afghanistan," positive is for "slanted for keeping troops in Afghanistan," scores close to zero indicate perceptions that the "story was balanced." 


\section{CHAPTER II}

\section{EXPERIMENT 1: EFFECTS OF EMOTIONALLY AROUSING NEWS PICTURES ON ATTITUDES ABOUT THE AFGHANISTAN WAR}

In a between-subjects procedure examining the influence of news images on human judgments, images were presented depicting servicemen injured or killed in combat during the Afghanistan war as an independent variable, manipulated to vary by degree of arousal, and paired with accompanying texts that were held constant. Comparisons were examined against a control group who were exposed to the text only condition. The procedure was designed in a three phase experimental protocol: Training, Experimental and Post-Experimental phases (see Figure 12).

\section{Method}

Participants. Participants were recruited from the pool of students at Old Dominion University (Appendix O), who completed the pre-screening procedure. Eligible participants were invited by email to the experiment, and were sent a password to sign up for the trials. A total of 137 participants (in 3 groups) participated in the oncampus study. This was $53 \%$ of all invited from the pre-screening. All were U.S. citizens, at least 18 years old, and received class credit as compensation for research participation.

\section{Apparatus and Materials}

As before, the experimental procedure was administered in a computer lab, using a series of PCs, and was programmed using E-Prime experimental programming software. 


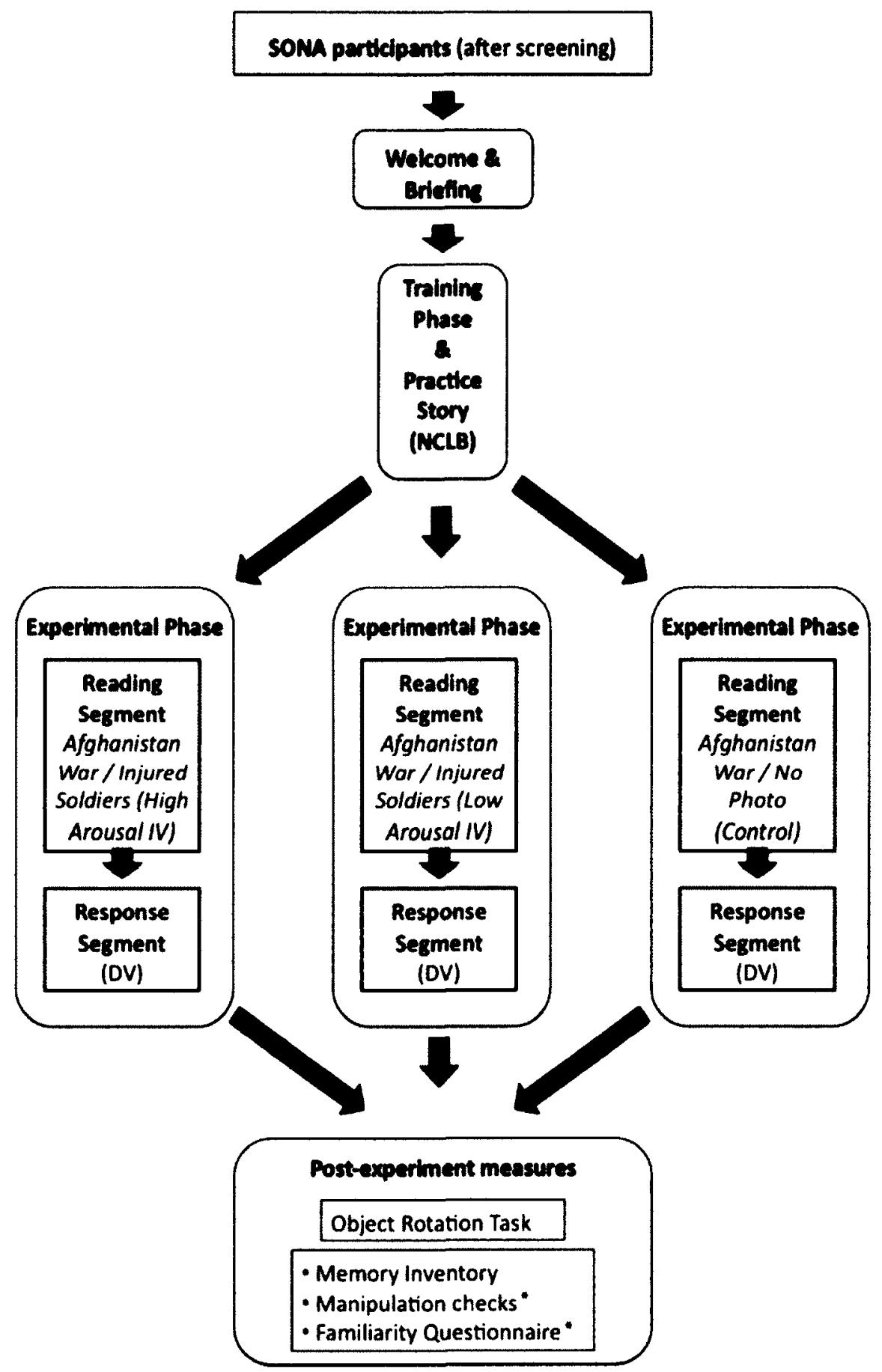

Figure 12: Experiment 1 paradigm. * Note: No manipulation checks or familiarity questions in the text-only (control) condition. 
Training video. A short training video (Running time: $6: 31$ ), produced to professional standards using Final Cut Pro software and a Canon EOS 7D camera system, was used to brief participants to the procedure. The video was similar to the pilot studies training video, with the addition of a part that addressed the text-input for the open memory inventory (see Appendix P).

Story and image materials. For use in the experiment's training procedure, an excerpt from a news story previously described in the text-pilot about the No Child Left Behind initiative (Rhodebeck, 2012) was paired with a wire service photo depicting an elementary school student working in a classroom.

Experimental materials and stimuli included the Afghanistan text from the pilot tests, and also the images depicting injured soldiers in Afghanistan, which were found to be either the most or least emotionally arousing from the pilot study.

Index for support of Afghanistan War. Participants received a 2-item index in the programmed experimental procedure that inquired about their support for U.S. involvement in the War in Afghanistan. They were asked directly about their explicit support of the war (e.g., "I SUPPORT the war in Afghanistan;" "I am AGAINST the war in Afghanistan"). Participants recorded their responses during the procedure via the 81 point Likert-formatted response bar. Scores on each item ranged from -40 ("Very Strongly Disagree,") to 40 ("Very Strongly Agree”). The support of the war index was created by averaging both items after reversing the scores for the second item addressing participants' opposition to the war, and showed very strong reliability as a measure of attitudes supporting the U.S. military presence in Afghanistan, Cronbach's alpha $=.94$. 
Inventory for General Militaristic Attitudes. Participants received a 6-item inventory that asked their opinions regarding the general use of military action in national policy, or “Hawkishness". These items (see Appendix Q) were pulled from two separate inventories that measure dispositional inclinations toward peace and diplomacy (Vail \& Motyl, 2010) as well as dispositions favoring aggressive militarism (Weise, et al., 2008). The items chosen from the Vail et al (2010), Support for Diplomacy (SDS) scale showed some of the highest factor loadings of that inventory. No factor loadings were available from the Weise, et al (2008) Military Might Scale (MMS). For the MMS, items were selected that predominantly addressed notions about conventional warfare and inclinations toward military intervention. As with the Index for support of Afghanistan War above, participants responded to items using the 81-point Likert-formatted response bar. The index was created by reversing the scores on the SDS items and averaging the all the items to create an index with a range from -40 to 40 . Both the SDS and the MMS overall scales show strong internal reliability, with Cronbach's alphas of .95 and .92 , respectively. The SDS and MMS scales is shown in the Vail et al (2010) piece, where strong correlations are found for voting intentions ( $r$ 's $=.41$ and .46 respectively). The two inventories indicate a very strong negative correlation with each other $(r=-.62)$. Collectively, the six items show good reliability in this research, with a Cronbach's alpha of .83 , indicating this to be a good measure of overall inclinations toward or away from military action.

Memory inventory. An open memory inventory was incorporated into the procedure. After reading directions, participants were instructed to type everything they 
recalled from the main story (about the Afghanistan war) into a white field. They could type in up to 2000 characters before the screen would automatically store.

\section{Design}

The study was a one way analysis of covariance design, with the photo condition as the independent variable (High emotional arousal photo/ Low emotional arousal photo / No photo), and using pretest judgments on the Support of Afghanistan War as the covariates, and post-test judgments on the same as the dependent variables. Participants were randomly assigned to one of these three groups.

\section{Procedure}

Introduction and Training Phase. After signing the agreement to volunteer in the research (Appendix R), the participants were welcomed as a group to the experiment, and were informed that they would do a "reading-comprehension" task. The experimenter informed the group that they would be reading short texts from popular media, and would participate in tasks immediately following the reading portion, which included getting their responses concerning their understandings and reactions to the texts.

The participants were asked to press a key to launch the experiment on the PC. The first screens and tasks that participants experienced was the Training Phase of the experiment. This included viewing a training video, and then a brief procedure to familiarize and step them through the presentations of the text and photo information, as well as questions and items. The Training Phase concludes with the participants responding to the training story, about the NCLB initiative.

Experimental Phase. Participants proceeded to the Experimental Phase, where they received the experimental stimuli and procedure. Each of these phases has two parts: 
a reading and a response segment. In all conditions of the reading segment, participants read a "news story" that discussed the political discourse about the U.S. military in Afghanistan. In the conditions where images and text were paired, the story was paired with either a high or low-arousal image of injured soldiers from the Afghanistan war. If participants were in a text-only group (i.e., control condition), they saw no image paired with the Afghanistan story.

Immediately after the reading segment, participants moved on to the response segment. Participants were questioned directly about their responses to the stories they just read, where they received, in randomized order, the inventories for support of Afghanistan War, and the General Militaristic Attitudes. Finally, participants were asked about their interest in the story (e.g., "I am interested in this topic.").

Post-Experimental Phase. After the Experimental Phase, participants proceeded through the object rotation procedure that served as a distracter task just prior to the memory inventory.

In the memory inventory task, participants recorded everything they remembered from the story by typing their responses into the computer. A series of manipulation checks immediately followed. All participants were asked about their perceptions of slant or bias in the stories presented to them, similar to items in the text pilot study, e.g., "I felt this story was slanted in favor of one of the sides of the argument;" "I felt this story made a strong case for taking the U.S. troops out of Afghanistan;" "I felt this story made a strong case for keeping the U.S. troops in Afghanistan;" "I think this story may have influenced me regarding how I feel about the subject;" "I think this story did not influence me regarding how I feel about the subject." 
Participants in the groups who were exposed to high or low emotionally arousing pictures with text went through further manipulation checks. These were configured the same as in the image pilot test. As in the pilot study, the items inquired about the direction of emotional valence and degree of emotional arousal for each image (e.g., the SAM dimensions for valence, and arousal, "How does this image make you feel?"; "I find this photo disturbing"; "I feel an emotional reaction when I look at this photo"; "I find this photo to be upsetting to me") as well as the level of familiarity of each image (e.g., "I have seen this specific photo before"; "This photo seems familiar to me"; "I have seen photos similar to this before").

Completion of these items concluded the experiment, after which the participants were debriefed, given a detailed explanation of the research's purpose (Appendix S), opportunities to ask questions about the procedure, and excused.

\section{Results}

Dependent variables. The judgments of interest for this research were participant's support of U.S. involvement in the Afghanistan War, and also their general pro-militaristic attitudes regarding US national policy, after being exposed to relevant and emotionally arousing news images. The first dependent variable, the index for support of Afghanistan War, was a simple and highly reliable index of the two items that explicitly inquire as to participant's support of the war, which was created by averaging both items, after reverse-coding the item that addressed opposition to the war. The second dependent variable was the centered and averaged scores from the General Militaristic Attitudes inventory. Both indexes produced scales with a range of -40 to 40 , with positive scores 
indicating higher support for the war or militarism, and negative scores showing less support, respectively.

Correlations were measured to examine relationships between the potential covariates and the dependent variables. The covariates under consideration from the prescreening inventories included two inventories in the pre-screening survey: the RWA and the SDO. A third covariate worthy of consideration was a support of war index (SWI). This was a simple 2-item index of explicit statements supporting and opposing the war taken from participant's responses to the pre-screening survey - effectively, a pretest version of the support of Afghanistan War dependent variable, measured in a 9-point Likert scale. All the measures were highly correlated with one another, with the correlations between the SDO and SWI being the highest-correlated with the DVs (see Table 18).

Results from the procedure were tabulated and analyzed (see descriptive statistics in Table 19). For the emotional effects of the images, indexes were created for the valence and emotional arousal of the images in the same manner used in the image pilot study. Manipulation checks confirmed that valence was significantly negative for both the highly emotionally arousing image, $t(43)=-16.90, p<.001, \mathrm{~d}=2.55,95 \% \mathrm{CI}[-$ $29.37,-23.11]$, as well as the image in the low arousal condition, $t(42)=-6.47, p<.001$, $d=0.99,95 \% \mathrm{CI}[-14.46,-7.58]$, thus successfully controlling for negative valence. For the degree of emotional arousal, there were differences between the groups, $F(1,85)=$ $34.80, p<.001, \eta_{p}{ }^{2}=.29$, power $=1.00$, indicating successful manipulation, with those exposed to the high emotional arousal condition reporting more emotional arousal than those in the low arousal condition. 
Table 18

Summary of correlations for Pre-screening Inventories with DVs in Experiment 1.

\begin{tabular}{|c|c|c|c|c|c|}
\hline Measure & 1. & 2. & 3. & 4. & 5. \\
\hline 1. RWA & -- & $.38^{* *}$ & $.29^{* *}$ & $.29^{* *}$ & $.33 * *$ \\
\hline 2. SDO & & -- & $.41^{* *}$ & $.42^{* *}$ & $.55^{* *}$ \\
\hline 3. SWI & & & -- & $.73^{* *}$ & $.54^{* *}$ \\
\hline $\begin{array}{l}\text { 4. Support of Afghanistan War } \\
\text { (DV) }\end{array}$ & & & & -- & $.62^{* *}$ \\
\hline $\begin{array}{l}\text { 5. General Militaristic } \\
\text { Attitudes (DV) }\end{array}$ & & & & & -- \\
\hline $\begin{array}{l}\text { Note. } N=132 . \mathrm{RWA}=\mathrm{Right} \mathrm{W} \\
\text { Support of war index; Support } \\
\text { General Militaristic Attitudes }= \\
{ }^{* *} p<.01\end{array}$ & han & $\begin{array}{l}\mathrm{DO}=\mathrm{S} \\
\mathrm{ar}=2 \mathrm{i} \\
\text { ristic ve }\end{array}$ & $\begin{array}{l}\text { Domina } \\
\text { plicit s } \\
\text { acifist }\end{array}$ & $\begin{array}{l}\text { rientat } \\
\text { tof wa } \\
\text { ation. }\end{array}$ & $\begin{array}{l}\mathrm{WI}= \\
\mathrm{x} ;\end{array}$ \\
\hline
\end{tabular}

\section{Table 19}

Summary of descriptive statistics for participant responses Experiment 1.

\begin{tabular}{|c|c|c|c|c|c|}
\hline & $N$ & $M$ & $S D$ & Kurt & Skew \\
\hline 1. "I support the U.S. War in Afghanistan." & 132 & -4.78 & 20.79 & -0.84 & 0.29 \\
\hline $\begin{array}{l}\text { 2. "I am against the U.S. War in } \\
\text { Afghanistan." }\end{array}$ & 132 & 6.42 & 20.55 & -0.84 & -0.30 \\
\hline $\begin{array}{l}\text { 3. "The United States should send more } \\
\text { troops to Afghanistan, so we can cripple } \\
\text { the terrorist threat there." }\end{array}$ & 132 & -14.12 & 15.89 & -0.48 & 0.24 \\
\hline
\end{tabular}


Table 19

Continued

4. "The United States should withdraw troops from Afghanistan immediately, even before the 2014 deadline for pulling troops out." *

5. Support for Afghanistan War index *

6. "The best way for the United States to address the problem of terrorism involves increasing U.S. military presence in troubled areas around the world e.g., Middle East." *

7. "If the U.S. wants peace, it must set a peaceful example."

8. "It is entirely appropriate to engage in preemptive attacks on countries e.g., Iran, North Korea, etc. that may pose a threat to the United States, even if there's no evidence they are planning to attack us right" *

9. "Fewer people will suffer if the United States aggressively pursued peaceful diplomacy instead of aggressively using its military."

10. "If our leaders advocate violent solutions, they can only expect more violence in return."

11. "The only chance we have to stop international terrorism is if the United States follows a strict and uncompromising approach to this problem, using military intervention."

12. General Militaristic attitude *

13. "I am interested in this topic." *

14. "I felt this story was slanted in favor of one of the sides of the argument." "

15. "I felt this story made a strong case for taking the U.S. troops out of Afghanistan."

16. "I felt this story made a strong case for keeping the U.S. troops in Afghanistan." " 17. "I think this story influenced me regarding how I feel about the subject." * 18. "I think this story did not influence me regarding how I feel about the subject." " 19. Index for self-reported INFLUENCE

\begin{tabular}{|c|c|c|c|c|}
\hline$N$ & $M$ & $S D$ & Kurt & Skew \\
\hline 132 & 0.84 & 18.97 & -0.34 & -0.09 \\
\hline 132 & -5.60 & 20.01 & -0.72 & 0.30 \\
\hline 132 & -6.94 & 15.65 & -0.15 & 0.18 \\
\hline 132 & 17.75 & 16.59 & 0.01 & -0.53 \\
\hline 132 & -15.23 & 16.21 & -0.67 & 0.39 \\
\hline 132 & 10.65 & 16.30 & -0.07 & -0.30 \\
\hline 132 & 19.16 & 16.11 & 0.46 & -0.75 \\
\hline 132 & -3.72 & 17.25 & -0.54 & -0.08 \\
\hline 132 & -12.24 & 11.75 & -0.21 & 0.22 \\
\hline 132 & 14.66 & 15.60 & 0.97 & -0.70 \\
\hline 132 & 0.82 & 11.61 & 4.24 & -0.38 \\
\hline 132 & -0.20 & 15.72 & 0.18 & -0.26 \\
\hline 132 & -1.75 & 16.24 & -0.01 & -0.35 \\
\hline 132 & -4.86 & 18.49 & -0.69 & -0.26 \\
\hline 132 & 9.29 & 19.82 & -0.76 & -0.12 \\
\hline 132 & -7.19 & 18.56 & -0.74 & -0.09 \\
\hline
\end{tabular}


Table 19

Continued

\begin{tabular}{|c|c|c|c|c|c|}
\hline & $N$ & $M$ & $S D$ & Kurt & Skew \\
\hline $\begin{array}{l}\text { 20. SAM Valence dimension for the high } \\
\text { arousal image. * }\end{array}$ & 44 & -26.18 & 11.41 & -0.73 & 0.63 \\
\hline $\begin{array}{l}\text { 21. SAM Arousal dimension for the high } \\
\text { arousal image. * }\end{array}$ & 44 & 5.30 & 17.40 & -0.57 & -0.22 \\
\hline $\begin{array}{l}\text { 22. "How does this image make you feel?" } \\
\text { for the high arousal image. " }\end{array}$ & 44 & -26.30 & 10.75 & -0.41 & 0.65 \\
\hline $\begin{array}{l}\text { 23. "I find this photo to be upsetting to me" } \\
\text { for the high arousal image." }\end{array}$ & 44 & 24.32 & 10.26 & -1.08 & -0.34 \\
\hline $\begin{array}{l}\text { 24. "I feel an emotional reaction when I } \\
\text { look at this photo" for the high arousal } \\
\text { image. " }\end{array}$ & 44 & 24.64 & 11.30 & -0.29 & -0.55 \\
\hline $\begin{array}{l}\text { 25. Valence Index manipulation check for } \\
\text { the high arousal image. }\end{array}$ & 44 & -26.24 & 10.30 & -0.58 & 0.60 \\
\hline $\begin{array}{l}\text { 26. Arousal Index manipulation check for } \\
\text { the high arousal image. }\end{array}$ & 44 & 18.08 & 11.18 & -0.22 & -0.40 \\
\hline $\begin{array}{l}\text { 27. "I have seen photos similar to this } \\
\text { before" for the high arousal image." }\end{array}$ & 44 & 16.45 & 21.53 & 0.30 & -1.03 \\
\hline $\begin{array}{l}\text { 28. "This photo seems familiar to me." for } \\
\text { the high arousal image. " }\end{array}$ & 44 & -8.06 & 28.50 & -1.23 & 0.57 \\
\hline $\begin{array}{l}\text { 29. "I have seen this photo before" for the } \\
\text { high arousal image." }\end{array}$ & 44 & -11.20 & 30.02 & -1.06 & 0.78 \\
\hline $\begin{array}{l}\text { 30. SAM Valence dimension for the low } \\
\text { arousal image. }\end{array}$ & 43 & -11.44 & 12.17 & 0.46 & 0.60 \\
\hline $\begin{array}{l}\text { 31. SAM Arousal dimension for the low } \\
\text { arousal image." }\end{array}$ & 43 & -9.44 & 13.40 & 0.21 & 0.19 \\
\hline $\begin{array}{l}\text { 32. "How does this image make you feel?" } \\
\text { for the low arousal image." }\end{array}$ & 43 & -10.60 & 13.38 & -0.50 & 0.21 \\
\hline $\begin{array}{l}\text { 33. "I find this photo to be upsetting to me" } \\
\text { for the low arousal image. " }\end{array}$ & 43 & 5.60 & 16.98 & 0.02 & -0.77 \\
\hline $\begin{array}{l}\text { 34. "I feel an emotional reaction when I } \\
\text { look at this photo" for low arousal image." }\end{array}$ & 43 & 18.65 & 10.06 & 0.32 & 0.04 \\
\hline $\begin{array}{l}\text { 35. Valence Index manipulation check for } \\
\text { low arousal image. }\end{array}$ & 43 & -11.02 & 11.18 & -0.12 & 0.51 \\
\hline $\begin{array}{l}\text { 36. Arousal Index manipulation check for } \\
\text { the low arousal image. }\end{array}$ & 43 & 4.94 & 9.52 & -0.06 & -0.11 \\
\hline $\begin{array}{l}\text { 37. "I have seen photos similar to this } \\
\text { before" for the low arousal image." }\end{array}$ & 43 & 13.12 & 20.47 & -0.25 & -0.66 \\
\hline $\begin{array}{l}\text { 38. "This photo seems familiar to me." for } \\
\text { the low arousal image. " }\end{array}$ & 43 & -11.53 & 24.61 & -0.57 & 0.71 \\
\hline 39. "I have seen this photo before" for the & 43 & -17.72 & 25.54 & 0.13 & 1.22 \\
\hline
\end{tabular}

Note. All variables are centered, a range of -40 to 40 . $=$ Likert format response bar: Negative scores indicates level of disagreement / positive is level of agreement; $*$ Opposing choice response bar: Negative scores is "slanted against keeping troops in Afghanistan" / positive is for "slanted for keeping troops in Afghanistan." 
MANCOVA. To test the hypotheses, a multiple analysis of covariance (MANCOVA) was used to examine the dependent variables of Afghanistan War support and General Militaristic Attitudes, using photo presentation as the independent variable (three levels: high emotional arousal photo, low arousal photo, no photo) and using covariates of RWA, SDO, and SWI, which were the highest correlated to the dependent variables (from Table 18).

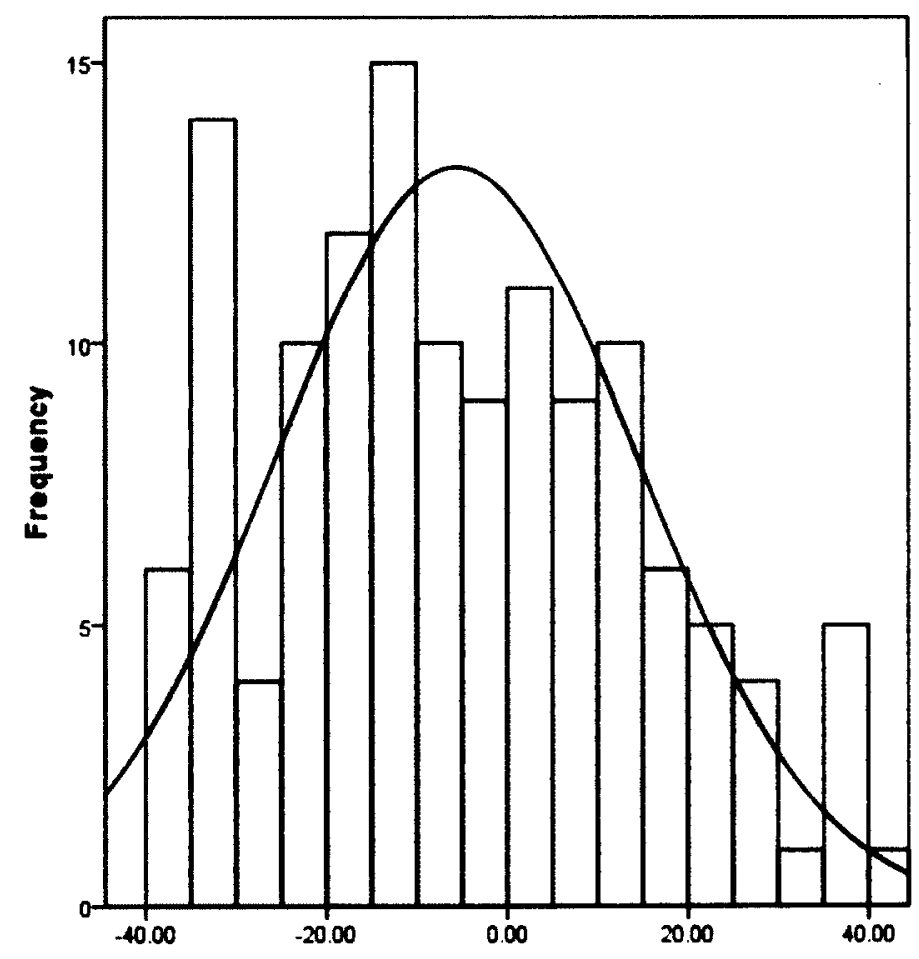

Figures 13. Distribution of scores among participants Experiment 1 for dependent variables (all groups): Index for support of Afghanistan War. 


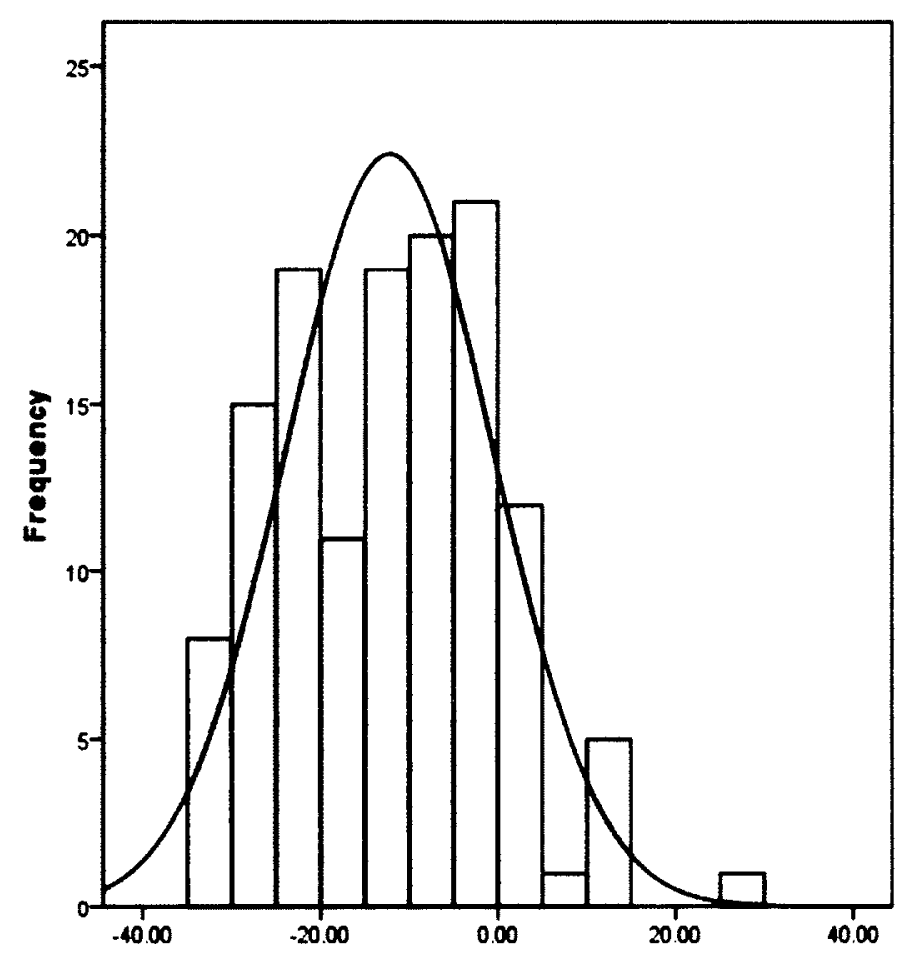

Figure 14. Distribution of scores among participants Experiment 1 for dependent variable in all groups for General Militaristic Attitudes inventory.

For the index for support of Afghanistan War and General Militaristic Attitudes inventory, the assumptions of normality for the dependent variable were examined, (see histograms in Figure 13 and 14). Normality of sampling distributions was analyzed, and despite acceptable skewness and kurtosis measures, a moderately bi-modal pattern was observed when viewing the histograms (see Figures 15 and 16). 


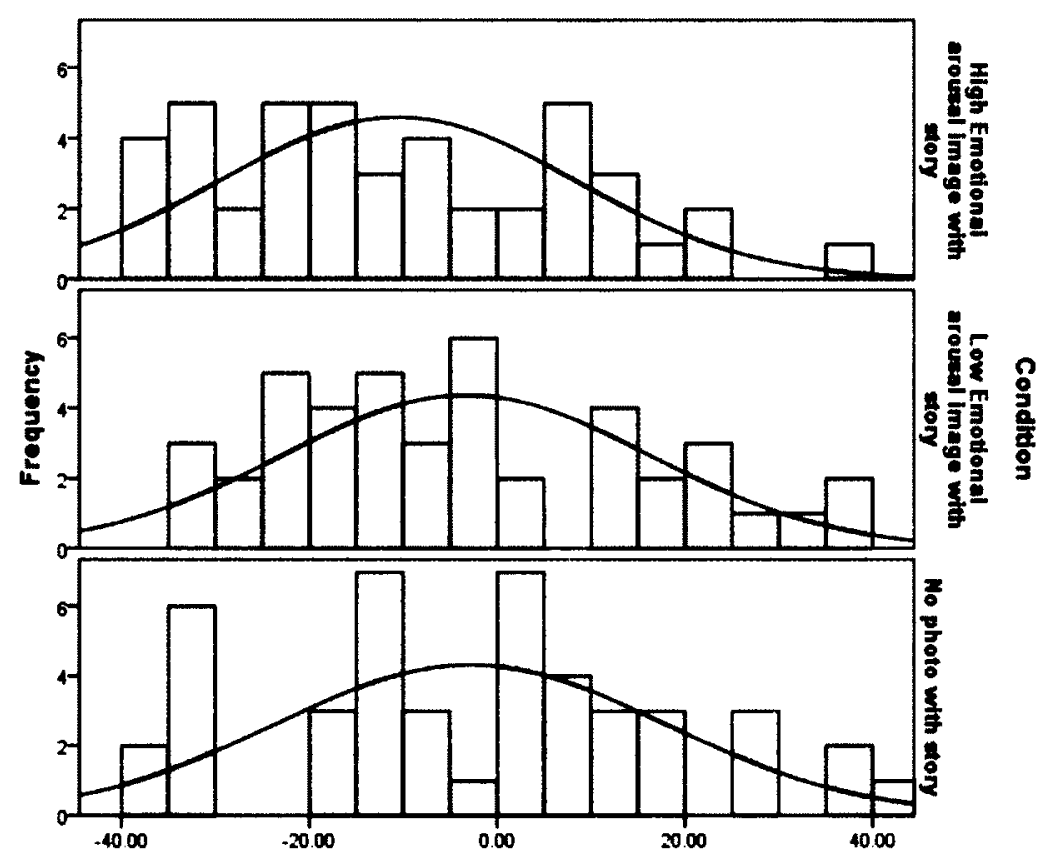

Figure 15. Distribution of scores among participants by group for the index for support of Afghanistan War, the first dependent variable in Experiment 1.

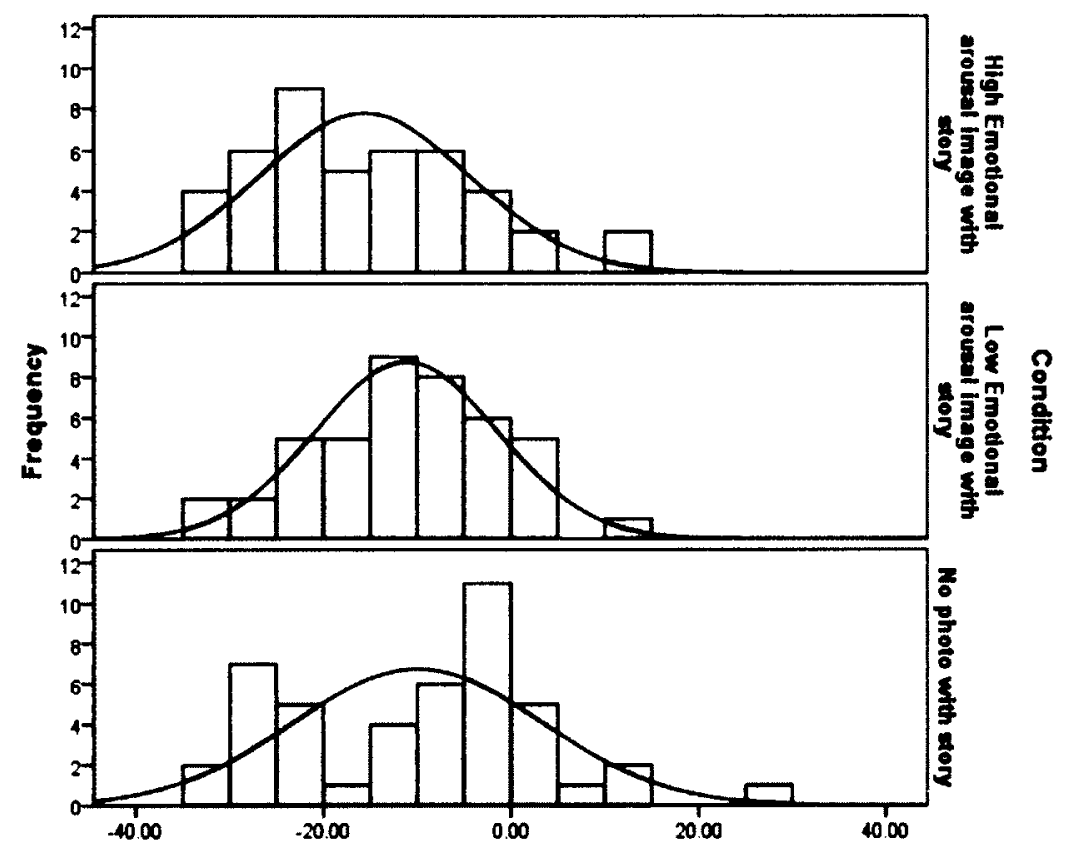

Figure 16. Distribution of scores of Experiment 1 participants by group for General Militaristic Attitudes inventory, the second dependent variable. 
For support of Afghanistan War, the assumption of homogeneity of variance was indicated by a non-significant Levene's test. For General Militaristic Attitudes, the Levene's test showed significance, $F(2,129)=4.00, p=.021$, indicating a heterogeneity of variance for that DV, however the MANCOVA is expected to be robust to this because of equal sizes of the sampling groups. Assumptions for homogeneity of variancecovariance matrices for both dependent variables were satisfied via Box's tests. Scores were examined for univariate outliers as well as multivariate outliers (examining for influence and leverage). Four univariate outliers were found and deleted for this analysis, using a cutoff for any value greater than three standard deviations (Tabachnick \& Fidell, 2001). Additionally, one case was found with a short completion time considered extreme - more than 3 standard deviations less than the mean reading time - and this case was omitted from this and all following analyses.

The overall model was tested for homogeneity of regression and no interaction was observed between the IV and the covariates. The first run of the MANCOVA indicated the covariates of SDO, and the SWI significantly adjusted the dependent variables (all $F$ 's $>3.98, p$ 's $<.048$ ). The levels of adjustment of RWA on the dependent variables was shown to be negligible, $F$ 's $<1.08, p$ 's $>.301$, and RWA was dropped from the model.

The second run of the MANCOVA model (using Roy's Largest Root) found that the combined dependent variables were significantly related to the combined covariates of SDO and SWI, $F(2,127)=6.14, p=.003, \eta_{p}{ }^{2}=.09$, power $=.88(\text { see Figure } 17)^{1}$. For support of the Afghanistan War, significant differences were observed in the follow-up univariate analysis between the participants, $F(2,127)=4.08, p=.019, \eta_{p}{ }^{2}=.06$, power

\footnotetext{
${ }^{1}$ This MANCOVA model showed a slight improvement over the first, $F(2,125)=5.87, p=.004, \eta_{p}^{2}=.09$, power $=.87$.
} 
$=.72$. In orthogonal post-hoc contrasts, significant differences were observed for support of the Afghanistan War between the groups that saw a highly emotionally arousing image and either a low arousal image, or no image, $F(1,127)=7.90, p=.006, \eta_{p}{ }^{2}=.06$, power $=.80$. Participants who saw a highly emotionally arousing image paired with a news story on the Afghanistan War were shown to be significantly less likely to support the war ( $M$ $=-10.14, S D=19.05)$ than were those who saw a low arousal image paired with a story $(M=-2.54, S D=19.63)$, or a story without a picture $(M=-4.09, S D=20.78)$. There were no significant differences observed between the low arousal picture and the no picture conditions, $F(1,127)=0.30, p=.582, \eta_{p}^{2}=.00$, power $=.09$

For General Militaristic Attitudes, significant differences were observed among the groups of participants in their feelings about a militaristic national policy, depending on the image presentation with the news story, while controlling for SDO and SWI, $F(2,127)$ $=4.06, p=.019, \eta_{p}{ }^{2}=.09$, power $=.71$. Orthogonal post-hoc contrasts found a similar pattern to the previous dependent variable, with significant differences for General Militaristic Attitudes observed between the groups that saw a highly emotionally arousing image and either a low arousal image, or no image, $F(1,127)=8.04, p=.005$, $\eta_{p}{ }^{2}=.06$, power $=80$. Participants in the group exposed to a highly emotionally arousing image with a news story reported significantly less preference for a militaristic national policy $(M=-15.32, S D=11.28)$, than did those who saw the story paired with a lowarousal image $(M=-10.96, S D=9.82)$, or the text-only version of the story $(M=-10.46$, $S D=13.30$ ). Again, there were no significant differences observed between the low arousal and the no picture conditions, $F(1,127)=0.07, p=.792, \eta_{p}{ }^{2}=.00$, power $=.06$. 


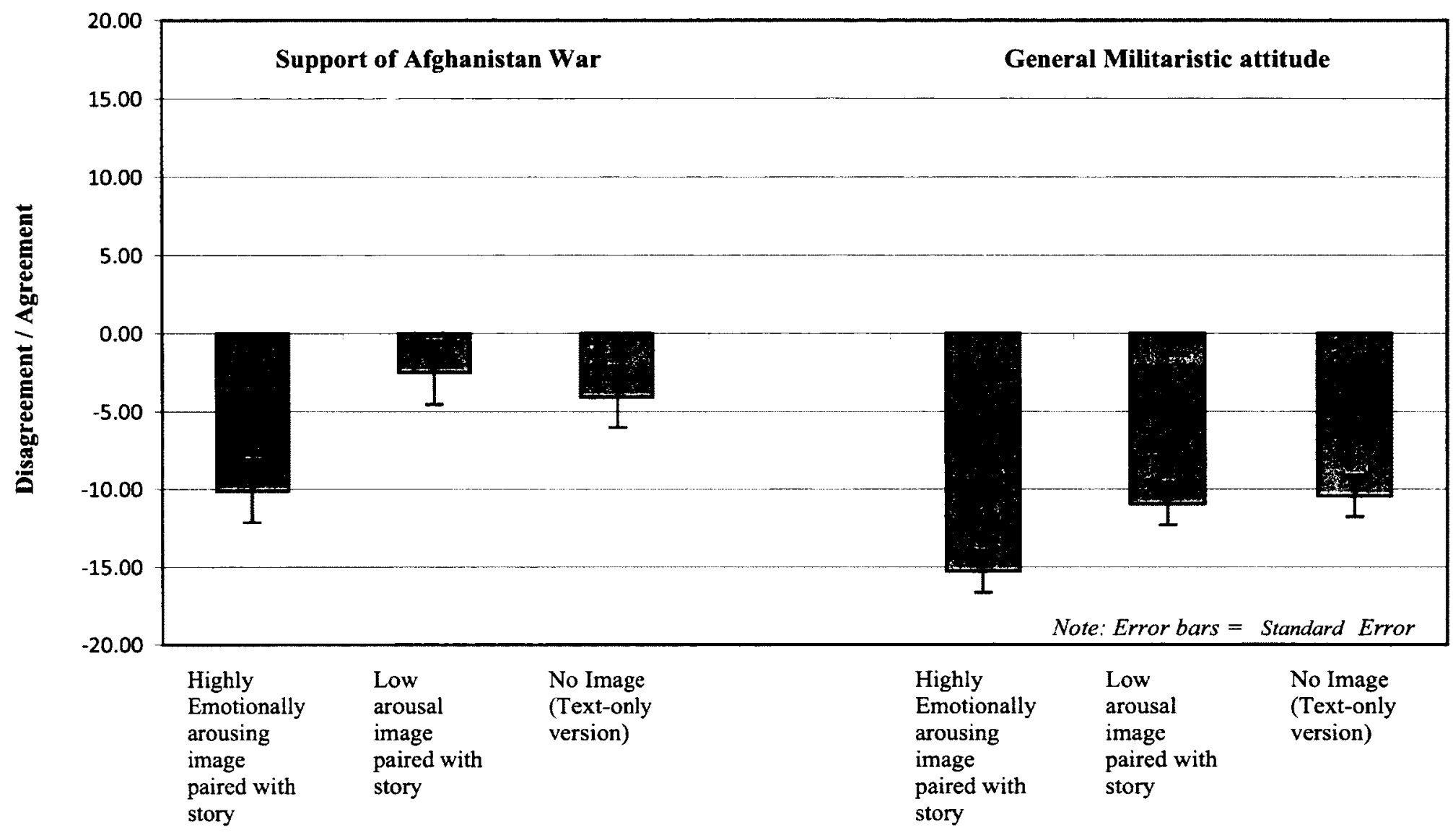

Figure 17. Adjusted means for dependent variables in Experiment 1. 
Exploratory measures. Memory data were coded by two independently working research assistants, who analyzed participants' responses from the memory inventory. The process involved each "coder" using a rubric that contained all the information from the story to count each response to the memory inventory. This produced a sum for all of the information details recalled from the story, as well as the sum of details recalled from the story that were supporting the war in Afghanistan, and also a sum of items opposing the war. After completion, analysis indicated good inter-rater reliability, the coder's data significantly correlating, $r(149)=.67, p<.001$. The data from the coders were averaged to construct scores from the memory data to be used as a variable for analysis. A between-subjects Analysis of Variance (ANOVA) did not show any differences between groups on information remembered from the stories that participants read, $F(2,128)=$ $0.66, p=.517, \eta_{p}^{2}=.01$, power $=.16$. Further analyses examined for differences among groups in recollected story information that either supported or opposed the war. Followup ANOVAs found no effects between groups for information supporting the war, $F(2,128)=1.77, p=.175, \eta_{p}{ }^{2}=.03$, power $=.36$, or information opposing the war, $F(2,128)=0.28, p=.759, \eta_{p}{ }^{2}=.00$, power $=.09$

Participants reported moderate interest in the story, had a general perception of balance and objectivity in the story, and also responded neutrally on whether the story made a strong case for either leaving U.S. troops in Afghanistan or removing the troops. There were no differences between groups for any of these measures, all $F$ 's $<0.83, p$ 's 438. Participants expressed general unfamiliarity with the images presented to them, but indicated seeing similar pictures before. Again, no differences were observed between the groups $\left(F^{\prime} \mathrm{s}<0.87, p>.353\right)$. Interestingly, participants did differ on whether or not they 
reported being influenced by the story, $F(2,128)=4.00, p=.021, \eta_{p}{ }^{2}=.06$, power $=.71$. Participants who saw a story without a photo $(M=-13.39, S D=19.26)$ reported being significantly less influenced by the story than those who saw a highly emotionally arousing image with the story $(M=-4.32, S D=17.38)$ or a low-arousal image with the story $(M=-3.50, S D=17.74)$.

\section{Discussion}

If a news image's power is defined as the ability to change a person's judgments, then Experiment 1 demonstrated that a picture can wield a certain power - but not just any picture. When the story content is held constant, and the photo's emotional valence is held constant (negative), and the analysis controlled for individual differences among the participants - pictures do have the power to change people's minds when the image content is emotionally arousing.

Hypothesis one wasn't supported when, during orthogonal contrasts, no differences were found in the support for the Afghanistan War between those who saw no photo paired with the text, and those who saw a photo, with low emotional arousal. However, when a photo that was highly emotionally arousing was paired with a story, participants reported significantly lower support for the war when compared to those who either saw a low-arousal image or no image at all paired with a story - supporting hypotheses two and three.

When a broader set of judgments was examined for attitudes favoring a militaristic national policy, the very same pattern of effects was observed. Participants exposed to the high arousal image with text were significantly less "hawkish" than those exposed to the low arousal picture with the text, or those who didn't see a photo with the text. 
In the exploratory procedure on recalled information, Experiment 1 was unable to find differences between the three groups in how much people remembered from the story in general, nor in what they recalled of the story that either supported or opposed the war. As disturbing or alarming as the high-arousal image may have been, these participants didn't appear to lose or gain aggregate story comprehension because this image was included in the presentation, at least as measured in the experiment. Further, patterns in recalled information either supporting or opposing the war, which correlated to participant's opinions of support or opposition to the war, might have been consistent with a cost-benefit decision path. No such patterns were observed in the data.

When the participants were polled about how much they felt the story influenced them, an intriguing pattern emerged. All participants indicated that, on the average, they were not influenced by the story. However, those who didn't see an image presented with the text reported significantly lower influence than those who did see an image presented with the story (i.e., either the high or low emotionally arousing images). Participants seem unaware whether they were being influenced or not, as they report as being largely uninfluenced by the story across all the groups. The pattern of effects observed in the dependent variables didn't replicate in this exploratory measure, where participants who had images paired with the text reporting higher levels of influence (or lower levels of non-influence) than those who saw the text-only presentation. An interesting development here was that participants in the low-arousal group indicating they were more influenced than the control (text only) group, when the measures indicated that they, in fact, were not. The results suggest that the degree of influence is not yoked to the metacognitive feeling of being influenced. Whatever influence or power these images 
may have, the mechanisms seem to be operating on an implicit level, beyond the bounds of the participant's own awareness.

A possible limitation to the research was the potential effect of conducting the study in a metropolitan area largely influenced by the military. The campus on which the experiment was conducted is less than 4 miles from the largest Navy base in the world, and within a metropolitan area that boasts a significant military population (SSRC, 2012). It would be difficult to overstate the direct and indirect effects of the social and economic influence of the military in such a location - and it might logically follow that one might see higher than normal support of military action in such an area, even after screening for people with combat experience, their dependents, or those with other direct experience with the War on Terror. There is no way of knowing what the impact or limitations were as a result of the prevailing military-friendly culture. While it may be suspected that the military culture of the area might somehow influence the results of Experiment 1, it is noteworthy to observe effects such as these shown in a strong military area.

A probable limitation was the overrepresentation of female participants in this experiment - not uncommon among convenience samples of those in the college-cohort. A more balanced sample might certainly increase external validity of these results.

Another noteworthy limitation was the level of attrition of participants between the phases of the study. Just over half of the participants invited from the pre-screening study elected to participate in Experiment 1. This "trickle-in effect" constrained the sample and lengthened the lab experiment in ways that could have been challenging to research that is examining effects based on current events and news. 


\section{Pilots for Experiment 2: African Famine Materials}

Experiment 2 was an attempt to replicate the results of Experiment 1 in a different decision domain. A sizable body of scholarly work discusses how photojournalistic depictions of famine have been said to motivate people toward famine aid donations and international assistance (Dogra, 2007; Plewes \& Stuart, 2007; Radley \& Kennedy, 1997). Alternately, repeated exposure to dire images of starvation and pathos has been said to contribute to a "moral habituation" (Zelizer, 1998) or "compassion fatigue" (Moeller, 1999), which has allegedly diminished support for famine assistance over time and mounting deaths (Moeller, 1999; Sontag, 2003). A well-focused empirical study can go far in telling us more about people's reactions to the content of famine imagery, adding to what is, again, a mostly qualitative line of literature.

Based on the attrition observed in Experiment 1, the design of Experiment 2 was re-thought. A two-part experiment was constructed, where both the pre-screening procedure and the primary experiment were both on-campus laboratory trials. In a between-subjects procedure to examine the influence of news images on human judgment formation, we measured directly stated support of U.S. assistance in African Famine Aid as a dependent variable. A second dependent variable was a 4 -item index measuring a broader set of attitudes toward helping others (AHO, Webb, Green, \& Brashear, 2000). As in Experiment 1, the independent variable in this study was the presentation of the news photo, at three levels: high emotional arousal, low emotional arousal, and no photo.

\section{Method: Famine Images Pilot Testing}

Just as before, to prepare for the second experiment, pre-experimental pilot tests measured emotional effects from the materials that were to be used. These pilot studies 
were largely identical to those for Experiment 1, with the exception of the experimental materials and stimuli that were presented to the participants.

Participants. Volunteers $(N=22)$ were recruited to the pilot study via the SONA Research participation system (Appendix T), volunteering in exchange for class research credit. Six of the participants were male and 18 were female. Participants ranged in age from 18 to 28 , with 15 participants $(62.5 \%)$ between 18 and 20 , and $9(37.5 \%)$ were between 21 and 28. All participants were fluent in English.

Materials. The training video, and the computer-administered experimental procedure were identical to those used in the pilot tests for the Afghanistan images, which were described earlier, with the exception of the famine-related photos used as experimental stimuli.

News photos. News photos were selected to depict a range of arousal levels from the Associated Press. The set contained seven images showing African famine victims. The content among this selection of images could be interpreted as having various degrees of emotionally arousing or disturbing content (Appendix U).

Procedure. The briefing of participants, and computer procedure Training Phase were identical to the previously described image pilot study. The image assessment phase was also the same as before, except for the inclusion of African famine-related news images. After completion, participants were debriefed, given opportunities to ask questions about the procedure, and excused.

Analysis. Response scores for all items were tabulated for the seven images (see Tables 20-26 for descriptive statistics on each image). The participants reported general unfamiliarity with all of the specific images, yet indicated that they had "seen photos like 
them before." As in the previous pilot studies, the valence was computed for the images, with all images scoring below midpoint, indicating significant negative valence for each of the images used in the pilot study (Figure 18). Measures of the emotional arousal were established for each image as before, (Figure 19). An image of hundreds of people gathered outside in food lines at a Somalia refugee camp (see Figure U6, in Appendix U) was identified as the image with the lowest level of emotional arousal among the responses $(M=-2.98 ; S D=14.15)$. An image of an emaciated and crying baby being held in a clinic at Somalia refugee camp (see Figure U3, in Appendix U) was selected as the image with high emotional arousal, $(M=26.71 ; S D=11.22)$, and showed significantly higher arousal than the low arousal image, $t(23)=-8.56, p<.001, d=.85,95 \% \mathrm{CI}[-$ $36.61,-22.36]$. These two images were selected as those to be used as stimuli in the second experiment.

\section{Table 20}

Summary of descriptive statistics for African Famine Pilot Image 1: Image of tents in a Somalia refugee camp during famine in late 2011. (AP Photo).

\begin{tabular}{lcccc}
\hline & $M$ & $S D$ & Kurt & Skew \\
\hline 1. SAM Valence dimension & -17.13 & 12.85 & -0.71 & 0.05 \\
2. SAM Arousal dimension & -9.00 & 20.65 & -1.45 & 0.09 \\
3. "How does this image make you feel?" (Unpleasant $~$ Pleasant) & -13.83 & 13.91 & -1.00 & 0.13 \\
4. "This photo is upsetting to me." & 12.13 & 15.69 & -0.53 & -0.44 \\
5. Averaged Valence Measures & -15.48 & 12.73 & -1.26 & 0.11 \\
6. Averaged Arousal Measures & -5.93 & 15.42 & -1.16 & -0.12 \\
7. "I feel an emotional reaction from looking at this photo." & 14.67 & 17.82 & 2.17 & -1.24 \\
8. "I have seen this photo before." & -22.75 & 19.93 & 3.07 & 1.91 \\
9. "This photo seems familiar" & -12.54 & 22.01 & -1.06 & 0.58 \\
10. "I have seen photos like this before." & 19.00 & 19.88 & 0.00 & -1.01
\end{tabular}

Note. $N=24$. All variables are centered, a range of -40 to 40 . See Figure U1, in Appendix U. 
Table 21

Summary of descriptive statistics for African Famine Pilot Image 2: People gathered within a shelter in a Somalia refugee camp during famine in late 2011. (AP Photo).

\begin{tabular}{lcccc}
\hline & $M$ & $S D$ & Kurt & Skew \\
\hline 1. SAM Valence dimension & -20.25 & 12.94 & -1.26 & 0.22 \\
2. SAM Arousal dimension & -4.96 & 18.51 & -0.82 & 0.10 \\
3. "How does this image make you feel?" (Unpleasant $~$ Pleasant) & -19.29 & 15.19 & -1.28 & 0.29 \\
4. "This photo is upsetting to me." & 15.21 & 19.53 & -0.59 & -0.66 \\
5. Averaged Valence Measures & -19.77 & 13.42 & -1.29 & 0.38 \\
6. Averaged Arousal Measures & 9.90 & 15.03 & -1.10 & -0.20 \\
7. "I feel an emotional reaction from looking at this photo." & 19.46 & 16.82 & 2.27 & -1.16 \\
8. "I have seen this photo before." & -19.42 & 21.88 & 0.59 & 1.28 \\
9. "This photo seems familiar" & -12.67 & 21.39 & 0.14 & 0.91 \\
10. "I have seen photos like this before." & 21.29 & 19.79 & 2.62 & -1.64
\end{tabular}

Note. $N=24$. All variables are centered, a range of -40 to 40 . See Figure U2, in Appendix U.

Table 22

Summary of descriptive statistics for African Famine Pilot Image 3: Hundreds gathered and sitting outside in a Somalia refugee camp during famine in late 2011. (AP)

\begin{tabular}{lcccc}
\hline & $M$ & $S D$ & Kurt & Skew \\
\hline 1. SAM Valence dimension & -12.88 & 15.68 & -0.66 & -0.52 \\
2. SAM Arousal dimension & -10.33 & 19.34 & 0.48 & 0.83 \\
3. "How does this image make you feel?" (Unpleasant $~$ Pleasant) & -12.08 & 16.01 & -1.12 & -0.66 \\
4. "This photo is upsetting to me." & 9.71 & 18.31 & -0.36 & -0.06 \\
5. Averaged Valence Measures & -12.48 & 15.66 & -0.91 & -0.64 \\
6. Averaged Arousal Measures & 4.36 & 15.34 & 0.00 & 0.69 \\
7. "I feel an emotional reaction from looking at this photo." & 13.71 & 15.10 & -0.82 & 0.47 \\
8. "I have seen this photo before." & -26.08 & 18.05 & 4.06 & 2.10 \\
9. "This photo seems familiar" & -13.00 & 21.94 & -1.00 & 0.67 \\
10. "I have seen photos like this before." & 17.92 & 21.36 & 0.72 & -1.26
\end{tabular}

Note. $N=24$. All variables are centered, a range of -40 to 40 . See Figure U4, in Appendix U. 
Table 23

Summary of descriptive statistics for African Famine Pilot Image 4: Hundreds gathered outside in food lines in a Somalia refugee camp during famine in late 2011. (AP)

\begin{tabular}{lcccc}
\hline & $M$ & $S D$ & Kurt & Skew \\
\hline 1. SAM Valence dimension & -10.00 & 13.12 & 0.17 & -0.74 \\
2. SAM Arousal dimension & -14.83 & 15.64 & -0.24 & 0.37 \\
3. "How does this image make you feel?" (Unpleasant Pleasant) & -6.50 & 11.31 & 1.55 & -1.13 \\
4. "This photo is upsetting to me." & -1.21 & 19.27 & -0.31 & -0.01 \\
5. Averaged Valence Measures & -8.25 & 11.14 & 1.59 & -1.16 \\
6. Averaged Arousal Measures & -2.78 & 14.15 & 0.35 & 0.05 \\
7. "I feel an emotional reaction from looking at this photo." & 7.71 & 14.97 & 2.57 & -0.76 \\
8. "I have seen this photo before." & -19.71 & 20.42 & 0.21 & 1.13 \\
9. "This photo seems familiar" & -13.50 & 24.34 & -0.94 & 0.71 \\
10. "I have seen photos like this before." & 14.46 & 20.46 & 0.73 & -1.15
\end{tabular}

Note. $N=24$. All variables are centered, a range of -40 to 40 . See Figure U6, in Appendix U.

Table 24

Summary of descriptive statistics for African Famine Pilot Image 5: Emaciated, crying baby held in a clinic at Somalia refugee camp during famine in late 2011. (AP)

\begin{tabular}{lcccc}
\hline & $M$ & $S D$ & Kurt & Skew \\
\hline 1. SAM Valence dimension & -32.42 & 9.85 & 1.17 & 1.43 \\
2. SAM Arousal dimension & 16.21 & 19.18 & -1.59 & -0.09 \\
3. "How does this image make you feel?" (Unpleasant $~$ Pleasant) & -31.58 & 10.19 & 1.17 & 1.54 \\
4. "This photo is upsetting to me." & 33.00 & 8.72 & 1.06 & -1.35 \\
5. Averaged Valence Measures & -32.00 & 9.66 & 1.52 & 1.55 \\
6. Averaged Arousal Measures & 26.71 & 11.22 & -0.85 & -0.47 \\
7. "I feel an emotional reaction from looking at this photo." & 30.92 & 15.54 & 10.16 & -2.89 \\
8. "I have seen this photo before." & -22.96 & 20.14 & 1.78 & 1.55 \\
9. "This photo seems familiar" & -3.21 & 27.28 & -1.49 & 0.20 \\
10. "I have seen photos like this before." & 26.21 & 17.20 & 4.37 & -1.91
\end{tabular}

Note. $N=24$. All variables are centered, a range of -40 to 40 . See Figure U3, in Appendix U. 
Table 25

Summary of descriptive statistics for African Famine Pilot Image 6: Emaciated, starving baby held in a clinic at Somalia refugee camp during famine in late 2011. (AP)

\begin{tabular}{lcccc}
\hline & $M$ & $S D$ & Kurt & Skew \\
\hline 1. SAM Valence dimension & -35.08 & 6.64 & 7.01 & 2.39 \\
2. SAM Arousal dimension & 14.00 & 22.32 & -0.74 & -0.58 \\
3. "How does this image make you feel?" (Unpleasant Pleasant) & -32.38 & 8.13 & 1.63 & 1.44 \\
4. "This photo is upsetting to me." & 32.92 & 9.76 & 1.43 & -1.38 \\
5. Averaged Valence Measures & -33.73 & 6.98 & 4.98 & 2.02 \\
6. Averaged Arousal Measures & 25.63 & 11.94 & -1.03 & -0.49 \\
7. "I feel an emotional reaction from looking at this photo." & 29.96 & 17.03 & 11.91 & -3.11 \\
8. "I have seen this photo before." & -24.50 & 20.60 & 2.29 & 1.82 \\
9. "This photo seems familiar" & -9.21 & 26.01 & -1.13 & 0.57 \\
10. "I have seen photos like this before." & 23.79 & 17.94 & 1.37 & -1.42
\end{tabular}

Note. $N=24$. All variables are centered, a range of -40 to 40 . See Figure U5, in Appendix U.

Table 26

Summary of descriptive statistics for African Famine Pilot Image 7: Emaciated, starving baby staring into camera in a clinic at Somalia refugee camp during 2011 famine. (AP)

\begin{tabular}{lcccc}
\hline & $M$ & $S D$ & Kurt & Skew \\
\hline 1. SAM Valence dimension & -34.42 & 6.79 & 4.08 & 1.95 \\
2. SAM Arousal dimension & 14.29 & 18.95 & -0.01 & -0.39 \\
3. "How does this image make you feel?" (Unpleasant $~$ Pleasant) & -32.67 & 8.71 & 2.95 & 1.82 \\
4. "This photo is upsetting to me." & 32.58 & 9.48 & 0.91 & -1.37 \\
5. Averaged Valence Measures & -33.54 & 7.29 & 4.84 & 2.08 \\
6. Averaged Arousal Measures & 26.75 & 10.19 & -0.83 & -0.40 \\
7. "I feel an emotional reaction from looking at this photo." & 33.38 & 8.45 & 0.16 & -1.08 \\
8. "I have seen this photo before." & -26.67 & 18.68 & 5.61 & 2.43 \\
9. "This photo seems familiar" & -10.08 & 26.74 & -1.46 & 0.44 \\
10. "I have seen photos like this before." & 19.83 & 22.01 & 1.03 & -1.33
\end{tabular}

Note. $N=24$. All variables are centered, a range of -40 to 40 . See Figure U7, in Appendix U. 


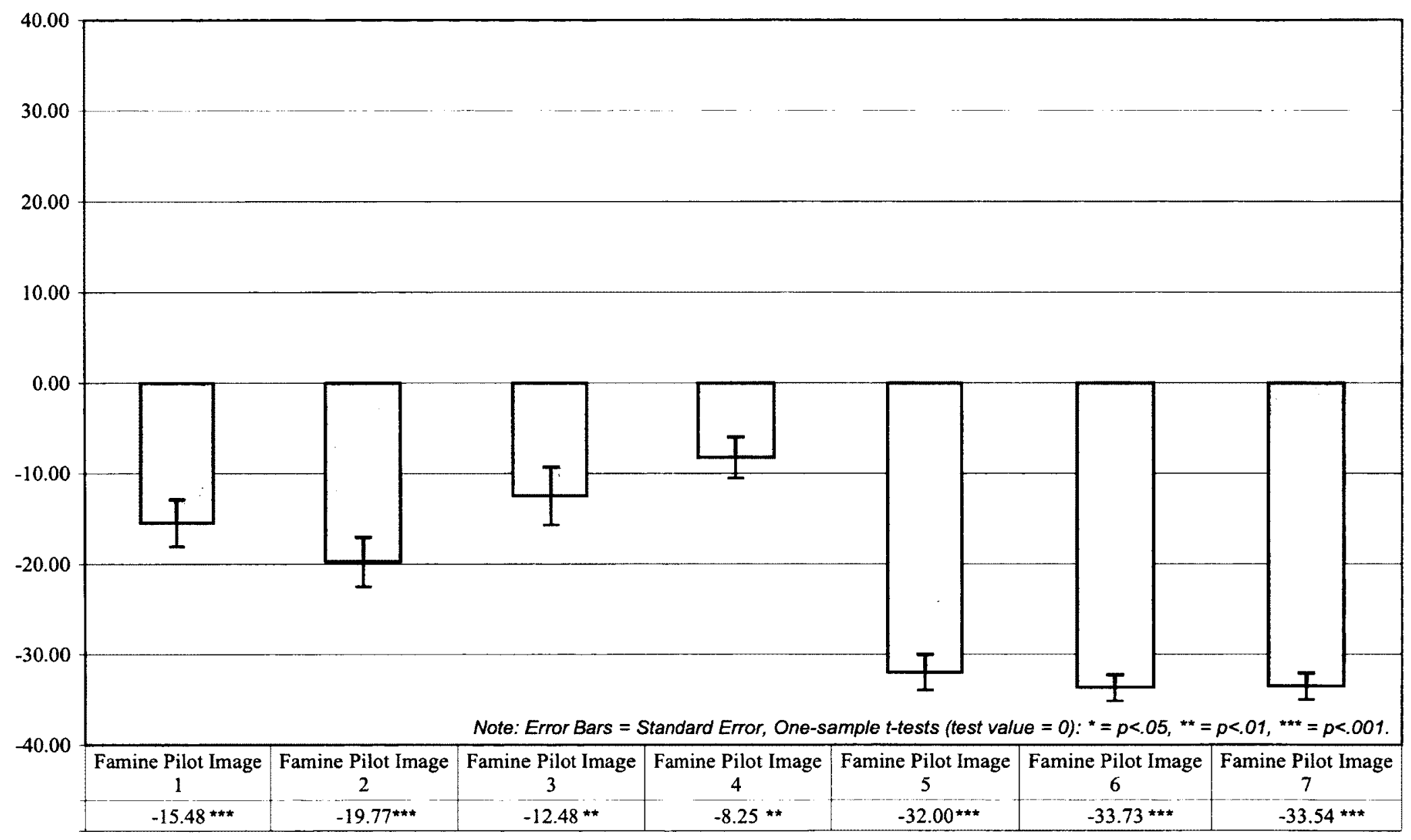

Figure 18. Directions of mean emotional valence measures for images in African Famine pilot study, showing $t$-tests results. 


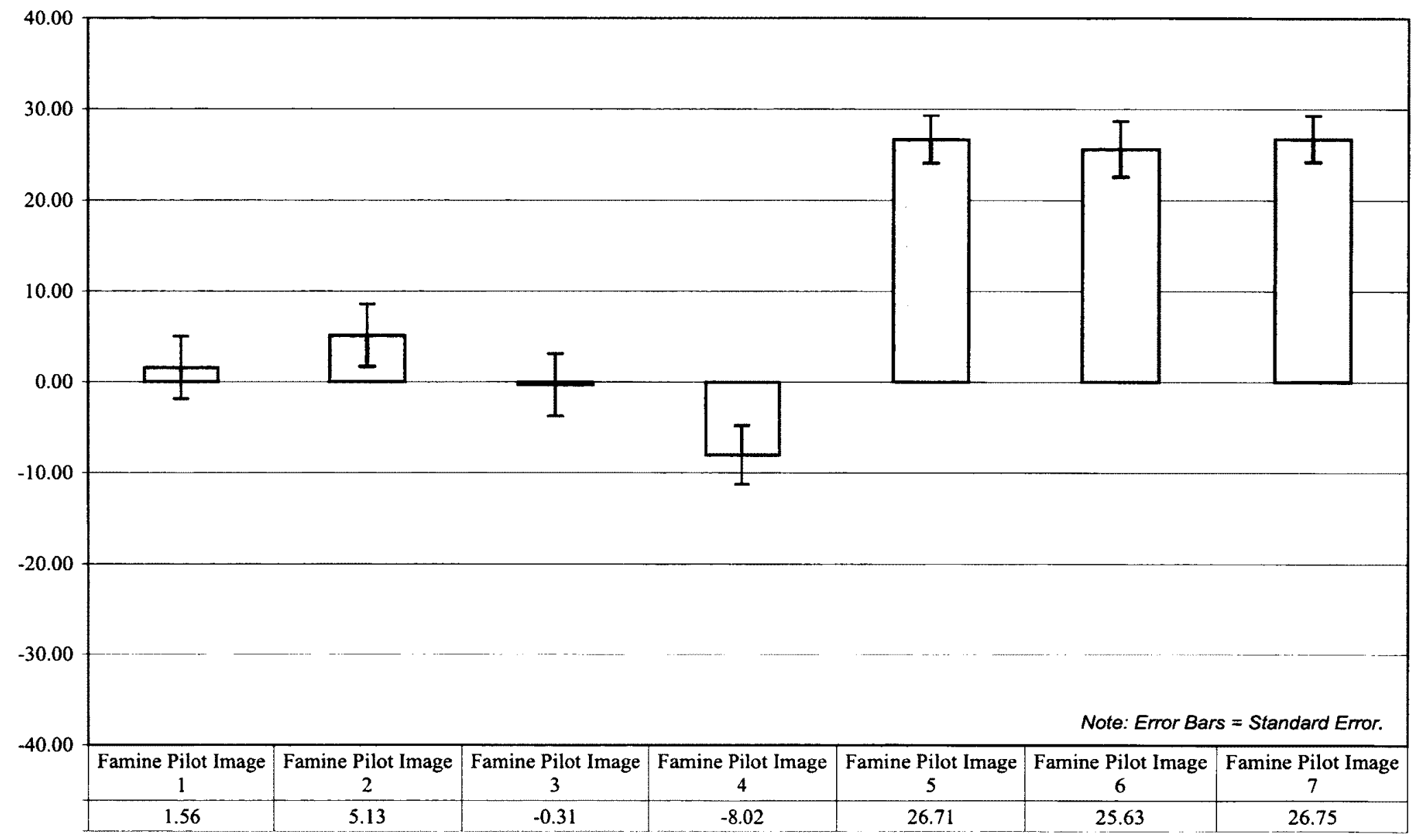

Figure 19. Means of emotional arousal for images in African Famine pilot study. 


\section{Method: Famine Text Pilot Testing}

As in Experiment 1, a pilot study was developed to test the degree of influence and balance of the accompanying text for use as stimuli for Experiment 2.

Participants. Subjects $(N=22)$ were recruited to the pilot study via the SONA Research participation system, and volunteered in exchange for class research credit. Four participants were male and 18 were female. They ranged in age from 18 to 22 , with $17(77.3 \%)$ between 18 and 20 , and with five participants $(22.7 \%)$ who were either 21 or 22. All were fluent in English.

Materials. All equipment and materials, including the computer procedures and training video, were identical to those used in the previous pilot study on the Afghanistan War text. The only difference in the computer procedure was the "news story" text about the U.S. support of African Famine Aid, and response items referring specifically to the text.

Famine text. A text was constructed to emulate a news story about U.S. support of humanitarian assistance for countries afflicted by the African Famine. The text was a heavily edited version of a story from the British newspaper, The Guardian (Tisdall, 2012). The 203-word text discussed the choices the United States faced in support of African Famine Aid (see Appendix V). As with the previous text about the Afghanistan War, the text was edited and constructed in such a way as to motivate the story into an ongoing debate, using inserts of quotes and reactions from online commenters. Quotes were inserted that depicted difference of opinions, balancing both pro and con statements to exert minimal influence on the reader. 
Procedure. The experimental procedure for the famine text pilot study was identical to the previous Afghanistan text pilot study, with the exception of the use of the famine-related text, and response items that referred explicitly to the text. These included items such as "I support the United States sending hunger assistance to African countries in famine," "I am against the United States sending hunger assistance to African countries in famine", in pre-test and post-test observations, measured using the 81-point response bar device. Also, items were included that asked about perceptions as to the general balance or editorial slant of the story, such as: "I felt this story made a strong case for continuing U.S. famine aid to Africa." "I felt this story made a strong case for halting U.S. famine aid to Africa."; "I felt this story was slanted in favor of one of the sides of the argument," where the responses were "slanted for [or 'against'] US sending famine aid."

Analysis. Responses for all items were calculated (see descriptive statistics in Table 27). The respondents reported only slight agreement in feeling influenced by the story, that it made a strong case for continuing U.S. Famine Aid to Africa, and in the influential nature of the text. For an index of general support of U.S. Famine Aid to Africa, centered scores of Famine Aid support were averaged with reversed scores of opposition to aid, which were found to be reliable, (Cronbach's alphas at .86 and .97 , respectively). The participant's general support of U.S. Famine Aid to Africa did not shift significantly after reading the text, $t(21)=0.89, p=.385, d=.19,95 \% \mathrm{CI}[-2.26,5.63]$. The results indicate that the famine text did not significantly influence participants, and was a good choice as experimental stimuli. 
Table 27

Summary of descriptive statistics for participant responses in the text pilot for the African Famine text.

\begin{tabular}{|c|c|c|c|c|}
\hline & $M$ & $S D$ & Kurt & Skew \\
\hline $\begin{array}{l}\text { 1. "I support the United States sending hunger assistance to } \\
\text { African countries in famine." (pre-test) }\end{array}$ & 25.43 & 12.22 & 0.40 & -0.94 \\
\hline $\begin{array}{l}\text { 2. "I am against the United States sending hunger assistance to } \\
\text { African countries in famine. (pre-test) }\end{array}$ & 21.26 & 13.70 & -0.19 & -0.94 \\
\hline $\begin{array}{l}\text { 3. "I support the United States sending hunger assistance to } \\
\text { African countries in famine." (post-test) }\end{array}$ & 23.74 & 13.56 & 0.58 & -1.09 \\
\hline $\begin{array}{l}\text { 4. "I am against the United States sending hunger assistance to } \\
\text { African countries in famine." (post-test) }\end{array}$ & 19.61 & 16.44 & 1.26 & -1.25 \\
\hline $\begin{array}{l}\text { 5. "I felt this story made a strong case for continuing U.S. famine } \\
\text { aid to Africa." }\end{array}$ & 5.04 & 18.16 & -0.90 & 0.19 \\
\hline $\begin{array}{l}\text { 6. "I felt this story made a strong case for halting U.S. famine aid } \\
\text { to Africa." }\end{array}$ & -9.43 & 18.07 & -0.96 & 0.02 \\
\hline $\begin{array}{l}\text { 7. "I think this story may have influenced me regarding how I feel } \\
\text { about the subject." }\end{array}$ & 12.39 & 13.85 & -0.99 & -0.21 \\
\hline $\begin{array}{l}\text { 8. "I think this story did not influence me regarding how I feel } \\
\text { about the subject." }\end{array}$ & -6.09 & 16.58 & -0.15 & 0.64 \\
\hline $\begin{array}{l}\text { 9. "I felt this story was slanted in favor of one of the sides of the } \\
\text { argument." }\end{array}$ & 7.52 & 14.14 & 1.46 & 0.13 \\
\hline 10. General support of African Famine Aid. (pre-test) & 24.35 & 12.17 & -1.06 & -0.63 \\
\hline 11. General support of African Famine Aid. (post-test) & 22.67 & 14.81 & 0.97 & -1.19 \\
\hline \multicolumn{5}{|c|}{$\begin{array}{l}\text { Note. } N=22 \text {. All variables are centered, a range of }-40 \text { to } 40.4=\text { Likert format response bar: Negative } \\
\text { scores indicates level of disagreement / positive is level of agreement; } *=\text { Opposing choice response } \\
\text { bar: Negative scores trend toward "slanted against US sending famine aid," positive trend toward } \\
\text { "slanted in favor of US sending famine aid," scores close to zero indicate perceptions that "story was } \\
\text { balanced." }\end{array}$} \\
\hline
\end{tabular}

\section{Method: Pre-screening survey for Experiment 2}

Experiment 2 was identical to the methods and measures in Experiment 1 in most

ways. The overarching design followed the Experiment 1 model, with a pre-screening procedure that was followed by a between-subjects experimental protocol in a subsequent session. The primary changes were that the pre-screening procedure would be administered within a laboratory environment. It became apparent that the attrition of participants in Experiment 1 presented some profound challenges to the completion of the 
first study, where $54 \%$ of participants passed the pre-screening, and with $53 \%$ of those going on to sign up for the on-campus procedures. With a finite pool of participants at a mid-sized university, a more parsimonious plan for Experiment 2 where the participants sign up for an entirely on-campus procedure was a way to control the erosion of participants.

Participants. Volunteers were recruited from the pool of undergraduate students for a two-part on-campus study (Appendix W). The 167 volunteers were restricted to U.S. citizens, at least 18 years of age, (demographics in Tables 28 and 29), and received class credit as compensation for their research participation.

Materials. The pre-screening survey was constructed using E-Prime experimental programming software, and was built to emulate the basic structure of the online prescreening survey for Experiment 1. A point-and-click interface (Appendix X) was designed to let participants respond to the surveys items of the pre-screening procedure, using "buttons" on the screen arranged in Likert scale formats as well as multiple-choice survey questions. The E-Prime design also allowed for use of the 81-point Likert-format response bar for some items. The procedure was administered using PCs available within a university computer lab.

Training video. A short training video (Running time: $4: 47$ ) was created by reediting old video material and shooting new material to show the new computer interface for the procedure, and produced in the same manner as previously (Appendix Y). 
Table 28

Prescreening Study for Experiment 2: Demographics on participants who completed the pre-screening procedure.

\begin{tabular}{lcccccc}
\hline & \multicolumn{2}{c}{ Gender } & & \multicolumn{3}{c}{ Age } \\
\cline { 2 - 5 } & $N$ & $\%$ & $M$ & $S D$ & Min/Max \\
\hline Male & 43 & 25.7 & 21.49 & 4.98 & $18 / 44$ \\
Female & 124 & 74.3 & 21.16 & 4.61 & $18 / 49$ \\
& 167 & & 21.25 & 5.65 & $18 / 49$
\end{tabular}

Table 29

Prescreen study Prescreening Study for Experiment 2: Frequency distribution of participants who completed prescreening study by age.

\begin{tabular}{rrr}
\hline & Frequency & Percent \\
\hline 18 & 39 & 23.4 \\
19 & 33 & 19.8 \\
20 & 26 & 15.6 \\
21 & 24 & 14.4 \\
22 & 16 & 9.6 \\
23 & 4 & 2.4 \\
24 & 5 & 3.0 \\
25 & 2 & 1.2 \\
26 & 1 & .6 \\
27 & 6 & 3.6 \\
28 & 1 & .6 \\
31 & 1 & .6 \\
32 & 2 & 1.2 \\
33 & 2 & 1.2 \\
34 & 2 & 1.2 \\
43 & 1 & .6 \\
44 & 1 & .6 \\
49 & 1 & .6 \\
& 167 & 100
\end{tabular}


$R W A, S D O$, and General Inventory. The same inventories used in the previous pre-screening procedure were administered in Experiment 2. The single difference will be in the General Inventory items, where participant responses were collected using the 81point Likert-format response bar. The General Inventory included items addressing dependent variables for Experiment 2 (e.g., "I support America sending aid to faminestricken countries in Africa; I am against America sending aid to famine-stricken countries in Africa; America should send more aid to famine stricken countries in Africa because it could save lives; America should gradually begin to stop sending aid to African countries stricken by famine and hunger"). This Support for Famine Aid Pretest (SFAP) produced a reliable measure for famine aid support by averaging the four items, after reversing the two items citing opposition and gradually stopping the aid, Cronbach's alpha $=.85$.

Attitude toward Charitable Organizations (ACO). A dimension worthy of consideration regarding the support of hunger relief is the individual attitudes regarding the humanitarian aid organizations themselves. A useful scale to evaluate such individual differences is the Attitude toward Charitable Organizations (ACO, Webb, et al., 2000). The ACO (Appendix Z), along with another scale (Attitudes toward Helping Others, $\mathrm{AHO}$ ), was developed to measure dimensions predictive of donating practices among individuals. The five items, presented in 7-point Likert responses, were collected and summed, with a range of 5 to 35 , with higher scores indicate attitudes favoring charitable organizations. The ACO is a reliable scale (Cronbach's alpha $=.82)$ and correlates significantly with people's giving behaviors (Webb, et al., 2000). The ACO was included in the pre-screening procedure in consideration for use as a covariate in the final analysis. 
Exclusionary screening questions. The restrictive screening items remained mostly unchanged from those in the previous pre-screening procedure. Two items screened for inattentive, or unreliable respondents (e.g., "I am paying attention to the questions on this survey," "Please select 'Moderately Agree' for this item."), and a colorblindness self-report item also remained. No items were included polling the participants of any direct involvement or experiences with African famine. One item was included inquiring if the participant was a United States citizen, in order to insure that the study's citizenship restriction was observed.

Procedure. Participants were welcomed, seated in the campus computer lab and, after signing the participation agreement, they began the briefing. They were informed that this was the first part of a two-session experiment, and that the first session was a series of demographic and opinion-seeking surveys. The experimental programs were launched by participants, and immediately entered a brief Training Phase, by watching the training video.

Following the video, the participants immediately went into a series of surveys. Each survey began by a screen showing brief instructions followed by the survey items, presented one question at a time. Participants began with the RWA, followed by the SDO. Before responding to the ACO inventory, participants completed a brief eight-item survey as a distracter task. The distracter survey was unrelated to the judgments of interest, yet similar in their inquiry into social attitudes (Belief in Just World for self, Lipkus, Dalbert, \& Siegler, 1996). This distracter survey was placed before the ACO to throw off participant's attention to the ACO's items, which directly address the topic of interest. After moving on to complete the ACO, participants proceeded through a second 
distracter survey, which was another eight item "companion" survey to the previous one (Belief in Just World for other, Lipkus, et al., 1996). Participants proceeded to complete the General Inventory, which was the last of the surveys. They were then debriefed, excused, and reminded to return for the second session on the following week.

Results. The 167 pre-screening participants all received screening items to determine their eligibility to be in the experimental sample. All of those in this sample reported that they were not colorblind. In the first screening item (i.e., "Please select 'Moderately agree' for this item") 13 volunteers (7.8\%) failed to choose "moderately agree". One participant $(0.7 \%)$ responded negatively to the second exclusionary item "I am paying attention to the questions in this survey." One participant $(0.6 \%)$ was excluded because they indicated they were 10 years old during the experimental procedure. One person $(0.6 \%)$ indicated that they were not a U.S. citizen.

In summary, of the original 167 participants who completed the survey, 16 participants (14.1\%) were screened, leaving 151 participants retained for the experimental sample. The remaining discussion of the pre-screening results will address this sample $(N=151$, see demographics in Tables 30-34). 
Table 30

Prescreening Study for Experiment 2: Demographics on participants in pre-screening who were retained for Experiment 2.

\begin{tabular}{lcccccc}
\hline & \multicolumn{2}{c}{ Gender } & & \multicolumn{3}{c}{ Age } \\
\cline { 3 - 3 } \cline { 5 - 7 } & $N$ & $\%$ & & $M$ & $S D$ & Min/Max \\
\hline Male & 37 & 24.5 & 21.73 & 5.28 & $18 / 44$ \\
Female & 114 & 75.5 & 21.17 & 4.63 & $18 / 49$ \\
Total & 151 & 100 & 21.30 & 4.78 & $18 / 49$
\end{tabular}

Table 31

Prescreening Study for Experiment 2:

Frequency distribution of participants who were retained for Experiment 2.

\begin{tabular}{rrr}
\hline & Frequency & Percent \\
\hline 18 & 36 & 23.8 \\
19 & 28 & 18.5 \\
20 & 23 & 15.2 \\
21 & 22 & 14.6 \\
22 & 15 & 9.9 \\
23 & 4 & 2.6 \\
24 & 4 & 2.6 \\
25 & 2 & 1.3 \\
26 & 1 & .7 \\
27 & 6 & 4.0 \\
28 & 1 & .7 \\
31 & 1 & .7 \\
32 & 2 & 1.3 \\
33 & 2 & 1.3 \\
34 & 1 & .7 \\
43 & 1 & .7 \\
44 & 1 & .7 \\
49 & 1 & .7 \\
& 151 & 100
\end{tabular}


Table 32

Prescreen study for Experiment 2: Frequency distribution of participants who were retained for Experiment 2, by religion.

\begin{tabular}{lll}
\hline & Frequency & Percent \\
\hline Protestant & 35 & 23.2 \\
Catholic & 18 & 35.1 \\
Jewish & 0 & 0 \\
Mormon / LDS & 0 & 0 \\
Islam & 1 & .7 \\
Hindu & 1 & .7 \\
Other & 60 & 39.7 \\
No preference / No religious affiliation & 29 & 19.2 \\
Would rather not say & 7 & 4.6 \\
Total & & 100.0
\end{tabular}

Table 33

Prescreen study for Experiment 2. Frequency distribution by "How active are you in the practice of your religion?"

\begin{tabular}{lll}
\hline & Frequency & Percent \\
\hline Very active & 22 & 14.6 \\
Somewhat active & 56 & 37.1 \\
Not very active & 41 & 27.2 \\
Not active & 0 & 0 \\
Does not apply & 30 & 19.9 \\
Would prefer not to say & 2 & 1.3 \\
Total & 151 & 100.0
\end{tabular}


Table 34

Prescreen study for Experiment 2: Frequency distribution of participants who were retained for Experiment 2, by political affiliation.

\begin{tabular}{lll}
\hline & Frequency & Percent \\
\hline Conservative & 25 & 16.6 \\
Green Party & 1 & .7 \\
Independent & 18 & 11.9 \\
Liberal & 36 & 23.8 \\
Libertarian & 3 & 2.0 \\
Moderate & 17 & 11.3 \\
Tea Party & 0 & 0 \\
None of the above & 29 & 19.2 \\
Would rather not say & 22 & 14.6 \\
& & 100
\end{tabular}

$R W A, S D O$ and $A C O$. The RWA, SDO and the ACO all produced summed index scores. Respondents averaged toward central tendencies and a normal distribution was observed in the RWA $(M=79.69, S D=22.64$, see histogram in Figure 20).

The SDO is again computed as the sum of the responses from the 7-point Likert scale items. Once again, respondents favored central tendencies in this inventory, $(M=$ $38.87, S D=10.95$, Figure 21).

The ACO was scored by totaling the responses from the five items using 7-point Likert scale items (ranging 1 to 7), after reverse coding one item ("Much of the money donated to charity is wasted"). This created an index that ranges from 5 to 35 , with higher scores indicating a more favorable attitude regarding charitable organizations.

Respondents showed ratings moderately favorable of charitable organizations, $(M=$ 27.92, $S D=4.63$ ), with the distribution showing a visible ceiling effect (Figure 22). 


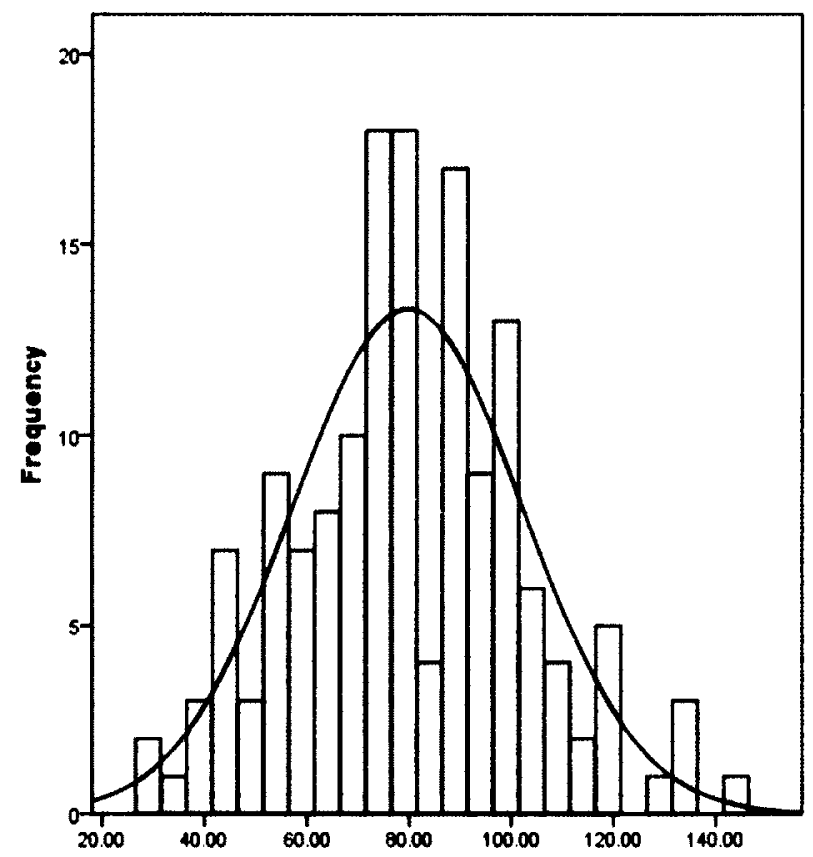

Figure 20. Distribution of Right Wing Authoritarianism (RWA) scores from the Experiment 2 pre-screening study.

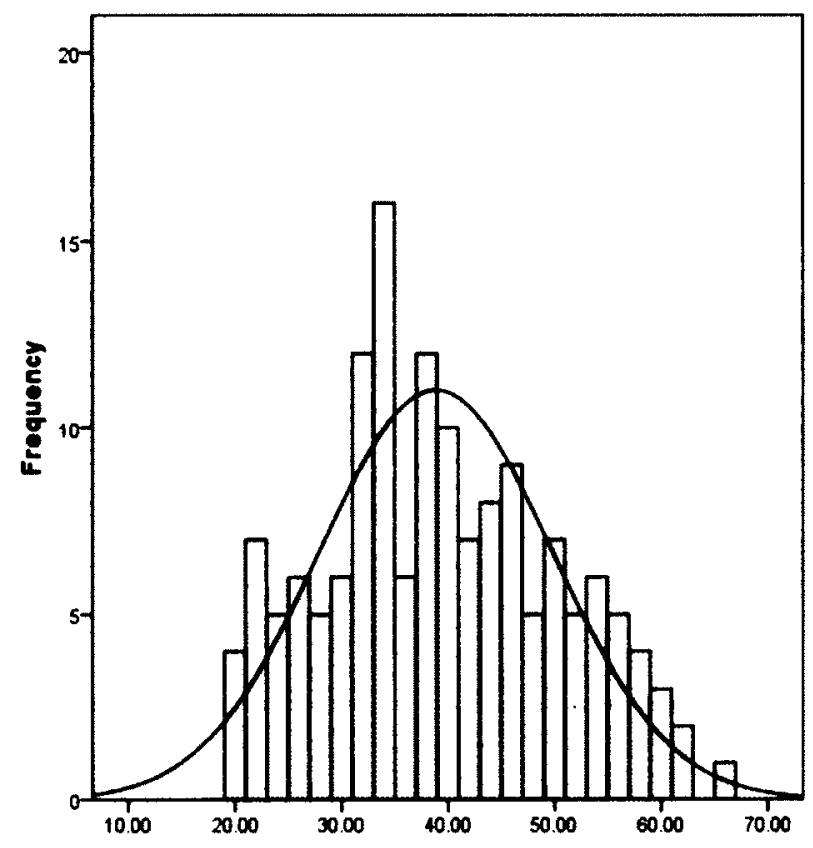

Figures 21. Distribution of Social Dominance Orientation (SDO) from the Experiment 2 pre-screening study. 


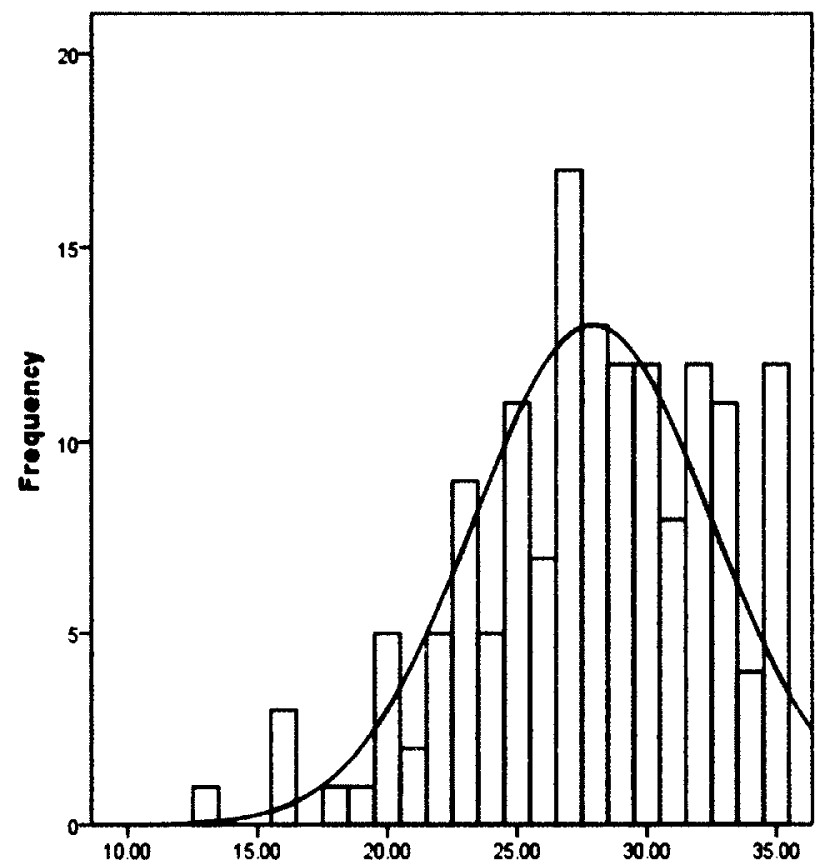

Figure 22. Distribution of scores from the Attitude toward Charitable Organizations (ACO), in the Experiment 2 pre-screening study.

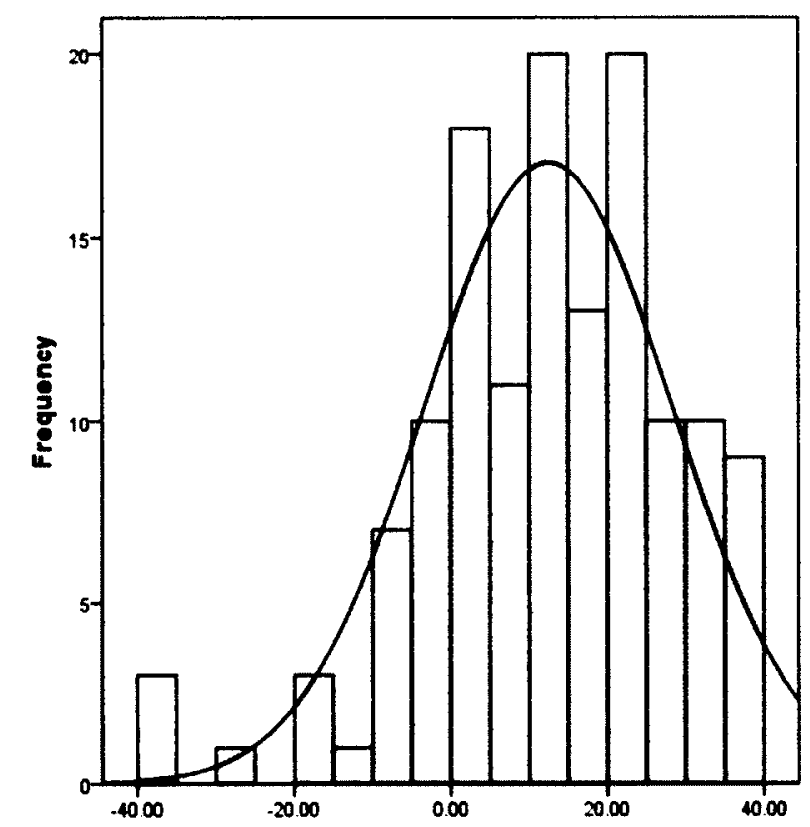

Figures 23. Distribution of scores from the Support for Famine Aid Pretest (SFAP), in the Experiment 2 pre-screening study. 
General Inventory. Responses to general inventory items addressing the variables of interest (i.e., Support for Famine Aid) were calculated for the pre-screening participants retained for Experiment 2. The data showed normality and also strong unimodal distributions (Table 35). The Support for Famine Aid Pretest (SFAP, Figure 23) was very strongly correlated with the ACO and negatively correlated with the SDO inventories, with $p$ 's $<.01$ (see correlations shown in Table 36). These results suggested that the ACO, the SDO and the SFAP were good choices for use as covariates in the final analysis.

Table 35

Prescreen study for Experiment 2: Descriptive Statistics of items in the General Inventory addressing topic of interest $(N=151)$.

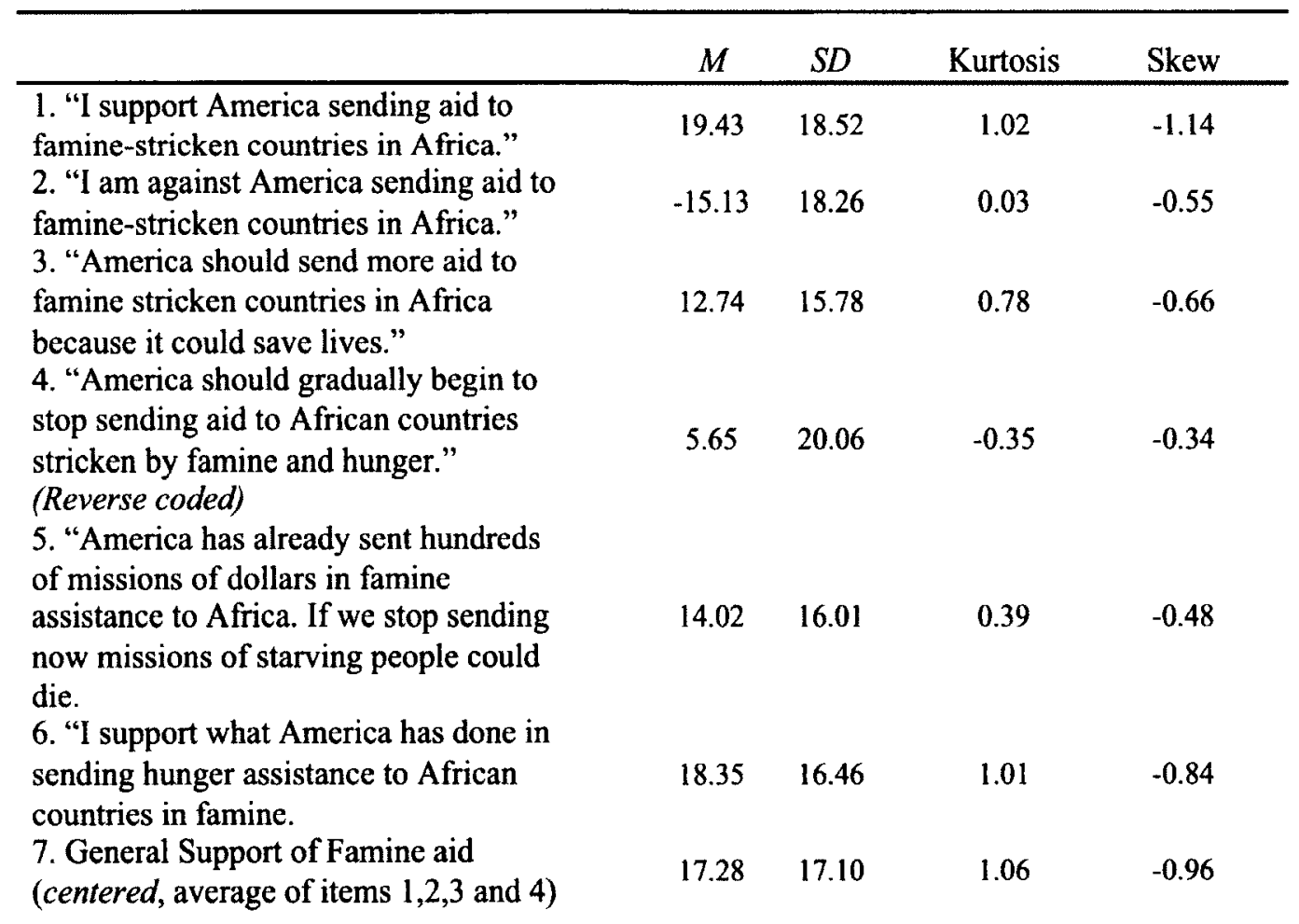


Table 36

Summary of correlations for Inventories in the Pre-screening study for Experiment 2.

\begin{tabular}{lcccc}
\hline Measure & 1 & 2 & 3 & 4 \\
\hline 1. RWA & -- & $.29^{* *}$ & .13 & .05 \\
2. SDO & & --- & -.01 & $-.31^{* *}$ \\
3. ACO & & & & $.31^{* *}$
\end{tabular}

4. General Support of U.S.

Famine Aid to Africa

(centered)

Note. $N=151 . \mathrm{RWA}=$ Right Wing Inventory; $\mathrm{SDO}=$ Social Dominance Orientation; $\mathrm{ACO}=$ Attitudes toward Charitable Organizations; General Support of U.S. Famine Aid to Africa $=4$ item index.

${ }^{* *} p<.01$ 


\section{CHAPTER III}

\section{EXPERIMENT 2: EFFECTS OF EMOTIONALLY AROUSING NEWS PICTURES ON ATTITUDES ABOUT AFRICAN FAMINE}

Experiment 2 was a between-subjects procedure examining the influence effects after presenting news images. News photos of human suffering during a famine in Africa were manipulated to vary by the degree of emotional arousal (high and low) with a no image control group. The pictures were paired with a news story text, held constant across conditions. As a replication, this procedure followed the same design as Experiment 1, containing Training, Experimental and Post-Experimental phases.

\section{Method}

Participants. Volunteers were retained from those who completed the screening procedure described above. Of those, 15 volunteers $(9.0 \%)$ failed to show up for the second part of the lab procedure that was Experiment 2. Of the remaining participants in the experimental sample $(N=136), 31(22.8 \%)$ were male and $105(77.2 \%)$ were female. They ranged in age from 18 to 44 , with 78 participants ( $57.4 \%$ ) between 18 and 20,50 (36.7\%) were between 21 and 27 , and eight participants between 31 and $44(5.9 \%)$. All spoke English as their primary language.

Apparatus and Materials. The experimental procedure was administered in a university computer lab, using the same PCs as before. The procedure was programmed in the same way as earlier, using E-Prime experimental programming software, with the exception of certain stimulus materials and response items. 
Training video, story and image materials. The same training video was used as in Experiment 1. The training materials were the same, including the news story on the No Child Left Behind initiative (Rhodebeck, 2012) and the follow-up training items.

Experimental materials and stimuli included the famine text from the pilot tests, and also the images depicting people suffering from African famine, which were found to be the most and least emotionally arousing from the famine images pilot study.

Index of support for African Famine Aid. Participants received a 4-item index in the experimental procedure that inquired about their support for U.S. aid to African countries suffering from famine. Two of the items inquired directly about participant's explicit support of famine assistance (e.g., "I SUPPORT the United States sending hunger assistance to African countries;" "I am AGAINST the United States sending hunger assistance to African countries"). Two more items inquired as to participant's feelings about either increasing or decreasing U.S. famine aid (e.g., "I feel that the United States should DOUBLE its hunger assistance to African countries;" "I feel that the United States should CUT IN HALF its hunger assistance to African countries"). Averaging all four items created an index of famine aid support - after reverse coding two items that addressed the opposition-to and the reduction-of famine aid. The index of support for African Famine Aid indicated good reliability as a measure of attitudes supporting U.S. aid to African countries suffering from famine, Cronbach's alpha $=.89$.

Attitude toward Helping Others. The AHO is an inventory (Appendix AA) of pro-social attitudes developed to determine individual differences in giving behaviors (Webb, et al., 2000). Responses to the items were collected and averaged using the Likert scale continuum, with a range of -40 to +40 . After averaging the responses, higher scores 
indicate attitudes disposed toward helping others. Together with another scale (Attitudes toward Charitable Organizations, $\mathrm{ACO}$ ) the $\mathrm{AHO}$ was shown to be predictive of donating practices. The AHO is a reliable scale (Cronbach's alpha $=.82)$ and like the ACO, it correlates significantly with people's giving behaviors (Webb, et al., 2000). As a second dependent variable, the AHO was included as a broader measure of prosocial concern, beyond the specific topics addressed in the stimulus materials addressing the famine in Africa.

Object rotation task and memory inventory. The object rotation task and open memory inventory were identical to those used previously.

\section{Design}

Similar to before, this study was a one way analysis of covariance design, with the photo condition as the independent variable (High emotional arousal photo/ Low emotional arousal photo / No photo), with on Support for Famine Aid and also attitudes toward helping others $(\mathrm{AHO})$ as the dependent variables. Covariates were the pretest judgments on the Support for Famine Aid. Participants were randomly assigned to one of the three groups: those exposed to a highly arousing image with a "news story" text, a low arousal image with the text, and no-photo condition.

\section{Procedure}

As before, participants were seated in a university computer lab and after a briefing, invited to launch the experimental procedure on their PCs. The Training Phase was identical to that of the previous experiment. Next was the Experimental Phase, which was also the same as Experiment 1, only presenting famine related material and measures to the participants. Here, participants were randomly selected to see a high arousal image, 
low arousal image or no image paired with the famine text. Immediately afterward, they responded to the items measuring support for the U.S. Aid to African Famine, and also the AHO. Participants went on to the Post-Experimental Phase, with the object rotation task, followed by the memory inventory. As in the previous experiment, the manipulation checks were the concluding part of the procedure. Participants received a full debriefing and then were excused.

Table 37

Summary of correlations comparing possible covariates with DV's for Experiment 2.

\begin{tabular}{|c|c|c|c|c|c|c|}
\hline Measure & 1 & 2 & 3 & 4 & 5 & 6 \\
\hline 1. RWA & -- & $.30^{* *}$ & .10 & .16 & .13 & .12 \\
\hline 2. SDO & & --- & -.06 & $-.29 * *$ & $-.25^{* *}$ & $-.36^{* *}$ \\
\hline 3. ACO & & & --- & $.39 * *$ & $.24 * *$ & $.24 * *$ \\
\hline $\begin{array}{l}\text { 4. Support for Famine Aid } \\
\text { Pretest (SFAP) }\end{array}$ & & & & --- & $.64 * *$ & $.55^{* *}$ \\
\hline $\begin{array}{l}\text { 5. Index of support for African } \\
\text { Famine Aid (DV) }\end{array}$ & & & & & --- & $.67^{* *}$ \\
\hline 6. AHO (DV) & & & & & & --- \\
\hline
\end{tabular}

Note. $N=128 . \mathrm{RWA}=$ Right Wing Inventory; $\mathrm{SDO}=$ Social Dominance Orientation; $\mathrm{ACO}=$ Attitudes toward Charitable Organizations; Support for Famine Aid Pretest (SFAP) $=4$ item index; Index of support for African Famine Aid; AHO = Attitudes toward Helping Others.

${ }^{* *} p<.01$

\section{Results}

Dependent variables. The judgments of interest for this experiment are attitudes concerning support of U.S. aid to African countries in famine, and also attitudes toward 
helping others after being exposed to news images of famine victims. The first dependent variable, support for African Famine Aid, is a simple and highly reliable index, averaging the four items that inquire as to participant's support of the famine aid and its continuance. The second dependent variable is simply the AHO scores.

Correlations were measured analyzing the relationships between the possible covariates and the dependent variables (Table 37). The SDO, ACO and Support for Famine Aid Pretest significantly correlated with both dependent variables, all $p$ 's $<.01$. The RWA was strongly correlated with only the SDO, and uncorrelated with any other measure. Indexes were created for the valence and emotional arousal as before. Results from the procedure were tabulated and analyzed - (see descriptive statistics Table 38 ). In manipulation checks, differences were observed between groups that were exposed to pictures. All who were exposed to photos reported negative valence from viewing the photos. The group assigned to the high arousal condition reported higher levels of arousal than did those assigned to the low arousal condition, $F(1,82)=36.23, p<.001, \eta_{p}{ }^{2}=.31$, power $=1.00$, indicating a successful manipulation of emotional arousal between the two stimuli images.

Table 38

Summary of descriptive statistics for participant responses Experiment 2.

1. "I SUPPORT the United States sending hunger assistance to African countries." "* 2. "I am AGAINST the United States sending hunger assistance to African countries." " 3. "I feel that the United States should DOUBLE its hunger assistance to African countries." *

\begin{tabular}{ccccc}
$N$ & $M$ & $S D$ & Kurt & Skew \\
\hline 128 & 17.48 & 17.37 & -0.07 & -0.61 \\
128 & -16.15 & 17.08 & 0.62 & -0.78 \\
128 & 1.66 & 17.51 & -0.34 & 0.15
\end{tabular}


Table 38

Continued

5. Index for Support of Famine Aid - average of $l$,

2, 3 and 4 ( 2 and 4 reversed)

\begin{tabular}{|c|c|c|c|c|}
\hline$N$ & $M$ & $S D$ & Kurt & Skew \\
\hline 128 & 10.92 & 14.16 & -0.53 & -0.01 \\
\hline 128 & 20.84 & 14.33 & 1.51 & -0.93 \\
\hline 128 & 23.40 & 13.15 & 0.22 & -0.64 \\
\hline 128 & 21.45 & 12.88 & -0.85 & -0.28 \\
\hline 128 & 19.79 & 13.98 & -0.55 & -0.38 \\
\hline 128 & 21.37 & 11.77 & -0.64 & -0.37 \\
\hline 128 & 9.32 & 17.36 & 0.27 & -0.31 \\
\hline 127 & 11.89 & 15.38 & -0.26 & 0.16 \\
\hline 127 & 10.17 & 16.67 & 0.18 & -0.41 \\
\hline 127 & -9.31 & 15.56 & 0.67 & 0.35 \\
\hline 127 & 5.03 & 15.97 & 0.57 & -0.37 \\
\hline 127 & -1.27 & 18.98 & -0.54 & -0.10 \\
\hline 127 & 3.15 & 16.65 & -0.11 & -0.11 \\
\hline 42 & -27.43 & 12.20 & -0.13 & 1.04 \\
\hline 42 & 9.24 & 22.29 & -0.66 & -0.44 \\
\hline 42 & -27.31 & 11.93 & 0.12 & 1.11 \\
\hline 42 & 26.24 & 15.09 & 1.62 & -1.31 \\
\hline 42 & 27.93 & 13.33 & 0.20 & -1.15 \\
\hline 42 & -27.37 & 10.97 & 0.32 & 1.12 \\
\hline 42 & 21.13 & 13.58 & -0.95 & -0.33 \\
\hline 42 & 24.40 & 16.60 & 4.53 & -1.81 \\
\hline 42 & 2.55 & 25.21 & -1.14 & -0.27 \\
\hline 42 & -9.40 & 28.12 & -1.10 & 0.61 \\
\hline
\end{tabular}

6. "Helping troubled people with their problems is very important to me." *

7. People should be willing to help others who are less fortunate. *

8. "People should be more charitable toward others in society." *

9. "People in need should receive support from others." *

10. Attitudes toward helping others (AHO)

11. "I am interested in this topic." *

12. "I felt this story was slanted in favor of one of the sides of the argument."

13. "I felt this story made a strong case for continuing U.S. famine aid to Africa." "

14. "I felt this story made a strong case for halting U.S. famine aid to Africa."

15. "I think this story influenced me regarding how I feel about the subject." "

16. "I think this story did not influence me regarding how 1 feel about the subject." "

17. Index for self-reported INFLUENCE

18. SAM Valence dimension for the high arousal image. *

19. SAM Arousal dimension for the high arousal image."

20. "How does this image make you feel?" for the high arousal image. *

21. "I find this photo to be upsetting to me" for the high arousal image. *

22. "I feel an emotional reaction when I look at this photo" for the high arousal image. "

23. Valence Index manipulation check for the high arousal image.

24. Arousal Index manipulation check for the high arousal image.

25. "I have seen photos similar to this before" for the high arousal image. "

26. "This photo seems familiar to me." for the high arousal image."

27. "I have seen this photo before" for the high arousal image." 
Table 38

Continued

28. SAM Valence dimension for the low arousal image. *

29. SAM Arousal dimension for the low arousal image. *

30. "How does this image make you feel?" for the low arousal image. "

31. "I find this photo to be upsetting to me" for the low arousal image."

32. "I feel an emotional reaction when I look at this photo" for low arousal image. *

33. Valence Index manipulation check for low arousal image.

34. Arousal Index manipulation check for the low arousal image.

35. "I have seen photos similar to this before" for the low arousal image. *

36. "This photo seems familiar to me." for the low arousal image. *

37. "I have seen this photo before" for the low arousal image. *

\begin{tabular}{ccccc}
$N$ & $M$ & $S D$ & Kurt & Skew \\
\hline 42 & -16.81 & 13.55 & -0.78 & 0.04 \\
42 & -12.90 & 17.37 & -0.45 & 0.47 \\
42 & -13.33 & 14.09 & -1.19 & -0.18 \\
42 & 9.79 & 18.67 & -0.07 & -0.39 \\
42 & 9.17 & 19.26 & -0.05 & -0.64 \\
42 & -15.07 & 12.74 & -0.98 & -0.15 \\
42 & 2.02 & 15.47 & -0.43 & -0.02 \\
42 & 14.00 & 22.02 & 0.58 & -1.14 \\
42 & -12.83 & 25.28 & -0.94 & 0.65 \\
42 & -16.19 & 24.93 & -0.45 & 0.89
\end{tabular}

Note. All variables are centered, a range of -40 to $40 .=$ Likert format response bar: Negative scores indicates level of disagreement / positive is level of agreement; $*=$ Opposing choice response bar: Negative scores is "slanted against U.S. sending Famine Aid" / positive is for "slanted for U.S. sending Famine Aid."

MANCOVAs. For hypothesis testing, a multiple analysis of covariance (MANCOVA) was used to examine the dependent variables of support African Famine aid, and also attitudes toward helping others, using photo presentation as the independent variable (three levels: high emotional arousal photo, low arousal photo, no photo) and using covariates of SDO, ACO and SFAP, the measures which correlated highest with the dependent variables (from Table 37).

The dependent variables were examined for normality (see histograms in Figure 24 and 25) and a moderate bi-modal pattern and ceiling effect was observed for AHO. 


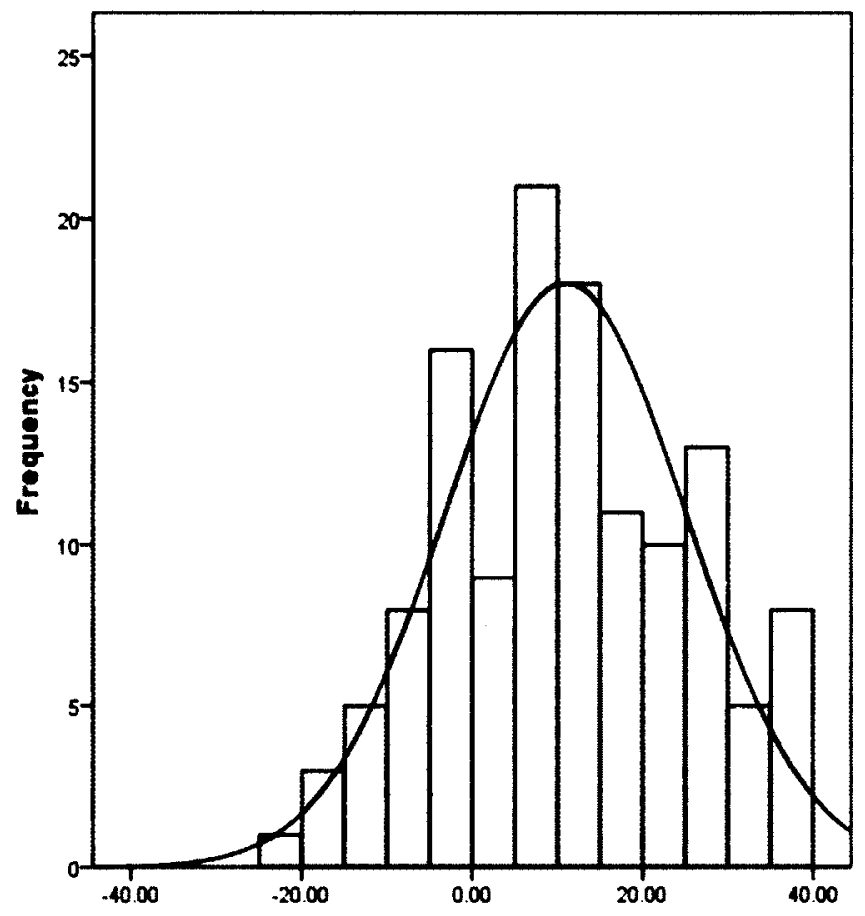

Figure 24. Score distribution in Experiment 2 for Index of Support for African Famine Aid.

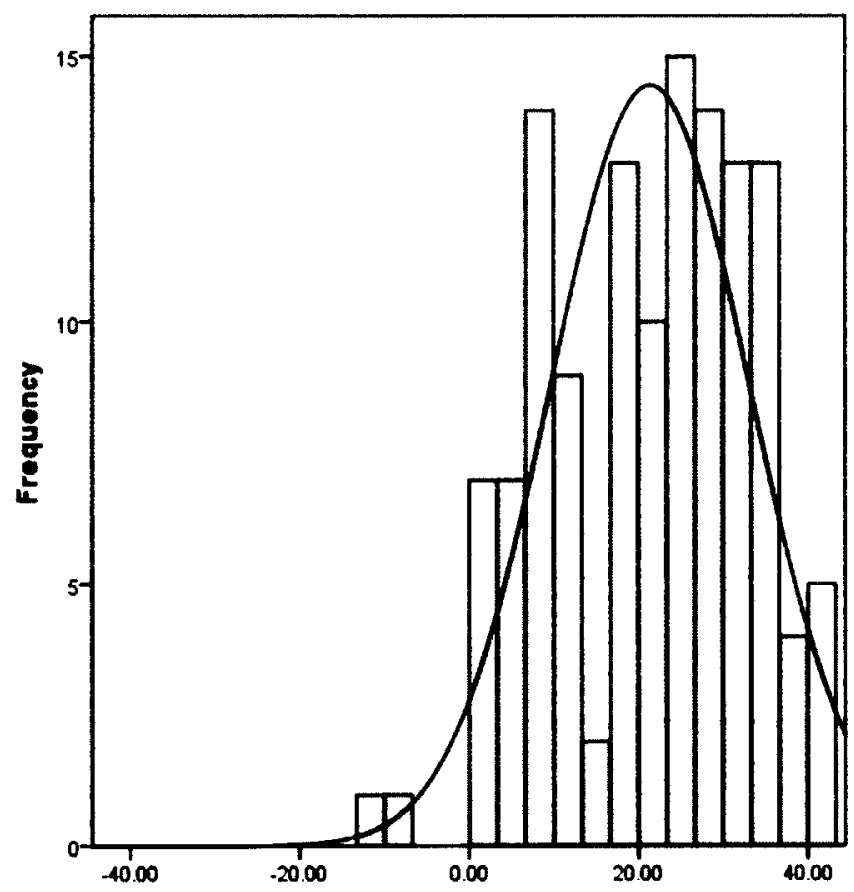

Figure 25. Score distribution for Attitudes toward Helping Others, (AHO). 
The dependent variables were examined for normality (see histograms in Figure 24 and 25) and a moderate bi-modal pattern and ceiling effect was observed for AHO. Normality of sampling distributions was examined, and despite acceptable skewness and kurtosis measures, a moderate bi-modal pattern was observed when viewing the histograms (see Figure 26 and 27). The assumption for homogeneity of variance-covariance matrices for both dependent variables were satisfied via a Box's test, and homogeneity of variance was confirmed with the Levene's test. Scores were examined for univariate and multivariate outliers, as before. Five univariate outliers were found and deleted for this analysis. Further checks for influence and leverage revealed no further multivariate outliers. Additionally, three cases were found with short completion times, considered to be at an outlier level, and deleted.

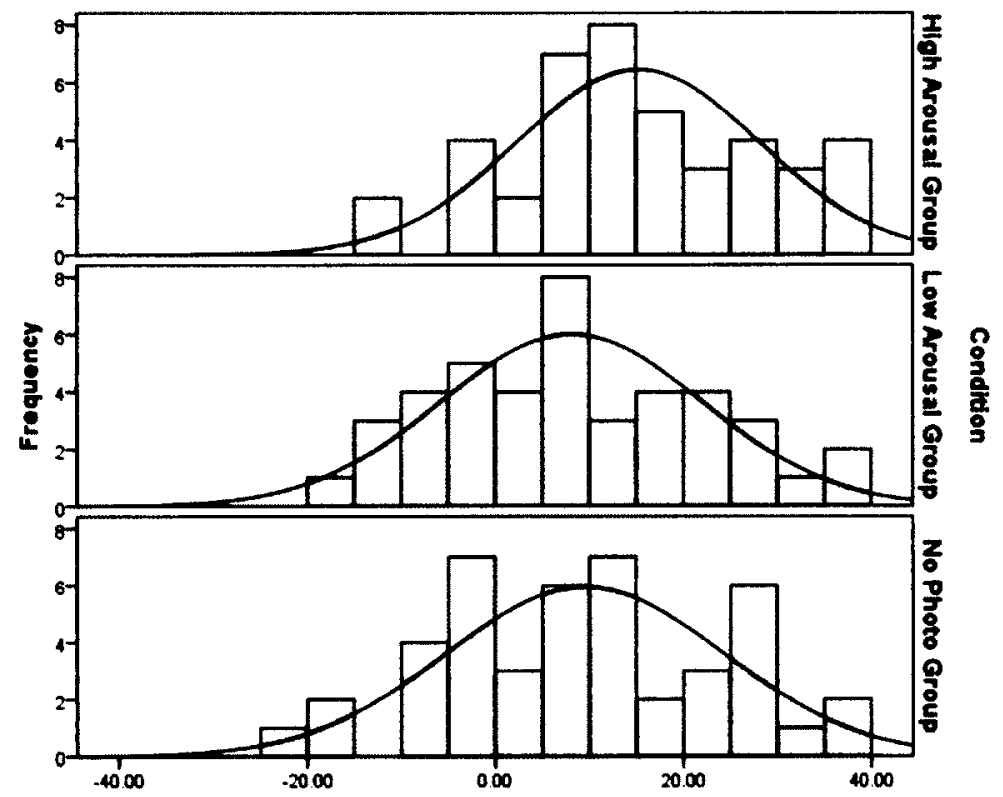

Figure 26. Distribution of the Index of support for African Famine Aid scores by group for Experiment 2. 


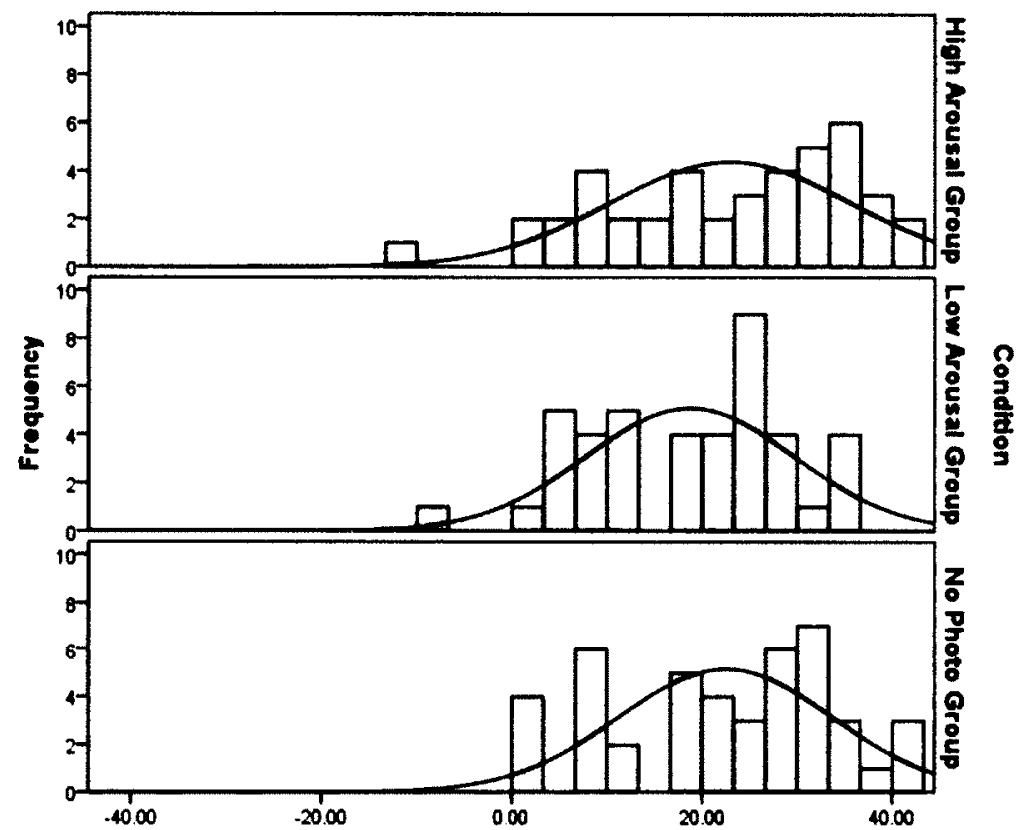

Figure 27. Distribution of the Attitudes toward Helping Others, or AHO (DV2) scores by group for Experiment 2.

The model was tested for homogeneity of regression and no interaction was observed between the IV and the covariates. The first run of the MANCOVA model indicated that, of all the pre-screening measurements that correlated with the dependent variables (SDO, ACO and SFAP), only the SDO and the SFAP were covariates that significantly adjusted the dependent variables. Specifically, the SFAP, significantly adjusted support of African Famine Aid, $F(1,122)=63.18, p<.001$, and also the AHO, $F(1,122)=29.85, p<.001$. The SDO significantly adjusted the AHO, $F(1,122)=8.35, p$ $=.005$. As a covariate, ACO did not significantly adjust either of the dependent variables, all $F$ 's $<0.37, p$ 's $>.563$, and therefore was dropped from the model.

The final MANCOVA model (using Roy's Largest Root) found that the combined dependent variables were significantly related to the combined covariates, $F(2,123)=$ 
$3.60, p=.030, \eta_{p}^{2}=.06$, power $=.66(\text { see Figure } 28)^{2}$. The covariate of SFAP adjusted support of African Famine Aid, $F(1,123)=74.01, p<.001$, and also the AHO, $F(1,123)$ $=38.29, p<.001$. The SDO significantly adjusted the $\mathrm{AHO}, F(1,123)=8.23, p=.005$. For support for African famine aid, significant differences were observed in the followup univariate analysis, between the participants, $F(2,123)=3.40, p=.036, \eta_{p}{ }^{2}=.05$, power $=.63$. In orthogonal post-hoc contrasts, significant differences were observed for support for African famine aid between the groups that saw a highly emotionally arousing image and either a low arousal image, or no image, $F(1,123)=6.77, p=.010$, $\eta_{p}{ }^{2}=.05$, power $=.73$. Participants who saw a highly emotionally arousing image paired with a news story about the African famine were shown to be significantly more in favor of U.S. supporting famine aid to Africa $(M=14.46, S D=12.99)$, than were those who saw a low arousal image paired with a story $(M=9.34, S D=13.95)$, or a story without a picture $(M=9.05, S D=14.77)$. No significant differences were observed between the low arousal picture and the no picture conditions, $F(1,123)=0.02, p=.90, \eta_{p}^{2}=.00$, power $=.05$. For AHO, the MANCOVA revealed no significant differences between the groups of participants in their attitudes toward helping others, $F(2,123)=1.05, \eta_{p}{ }^{2}=.02$, power $=.23$.

Exploratory measures. As earlier, the responses from the memory inventory were interpreted by two independent research assistants, who coded the responses for pieces of information recalled from the story, producing averaged totals of what participants recalled from the story, as well as sums of story details remembered that either opposed

\footnotetext{
2 This showed a slight improvement from the first MANCOVA model, $F(2,123)=3.57, p=.031, \eta_{p}{ }^{2}=$ .06, power $=.65$.
} 
Experiment 2: Adjusted means for Support U.S. Famine Aid to Africa and Attitude toward Helping Others (AHO)

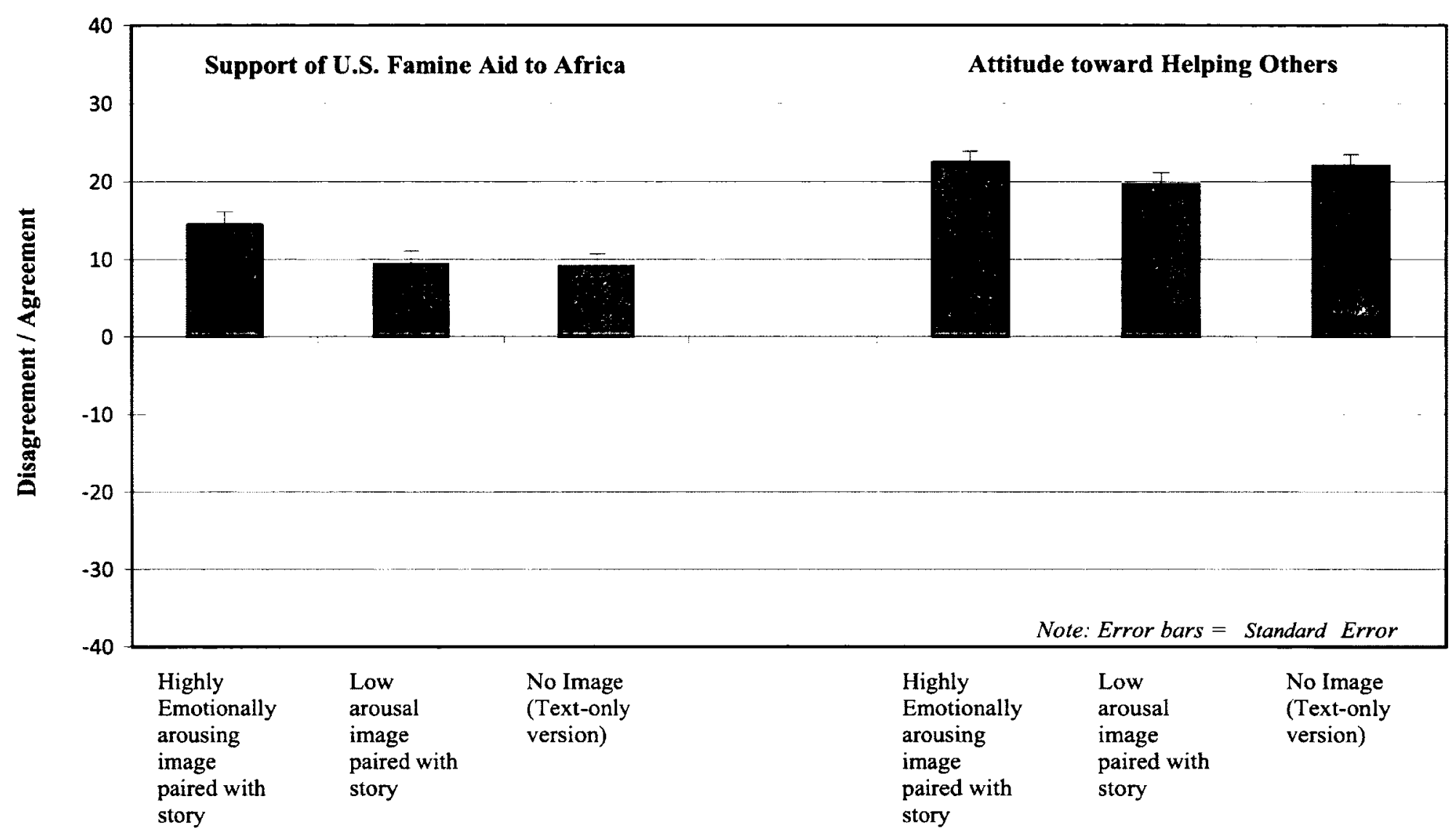

Figure 28. Adjusted means for dependent variables in Experiment 2. 
or supported U.S. Famine Aid to Africa. Analysis indicated strong inter-rater reliability for the coding of the recalled information from the text, with both raters correlating significantly, $r(167)=.80, p<.001$. After observing heterogeneity of variance in the memory data, a series of $t$-test analyses showed no differences between the groups, all $t$ 's $<0.43, p$ 's $>.67$. Further analysis of memory data using ANOVAs ${ }^{3}$ supported a null hypothesis in both recollections of story information that supported famine aid, $F(2,121)$ $=.71, p=.493, \eta_{p}{ }^{2}=.01$, power $=.17$, and also that opposed famine aid, $F(2,121)=$ $0.53, p=.588, \eta_{p}^{2}=.01$, power $=.14$.

Overall, participants reported slight interest in the story. They also reported a general perception of slight to moderate bias in the story, favoring the continuation of U.S. aid to African countries in famine. Participants differed significantly on how they responded to the item "I felt this story made a strong case for continuing U.S. famine aid to Africa," depending on which image was paired with the story, $F(2,124)=7.79, p=$ $.001, \eta_{p}{ }^{2}=.11$, power $=.95$. Participants who saw a highly arousing photo with a story felt the story made a stronger case for continuing famine aid to Africa $(M=18.00, S D=$ 13.49), than did those who saw a low arousal image $(M=7.14, S D=17.32)$, or no image paired with the story, $(M=5.47, S D=16.45)$. However, there were no differences among groups for participants who responded to the item "I felt this story made a strong case for halting U.S. famine aid to Africa," $F(2,124)=0.19, p=.829, \eta_{p}^{2}=.00$, power $=.08$.

Furthermore, no differences were found between groups for the item "I felt this story was slanted in favor of one of the sides of the argument," $F(2,124)=0.32, p=.730, \eta_{p}{ }^{2}=.00$, power $=.10$

\footnotetext{
${ }^{3}$ Homogeneity of variance was assumed for these analyses, following Levene's tests. The heterogeneity of variance issue in the Experiment 2 memory data resided among recollections of neutral story information.
} 
As before, an index was created from items measuring self-reported influence, where again, significant differences were observed between groups, $F(2,124)=4.85, p=$ $.009, \eta_{p}{ }^{2}=.07$, power $=.79$. Responses showed higher feelings of influence when the text was accompanied by an emotionally arousing image $(M=9.21, S D=15.49)$, than the more neutral responses of those who saw a low-arousing image $(M=-1.50, S D=16.38)$, or if they saw no image at all $(M=1.77, S D=16.59)$.

Participants in groups that had pictures paired with a story reported a general impression that they had seen similar pictures before, and differences were observed between groups, $F(1,82)=5.98, p=.017, \eta_{p}{ }^{2}=.07$, power $=.68$. People who saw a highly arousing image paired with a story were significantly more likely to indicate they had seen similar pictures before $(M=24.40, S D=16.60)$ when compared with those who saw a low arousal image, $(M=14.00, S D=22.02)$. Significant differences were also observed for participants responses to whether the pictures seemed familiar, depending on which picture they saw, $F(1,82)=7.80, p=.007, \eta_{p}{ }^{2}=.09$, power $=.79$. Finally, participants on the average expressed that they had not seen the photo which was presented to them before, and no differences were observed between groups $F(1,82)=$ $1.37, p=.245, \eta_{p}{ }^{2}=.02$, power $=.21$.

\section{Discussion}

For attitudes of support for U.S. aid to African countries in famine, the pattern of effects was replicated once again in Experiment 2. Participants who saw an image with high emotional arousal were more inclined to endorse the U.S. sending African famine aid than if they saw a low arousal image or no image paired with the "news story." As in 
Experiment 1, there were no differences between seeing a low arousal photograph and no photograph at all, at least as far as these measurements were concerned.

For the set of broader cognitions that were measured, the AHO, no differences were seen between the groups of participants with regard to their perspectives about helping others. The AHO was initially intended as a measure of broader attitudes, which were not specific to the content to the story, yet related more generally in their prosocial focus. The AHO is described as "global and relatively enduring evaluations with regard to helping or assisting other people" (Webb, et al., 2000, p. 300), and thus, may operate as more of a trait or dispositional measure than a (slightly more malleable) set of attitudes (Ajzen, 1987, 2005; Allport, 1931). Attitudes tend to be evaluative in their nature with regard to specific targets, such as certain people, places, events, institutions, etc. Traits, on the other hand, tend to be broader in scope, and operate in a larger domain of behavior, examples including conscientiousness, aggression, altruism, etc, (Ajzen, 2005; Wiggins, 1979). Attitudes and traits are often discussed together as dispositional mechanisms. They can be nuanced and difficult to differentiate, and sometime suffer from conceptual murkiness (Ajzen, 1987, 2005). Some researchers have used the AHO as measure for altruism, deeming it as conceptually identical to the trait (Ranganathan \& Henley, 2008). Be it labeled as a trait, disposition or as attitudes, the AHO as an enduring and well-sustained set of cognitions may be resistant to experimental manipulation. The results suggest that the AHO may serve as a better predictor than a dependent variable, and future replications of this experiment would do well to consider it for use as a covariate. 
In the memory measures or aggregate and recall of story information, once again no effects were observed between groups. Further, no differences were observed for recall of nuanced information, either supporting or opposing US famine aid to Africa. Again, this suggests that the effects for influence of the photos appears unrelated to the participant's story comprehension of the accompanying stories. For self-reports of influence, participants reported that they were more influenced by the story if they saw the highly emotionally arousing image than those in the low arousal and no-photo groups. The pattern of effects more closely mirrored those for the attitudes for the support of African famine aid than what was observed in Experiment 1, suggesting that those in Experiment 2 had higher awareness of being influenced by the story. Taken together, these exploratory measures suggest that one's metacognitive feelings about being influenced may be (at best) loosely correlated to whether or not one actually was influenced by the story. More research is necessary to explore a possible connection. 


\section{CHAPTER IV}

\section{GENERAL DISCUSSION}

This research began a line of empirical study to understand how news photos influence human judgment and decision-making. Specifically, the research on news photos focused on the role of the Affect Heuristic as a decision strategy. The studies replicated a shift in attitudinal judgments in both experiments, based on the presentation of a highly emotionally arousing image paired with a "news story." A shift of broader judgments also was observed in the first experiment, where participants reported less "hawkish" attitudes on a militaristic U.S. foreign policy after seeing a highly arousing image. Shifts in opinion did not correlate with the amount of information remembered from the text, the type of information recalled from the text (either supporting or opposing the war/famine aid), nor did it always correlate to whether or not participants felt influenced by the story. Based on these results, it is difficult to draw a connection between the way a news image influences our opinions, and the way we might actually recollect or comprehend an accompanying story. This is consistent with the foundational assumptions of the Affect Heuristic: that, for these images, the paths to an attitude change reside in the emotional channels of the mind rather than largely rationalized thinking.

This study validates quantitatively some of what political and media elites have qualitatively asserted for a very long time: that photos do have power. However, based on the failure of the first hypothesis, not just any photo holds power, or for that matter can even "move the needle," in rousing the human mind. As the Affect Heuristic predicts, it is the negatively valenced and highly emotionally arousing image that can bring observable effects in judgments and attitudes. That the research empirically supports 
longstanding conventional wisdom is perhaps less interesting than the results suggesting that readers may or may not realize if they are being swayed by a powerful image. That there is a danger in activating what may be implicit mechanisms, to ultimately bring about some sort of manipulation on human judgment is a compelling, if not outright sobering, implication. This will be further discussed a little later.

This research contributes to scholarly literature in a number of substantial ways. First, scholars have criticized the extant literature on the influence or "power" of news images to be mostly led by a line of qualitative scholarly writing and conventional wisdom, rather than empirical support (Domke, et al., 2002; Smith-Rodden \& Ash, 2012). As such, this research helps fill the "empirical vacuum." Secondly, while the affect heuristic may intuitively seem a highly plausible mechanism for a decision strategy following exposure to a compelling news photo, research on this mechanism in this domain is virtually unheard of. Last, as a relatively-recently theorized cognitive mechanism, the affect heuristic has been similarly under-researched with regard to public support for a war, while cognitively improbable theories such as cost-benefit analysis are still presented as viable explanations for human behavior. While it's undeniable that the content in the high arousal images depicted a dreaded cost - thus cost-benefit can't be entirely ruled out as an explanation - main findings in both experiments showed results entirely consistent with affect heuristic predictions, while the memory data results failed to support what one might expect from cost benefit reasoning.

\section{Future Directions}

Future lines of research can explore effects from other types of images. This might include an experimental replication using images from local or domestic news 
rather than national or international news. Another direction would be to study the affect heuristic while controlling the image content to images of positive valence. Historically, it has long been lamented that the "bad news sells" philosophy has contributed to a dearth of positive news and images in conventional media. However, the emergence of social media has manifested more opportunities to find and examine material that might be classified as "good news." Examples of this trend are websites and blogs such as the "Good News" channel on the Huffington Post (Shah, 2013), The Good News Network (Weis-Corbley, 2013), and The Happiness Project (Rubin, 2013), where the explicit focus is on uplifting and inspirational news. Such a trend toward "positive" media may prove useful with the practical issues of finding material for use in experimental stimuli, as well as increasing external validity of research on positive news images.

Yet another focus of future research would be to explore differences in age, gender and culture demographics. As this research focused on a college population - and as such, skewed younger - it might be useful to broaden the focus to other age cohorts, such as mid-life or older readers. Further, it may be useful to examine how participants in another culture or country might respond. It has been noted that the tolerance for publishing graphic imagery can vary country by country, and that Western media, especially the U.S. mainstream media, tend to be more conservative when it comes to publishing imagery depicting mortality and death (Hanusch, 2008; Morrison, 2013). If participants are more accustomed to seeing graphic media images, then they might respond differently, perhaps with attenuated effects.

Last, while this was a clearly articulated preliminary series of experiments applying the affect heuristic to news imagery, which focused on arousal measures among 
images of negative valence, there are many ways to approach measures of high affect.

For instance, it can be hard to parse out the affective assessments of high arousal images from those of extreme negative valence, due to what is often a high correlation between the two ${ }^{4}$. Future research may do well to focus on valence measures as opposed to arousal, as a more parsimonious paradigm. Further, continued examinations of arousal might benefit from incorporating physiological measures to help in fine-tuning the focus on arousal, and further distinguishing it from extreme levels of valence.

\section{Implications for Practitioners and Gatekeepers}

The implications are clear for gatekeepers handling and editing visuals: images matter. However, not just any image matters. News photos with arousing emotional content are the images that are most likely to reach and stir the human psyche. At least for the purpose of the current research, publishing a news photo that fails to emotionally arouse the reader is roughly as effective as not using a photo at all. This research not only demonstrates to editors and journalists that their choices of images do matter, and reach people, just as conventional wisdom suggests - but also goes a little farther in demonstrating just how the images might reach people. Be it labeled a "powerful image" or "an iconic photo," such an image most probably reaches people through their emotional channels, and reaches people in ways that can literally change their thinking.

Visual communicators often wrestle with making arguments for the use of strong photos in publication - especially those in traditionally minded organizations. Often, gatekeepers will avoid certain photos if they are deemed too graphic, being reluctant to invite the ire of their customers over the grim content or ethical concerns (Zelizer, 2010).

\footnotetext{
4 The correlations between arousal and valence in Experiments 1 and 2 are $r(86)=-.75$ and $r(83)=-.84$, respectively, both $p$ 's $<.001$.
} 
The tension to honestly inform - yet not upset - has become dramatically apparent in certain high-profile cases, where some news organizations have gone so far as to use Adobe Photoshop software to digitally manipulate and remove graphic content. A recent example was the choice of The New York Daily News to digitally remove bloody gashes and leg injuries from a victim of the Boston Marathon bombing (Apple, 2013; Morrison, 2013; Ross, 2013). Such "content edits" are in violation of widely accepted professional standards on visual ethics, which rigorously oppose such digital manipulations (NPPA, 2011). As such, The Daily News was highly criticized (Apple, 2013; Morrison, 2013; Ross, 2013).

The inelegant lengths that The Daily News underwent in altering their image and later, in defending their decision - underscores that news organizations continue to grapple with the use of graphic and emotionally arousing photos. Traditionally, print media gatekeepers trend toward more conservative and inhibited practices in using graphic images than do those who manage online content. The lack of consistency across media platforms, sometimes even within the same parent company, might create confusion and shifting expectations for the consumers of these news sources. This inconsistency invites a number of questions. Would the images from online sources be considered more "honest?" Would there be greater trust in news sources willing to publish images that might not be published elsewhere? Are more inhibited and traditional practices of not publishing certain graphic images best serving the readers? Or the victims depicted in the news stories? ... Or even the news organizations?

A full discussion of all the ethical implications would go far beyond the scope of this manuscript on empirical research. Yet, this author would observe that the age-old 
assumptions about powerful photos, outlined in the earlier Introduction section, are still worth considering. Among those assumptions is that powerful imagery can inform distant readers with "need to know" information about important events that have life and death consequences (e.g., famines, wars, or acts of terrorism). In essence, such images inform and engaging readers and providing the experiences of important events in ways that, as this research suggests, verbal communication cannot. Indeed, many would say that meaningfully and fully informing people would be the role of a relevant news organization.

As the research reaffirms that certain photos do have power, gatekeepers should be reminded that the choice to use a powerful photo should be well deliberated and thoughtfully assessed. Powerful photos do wield certain effects and change thinking. Worse - as the current research shows us - they can manipulate. Editors who make such choices should be clear-minded about why to use such a photo, in which way to use the photo, what is being communicated, and how it might stir people (over and above a facile concern that some readers might find the photo disaffecting or upsetting). As with any potent material, the use of powerful imagery should be strategic and measured: excessive use will fail to serve if it risks desensitizing the audience, or causing them to question the media's motives. However, this research suggests that there may be more opportunities to reach and inform people to crucially important news than many media outlets may be disposed to using. 


\section{REFERENCES}

Ajzen, I. (1987). Attitudes, traits, and actions: Dispositional prediction of behavior in personality and social psychology. Advances in experimental social psychology, 20,63 .

Ajzen, I. (2005). Attitudes and personality traits Attitudes, personality, and behavior (pp. 1-23). Berkshire, England: McGraw-Hill International.

Allport, G. W. (1931). What is a trait of personality? The Journal of Abnormal and Social Psychology, 25, 368.

Altemeyer, B. (1998). The other "authoritarian personality". In M. P. Zanna (Ed.), Advances in experimental social psychology (Vol. 30, pp. 47-92). San Diego: Academic Press.

Altemeyer, B. (2006). The Authoritarians Retrieved from http://members.shaw.ca/jeanaltemeyer/drbob/TheAuthoritarians.pdf

Althaus, S., Swigger, N., Chernykh, S., Hendry, D., Wals, S., \& Tiwald, C. (2008). Uplifting manhood to wonderful heights? Newspaper reporting of American combat deaths from World War One to Gulf War Two. Paper presented at the Chicago-Area Social and Behavior Workshop, Evanston, IL,

AP. (2012, January 19, 2012). Report finds slow response to famine, International News Article, New York Times via The Associated Press, p. A3. Retrieved from http://www.nytimes.com/2012/01/19/world/africa/report-finds-slowresponse-to-east-africa-famine.html 
Apple, C. (2013, April 16). I hate to make an accusation here, but.... Visual Journalism blog Retrieved from http://apple.copydesk.org/2013/04/16/i-hate-to-makean-accusation-here-but/ - comments

ASNE. (2006). American Society of News Editors statement of principles Retrieved April 15, 2013, from http://asne.org/content.asp?pl=24\&sl=171\&contentid=171

Baddeley, A. (1992). Working memory. Science, 255, 556-559.

Baddeley, A. (2003). Working Memory: Looking back and looking forward. Nature Reviews Neuroscience, 4, 829-839.

Baddeley, A., \& Andrade, J. (2000). Working memory and the vividness of imagery. Journal of Experimental Psychology: General, 129, 126-145.

Baddeley, A., \& Hitch, G. (1974). Working memory. In G. Bower (Ed.), The Psychology of learning and motivation (Vol. 8, pp. 47-89). New York: Academic Press.

Bard, M. (2012, March 15, 2012). Karzai asks us to leave (most of) Afghanistan, and we should listen [Blog]. Web Blog Retrieved from http://www.huffingtonpost.com/mitchell-bard/karzai-asks-us-to-leavem b $1348035 . h t m l$

Bateman, I., Dent, S., Peters, E., Slovic, P., \& Starmer, C. (2007). The affect heuristic and the attractiveness of simple gambles. Journal of Behavioral Decision Making, $20,365-380$.

Bradley, M. M., \& Lang, P. J. (1994). Measuring emotion: the Self-Assessment Manikin and the Semantic Differential. [Comparative Study 
Research Support, U.S. Gov't, P.H.S.]. Journal of behavior therapy and experimental psychiatry, 25, 49-59.

Breckenridge, J. N., \& Zimbardo, P. G. (2007). The strategy of terrorism and the psychology of mass-mediated fear. In B. Bongar, L. M. Brown, L. E. Beutler, J. N. Breckenridge \& P. G. Zimbardo (Eds.), Psychology of terrorism. (pp. 116133): New York, NY, US: Oxford University Press.

Breckenridge, J. N., Zimbardo, P. G., \& Sweeton, J. L. (2010). After years of media coverage, can one more video report trigger heuristic judgments? A national study of American terrorism risk perceptions. Behavioral Sciences of Terrorism and Political Aggression, 2, 163-178.

Broadbent, D. E. (1982). Task combination and selective intake of information. Acta Psychologica;Acta Psychologica, 50, 253-290.

Bröder, A. (2002). Take the best, Dawes' Rule, and compensatory decision strategies: A regression-based classification method. Quality \& Quantity, 36, 219-238.

Cooper, L. A., \& Shepard, R. N. (1973). Chronometric studies of the rotation of mental images Visual information processing (pp. xiv, 555). Oxford, England: Academic.

Cowan, N. (1988). Evolving conceptions of memory storage, selective attention, and their mutual constraints within the human information-processing system. Psychological Bulletin, 104, 163-191.

Cowan, N. (2010). The Magical Mystery Four. Current Directions in Psychological Science, 19, $51-57$.

Crowson, H. M. (2009a). Predicting perceptions of symbolic and realistic threat from terrorists: The role of right-wing authoritarianism and social dominance 
orientation. Individual Differences Research;Individual Differences Research, 7, $113-118$.

Crowson, H. M. (2009b). Right-wing authoritarianism and social dominance orientation: As mediators of worldview beliefs on attitudes related to the war on terror. Social Psychology; Social Psychology, 40, 93-103.

Crowson, H. M., DeBacker, T. K., \& Thoma, S. J. (2005). Does authoritarianism predict post-9/11 attitudes? Personality and Individual Differences, 39, 1273-1283.

de Gelder, B. (2000). More to Seeing than Meets the Eye. Science, 289, 1148-1149.

Dogra, N. (2007). 'Reading NGOs visually'-Implications of visual images for NGO management. Journal of International Development, 19, 161-171.

Domke, D., Perlmutter, D., \& Spratt, M. (2002). The primes of our times? An examination of the 'power' of visual images. Journalism, 3, 131-159.

Eichenberg, R. C. (2005). Victory has many friends: U.S. public opinion and the use of military force, 1981-2005. International Security, 30, 140-177.

Engle, R. W. (2002). Working memory capacity as executive attention. Current Directions in Psychological Science, 11, 19-23.

Finucane, M. L., Alhakami, A., Slovic, P., \& Johnson, S. M. (2000). The affect heuristic in judgments of risks and benefits. Journal of Behavioral Decision Making, 13, 117.

Friedman, M. (1953). Essays in positive economics. Chicago, Ill.: University of Chicago Press.

Gartner, S. (2008). The multiple effects of casualties on public support for war: An experimental approach. American Political Science Review, 102, 95-106. 
Gigerenzer, G., \& Goldstein, D. G. (1996). Reasoning the fast and frugal way: Models of bounded rationality. Psychological Review; Psychological Review, 103, 650-669.

Gigerenzer, G., \& Todd, P. M. (1999). Fast and frugal heuristics: The adaptive toolbox Simple heuristics that make us smart. (pp. 3-34): New York, NY, US: Oxford University Press.

Gigerenzer, G., Todd, P. M., \& ABC Research Group. (1999). Simple heuristics that make us smart. New York: Oxford University Press.

Gilovich, T. D., \& Griffin, D. W. (2010). Judgment and decision making Handbook of Social Psychology: John Wiley \& Sons, Inc.

Goldberg, V. (1991). The power of photography: how photographs changed our lives (1st ed.). New York: Abbeville Press.

Hanusch, F. (2008). Graphic death in the news media: present or absent? Mortality, 13, 301-317.

Heaven, P. C. L., Organ, L.-A., Supavadeeprasit, S., \& Leeson, P. (2006). War and prejudice: A study of social values, right-wing authoritarianism, and social dominance orientation. Personality and Individual Differences, 40, 599-608.

Henry, P. J., Sidanius, J., Levin, S., \& Pratto, F. (2005). Social Dominance Orientation, Authoritarianism, and support for intergroup violence between the Middle East and America. Political Psychology, 26, 569-584.

Hill, C. A., \& Helmers, M. H. (2004). Defining visual rhetorics. Mahwah, NJ: Lawrence Erlbaum. 
Hine, D. W., Marks, A. D., Nachreiner, M., Gifford, R., \& Heath, Y. (2007). Keeping the home fires burning: The affect heuristic and wood smoke pollution. Journal of Environmental Psychology, 27, 26-32.

Hoffman, D. D. (1998). Visual intelligence: how we create what we see (1st ed.). New York: W.W. Norton.

Jensen, K. B., \& Jankowski, N. (1991). A Handbook of qualitative methodologies for mass communication research. London; New York: Routledge.

Kahneman, D. (2003a). Maps of Bounded Rationality: Psychology for Behavioral Economics. American Economic Review, 93.

Kahneman, D. (2003b). A perspective on judgment and choice: Mapping bounded rationality. American Psychologist;American Psychologist, 58, 697-720.

Kane, M. J., Poole, B. J., Tuholski, S. W., \& Engle, R. W. (2006). Working memory capacity and the top-down control of visual search: Exploring the boundaries of "executive attention". Journal of Experimental Psychology: Learning, Memory, and Cognition, 32, 749-777.

Kellner, D. (2004). 9/11, spectacles of terror, and media manipulation. Critical Discourse Studies, 1, 41-64.

Larrick, R. P., Morgan, J. N., \& Nisbett, R. E. (1990). Teaching the use of cost-benefit reasoning in everyday life. Psychological Science, 1, 362-370.

Larrick, R. P., Nisbett, R. E., \& Morgan, J. N. (1993). Who uses the cost-benefit rules of choice? Implications for the normative status of microeconomic theory. Organizational Behavior and Human Decision Processes, 56, 331-347. 
Larson, E. V., \& Rand Corporation. (1996). Casualties and consensus : the historical role of casualties in domestic support for U.S. military operations. Santa Monica, CA: RAND.

Larson, E. V., \& Savych, B. (2005). American public support for U.S. military operations from Mogadishu to Baghdad. Santa Monica, CA: RAND.

Lindlof, T. R., \& Taylor, B. C. (2011). Qualitative communication research methods (3rd ed.). Thousand Oaks, Calif.: SAGE.

Lipkus, I. M., Dalbert, C., \& Siegler, I. C. (1996). The importance of distinguishing the Belief In A Just World for self versus for others: implications for psychological well-being. Personality and Social Psychology Bulletin, 22, 666-677.

Loewenstein, G. F., Weber, E. U., Hsee, C. K., \& Welch, N. (2001). Risk as feelings. Psychological Bulletin;Psychological Bulletin, 127, 267-286.

Mandel, D. (2011). Chapter 14 - Affect and risk perception in the context of terrorism: Towards an understanding of its psychosocial aspects Psychosocial, Organizational, and Cultural Aspects of Terrorism: Final Report to NATO. Toronto: NATO Research and Technology Organisation.

Massaro, D. W., \& Cowan, N. (1993). Information processing models: Microscopes of the mind. Annual Review of Psychology, 44, 383-425.

Mehrabian, A., \& Russell, J. A. (1974). The basic emotional impact of environments. Perceptual and motor skills, 38, 283-301.

Michel-Kerjan, E., \& Slovic, P. (2010). The irrational economist : making decisions in a dangerous world. New York: PublicAffairs.

Moeller, S. (1999). Compassion Fatigue. New York and London: Routledge. 
Morrison, P. (Writer) \& L. Mantle (Director). (2013). Why does the US media recoil at the idea of running graphic images? [Radio], Airtalk. U.S.A.: Southern California Public Radio.

Mueller, J. E. (1971). Trends in popular support for the wars in Korea and Vietnam. The American Political Science Review, 65, 358-375.

Mueller, J. E. (1973). War, presidents, and public opinion. New York,: Wiley.

Mueller, J. E. (2005). The Iraq Syndrome. Foreign Affairs, 84, 44-54.

NPPA. (2011). National Press Photographers Association Code of Ethics Retrieved May 11,2011, from http://www.nppa.org/professional development/business practices/ethics. html

NPR (Producer). (2012, April 15, 2013). British envoy: Afghanistan plan makes sense. Morning Edition. [Radio Transcript] Retrieved from http://www.npr.org/2012/03/14/148574420/westmacott-afghan-planmakes-sense

OXFAM. (2012). A Dangerous Delay: The cost of late response to early warnings in the 2011 drought in the Horn of Africa (Vol. 2012, pp. 6). London: OXFAM.

Perlmutter, D. D. (1998). Photojournalism and foreign policy: icons of outrage in international crises. Westport, Conn.: Praeger.

Perlmutter, D. D. (2001). Visions of war: picturing warfare from the Stone Age to the Cyber Age (1st St. Martin's Griffin ed.). New York: St. Martin's Press.

Perlmutter, D. D. (2005). Photojournalism and foreign affairs. Orbis, 49, 109-122.

Plato, \& Reeve, C. D. C. (2004). Republic. Indianapolis: Hackett Pub. Co. 
Plewes, B., \& Stuart, R. (2007). The pornography of poverty: A cautionary fundraising tale. In D. Bell \& J.-M. Coicaud (Eds.), Ethics in action : the ethical challenges of international human rights nongovernmental organizations (pp. 23-37). Cambridge; New York: Cambridge University Press.

Pratto, F., Sidanius, J., Stallworth, L. M., \& Malle, B. F. (1994). Social dominance orientation: A personality variable predicting social and political attitudes. Journal of Personality and Social Psychology; Journal of Personality and Social Psychology, 67, 741-763.

Radley, A., \& Kennedy, M. (1997). Picturing need: Images of overseas aid and interpretations of cultural difference. Culture \& Psychology, 3, 435-460.

Ranganathan, S. K., \& Henley, W. H. (2008). Determinants of charitable donation intentions: a structural equation model. International Journal of Nonprofit and Voluntary Sector Marketing, 13, 1-11.

Rhodebeck, A. (2012, April 21, 2012). The good and bad of No Child Left Behind, Newspaper Article, Kane County Chronicle. Retrieved from http://www.kcchronicle.com/mobile/article.xml/articles/2012/04/17/r tih mz5oattqjxhgfkw0cgq/index.xml

Ross, P. (2013). Doctored Boston photo: Why did the NY Daily News alter the gory photo? International Science Times. Retrieved from International Science Times website: http://www.isciencetimes.com/articles/4952/20130417/doctoredboston-photo-why-ny-daily-news.htm

Rubin, G. (2013, July 30). The Happiness Project [Blog]. Blog Retrieved from http://www.happiness-project.com/ 
Schneider, W., Eschman, A., \& Zuccolotto, A. (2002a). E-Prime Reference Guide: Version 1.0. Pittsburgh; Psychology Software Tools, Inc.

Schneider, W., Eschman, A., \& Zuccolotto, A. (2002b). E-Prime User's Guide: Version 1.0. Pittsburgh: Psychology Software Tools, Inc.

Sereno, M. I., Dale, A. M., Reppas, J. B., Kwong, K. K., Belliveau, J. W., Brady, T. J., et al. (1995). Borders of multiple visual areas in humans revealed by functional magnetic resonance imaging. Science, 268, 889-893.

Shah, R. (2013). Huffpost Good News Retrieved July 30, 2013, from http://www.huffingtonpost.com/good-news/

Shepard, R. N., \& Metzler, J. (1971). Mental rotation of three-dimensional objects. Science, 171, 701-703.

Siegrist, M., Keller, C., \& Cousin, M.-E. (2006). Implicit attitudes toward nuclear power and mobile phone base stations: Support for the Affect Heuristic. Risk Analysis: An International Journal, 26, 1021-1029.

Silberstein, S. (2002). War of words: language, politics and 9/11. London; New York: Routledge.

Simon, H. A. (1955). A behavioral model of Rational Choice. The Quarterly Journal of Economics, 69, 99-118.

Simon, H. A. (1978). Information-processing theory of human problem solving Handbook of learning \& cognitive processes: V. Human information. (pp. 271295): Oxford, England: Lawrence Erlbaum.

Slovic, P. (2004). What's fear got to do with it- It's affect we need to worry about. Missouri Law Review, 69, 971. 
Slovic, P., Finucane, M., Peters, E., \& MacGregor, D. G. (2002). The affect heuristic. In T. Gilovich, D. Griffin \& D. Kahneman (Eds.), Heuristics and biases: The psychology of intuitive judgment. (pp. 397-420). New York, NY US: Cambridge University Press.

Slovic, P., \& Peters, E. (2006). Risk perception and affect. Current Directions in Psychological Science (Wiley-Blackwell), 15, 322-325.

Slovic, P., \& Västfjäll, D. (2010). Affect, Moral Intuition, and Risk. Psychological Inquiry, 21, 387-398.

Smith-Rodden, M., \& Ash, I. (2012). Investigating the psychological effects of news imagery: A case for evidence-based decision making and practices. Visual Communication Quarterly, 19, 20-32.

Sontag, S. (2003). Regarding the pain of others (1st ed.). New York: Farrar, Straus and Giroux.

SPJ. (1996). Society of Professional Journalists Code of Ethics Retrieved May 11, 2011, from http://www.spj.org/ethicscode.asp

SSRC. (2012). 2012 Life in Hampton Roads Survey. In J. Richman \& T. VandecarBurdin (Eds.). Norfolk, VA: Old Dominion University.

Tabachnick, B. G., \& Fidell, L. S. (2001). Using multivariate statistics (4th ed.). Boston: Allyn and Bacon.

Tisdall, S. (2012, January 17, 2012). East Africa's drought: the avoidable disaster, The Guardian. Retrieved from http://www.guardian.co.uk/world/2012/jan/18/east-africa-droughtdisaster-report 
Tversky, A., \& Kahneman, D. (1992). Judgment under uncertainty: Heuristics and biases. In T. O. Nelson (Ed.), Metacognition: Core readings (pp. 379-392). Boston: Allyn \& Bacon.

UNICEF. (2012). Press release: Horn of Africa crisis one year on: Famine reversed, countless lives saved, but situation of millions of women and children still grave Retrieved August 6, 2012, from http://www.unicef.org/media/media_65385.html

Vail, K. E., \& Motyl, M. (2010). Support for diplomacy: Peacemaking and militarism as a unidimensional correlate of social, environmental, and political attitudes. Peace and Conflict: Journal of Peace Psychology, 16, 29-57.

VandenBos, G. R. (2007). APA dictionary of psychology / Gary R. VandenBos, editor in chief: Washington, DC : American Psychological Association, c2007.

1 st ed.

Wargo, E. (2012). The mechanics of choice. [review]. The Observer-Association for Psychological Science, 25.

Webb, D., Green, C., \& Brashear, T. (2000). Development and validation of scales to measure attitudes influencing monetary donations to charitable organizations. [Article]. Journal of the Academy of Marketing Science, 28, 299-309.

Weis-Corbley, G. (2013). The Good News Network Retrieved July 30, 2013, from http://www.goodnewsnetwork.org/

Weise, D. R., Pyszczynski, T., Cox, C. R., Arndt, J., Greenberg, J., Solomon, S., et al. (2008). Interpersonal politics: The role of Terror Management and attachment 
processes in shaping political preferences. [Article]. Psychological Science (Wiley-Blackwell), 19, 448-455.

Wiggins, J. S. (1979). A psychological taxonomy of trait-descriptive terms: The interpersonal domain. Journal of Personality and Social Psychology, 37, 395-412.

Woods, J. (2011a). The 9/11 effect: Toward a social science of the terrorist threat. The Social Science Journal, 48, 213-233.

Woods, J. (2011b). Framing terror: an experimental framing effects study of the perceived threat of terrorism. Critical Studies on Terrorism, 4, 199-217.

Wyer, R. S., Jr. (2007). Principles of mental representation. In A. W. Kruglanski \& E. T. Higgins (Eds.), Social psychology: Handbook of basic principles (2nd ed.). (pp. 285-307). New York, NY US: Guilford Press.

Zelizer, B. (1998). Remembering to forget : Holocaust memory through the camera's eye. Chicago: University of Chicago Press.

Zelizer, B. (2002). Photography, journalism, and trauma. Journalism after September, 11, 48-68.

Zelizer, B. (2010). About to die: How news images move the public: Oxford University Press. 


\section{APPENDIX A}

\section{RECRUITMENT TO THE PRE-SCREENING SURVEY}

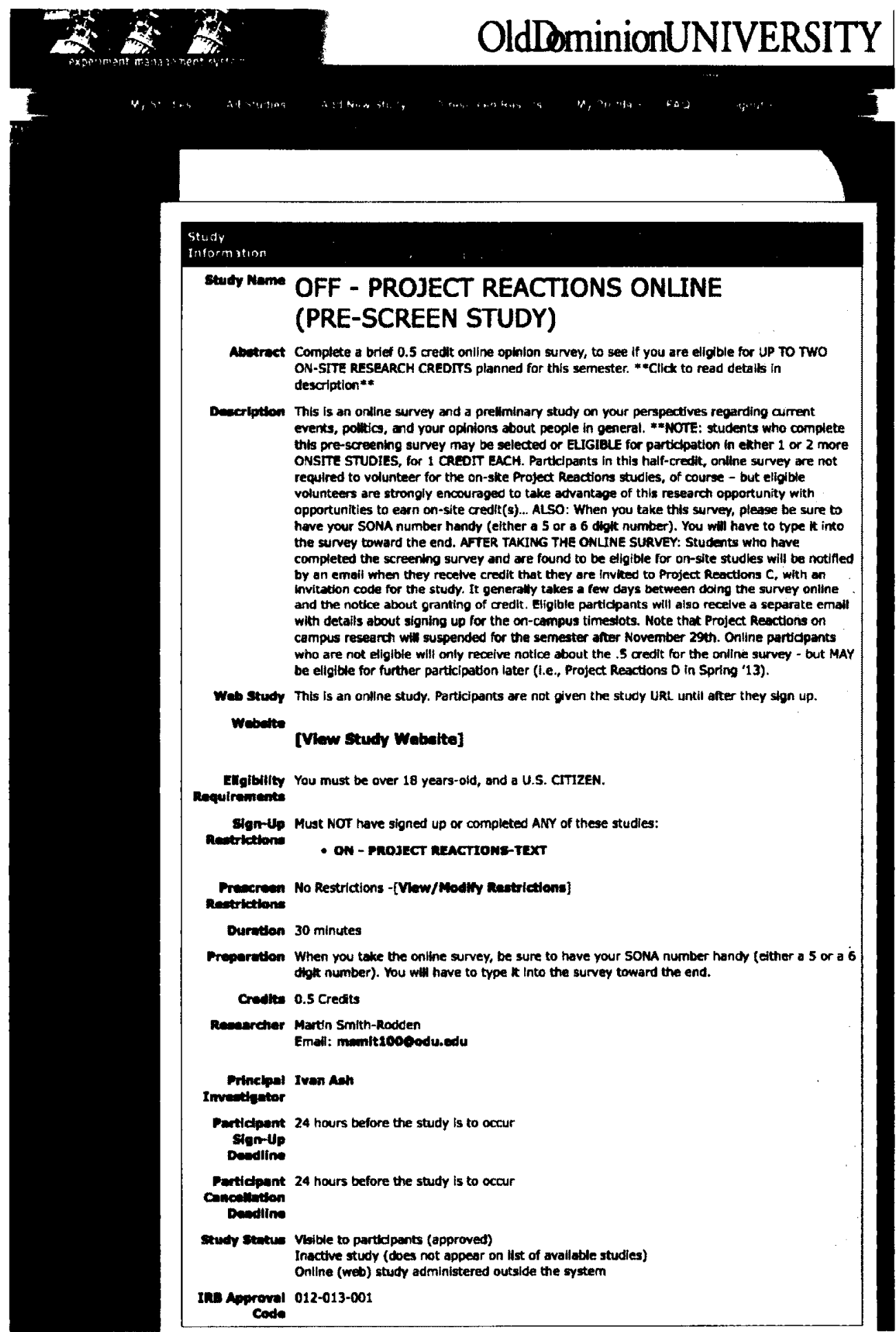




\section{APPENDIX B}

\section{UNIVERSITY HUMAN SUBJECTS COMMITTEE / INSTITUTIONAL REVIEW BOARD DOCUMENTATION}

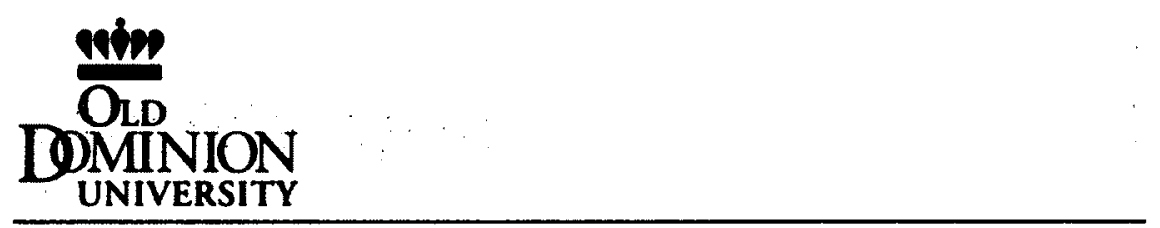

COLLEOE OF SCIENCES

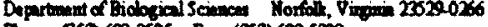

Phow: (757) 683.3095 Fax (757)683.5383

18 Sept 2012

MEMO

To. DrAsh (Psychology)

FROM: Christopher Osgood. Chair, College of Saiences Hurnan Subjects Committe $(\infty)$

RE: Your recent proposal, 012-013-001, "Reaction"

Your recent submissions to the COS Human Subjects Committee have been found to exempt from IRB review and we have approved your request to pursue this proposal indefinitely, provided no modifications occur. Also note that if you are funded externally for this project. you will ikely have to submit it to the IRB for their approval as well 


\section{APPENDIX C \\ THE RIGHT WING AUTHORITARIAN SCALE (RWA, 2006)}

Instructions: This survey is part of an investigation of general public opinion concerning a variety of social issues.

You will probably find that you agree with some of the statements, and disagree with others, to varying extents. Please indicate your reaction to each statement on the line to the left of each item according to the following (9-point Likert) scale.

If you feel exactly and precisely neutral about an item, Please indicate "Neutral"

Important: You may find that you sometimes have different reactions to different parts of a statement. For example, you might very strongly disagree ("-4") with one idea in a statement, but slightly agree ("+1") with another idea in the same item. When this happens, please combine your reactions, and write down how you feel on balance (a "- 3 " in this case).

1. The established authorities generally turn out to be right about things, while the radicals and protestors are usually just "loud mouths" showing off their ignorance. ${ }^{\otimes}$

2. Women should have to promise to obey their husbands when they get married. ${ }^{\ominus}$

3. Our country desperately needs a mighty leader who will do what has to be done to destroy the radical new ways and sinfulness that are ruining us.

4. Gays and lesbians are just as healthy and moral as anybody else. *

5. It is always better to trust the judgment of the proper authorities in government and religion than to listen to the noisy rabble-rousers in our society who are trying to create doubt in people's minds

6. Atheists and others who have rebelled against the established religions are no doubt every bit as good and virtuous as those who attend church regularly. *

7. The only way our country can get through the crisis ahead is to get back to our traditional values, put some tough leaders in power, and silence the troublemakers spreading bad ideas.

8. There is absolutely nothing wrong with nudist camps. *

9. Our country needs free thinkers who have the courage to defy traditional ways, even if this upsets many people. *

10. Our country will be destroyed someday if we do not smash the perversions eating away at our moral fiber and traditional beliefs.

11. Everyone should have their own lifestyle, religious beliefs, and sexual preferences, even if it makes them different from everyone else. * 
12. The "old-fashioned ways" and the "old-fashioned values" still show the best way to live.

13. You have to admire those who challenged the law and the majority's view by protesting for women's abortion rights, for animal rights, or to abolish school prayer. *

14. What our country really needs is a strong, determined leader who will crush evil, and take us back to our true path.

15. Some of the best people in our country are those who are challenging our government, criticizing religion, and ignoring the "normal way things are supposed to be done." *

16. God's laws about abortion; pornography and marriage must be strictly followed before it is too late, and those who break them must be strongly punished.

17. There are many radical, immoral people in our country today, who are trying to ruin it for their own godless purposes, whom the authorities should put out of action.

18. A "woman's place" should be wherever she wants to be. The days when women are submissive to their husbands and social conventions belong strictly in the past. *

19. Our country will be great if we honor the ways of our forefathers, do what the authorities tell us to do, and get rid of the "rotten apples" who are ruining everything.

20. There is no "ONE right way" to live life; everybody has to create their own way. *

21. Homosexuals and feminists should be praised for being brave enough to defy "traditional family values. *

22. This country would work a lot better if certain groups of troublemakers would just shut up and accept their group's traditional place in society.

Q Table setter item: not scored.

* Reverse scored. 


\section{APPENDIX D \\ SOCIAL DOMINANCE ORIENTATION SCALE (SDO, 1994)}

Instructions: Which of the following objects or statements do you have a positive or negative feeling towards? Beside each object or statement, place a number from ' 1 ' to ' 7 ' which represents the degree of your positive or negative feeling." The scale was labeled very positive (7), positive (6), slightly positive (5), neither positive nor negative (4), slightly negative (3), negative (2), and very negative (1).

1. Some groups of people are simply not the equals of others.

2. Some people are just more worthy than others.

3. This country would be better off if we cared less about how equal all people were.

4. Some people are just more deserving than others.

5. It is not a problem if some people have more of a chance in life than others.

6. Some people are just inferior to others.

7. To get ahead in life. It is sometimes necessary to step on others.

8. Increased economic equality. *

9. Increased social equality.*

10. Equality.*

11. If people were treated more equally we would have fewer problems in this country."

12. In an ideal world, all nations would be equal.*

13. We should try to treat one another as equals as much possible. (All humans should be treated equally.)*

14. It is important that we treat other countries as equals.*

Notes: ${ }^{*} \sim$ indicates a con-trait item, for which the scoring key is reversed. The pro-trail and contrail items should be intermixed or randomized. Items 1 and 2 "table-setters." Two statements from Pratto et al.'s (1994) item pool that were eventually dropped: "'As a country's wealth increased, more of its resources should be channeled to the poor." and "This country would be better off if inferior groups stayed in their place," (Altemeyer, 1998) 


\section{APPENDIX E \\ GENERAL INVENTORY}

Final survey questions (screening, distracter, demographic and DV-related items)

\section{INSTRUCTIONS:}

These final questions will inquire as to what feelings you may have about some specific current events and political ideologies.

The last six questions at the bottom are a few more demographic questions. They are largely designed to tell us more about what experience or perspectives you may have regarding the issues we've asked you.

Again, there are no right or wrong answers to these questions, and all responses are anonymous and kept absolutely confidential.

1.

One year after the fall of Hosni Mubarak, Egypt is better off. ${ }^{\otimes}$

[9-point Likert scale responses: Very Strongly Disagree to Very Strongly Agree]

2.

I am very concerned about the situation in Syria. ${ }^{\otimes}$

[9-point Likert scale responses: Very Strongly Disagree to Very Strongly Agree]

3.

I support America sending aid to famine-stricken countries in Africa. $†$

[9-point Likert scale responses: Very Strongly Disagree to Very Strongly Agree]

4.

I am optimistic about the state of the world. ${ }^{\theta}$

[9-point Likert scale responses: Very Strongly Disagree to Very Strongly Agree]

5.

I would rather live in the United States than anywhere else. ${ }^{\theta}$

[9-point Likert scale responses: Very Strongly Disagree to Very Strongly Agree] 
6.

America has already sent hundreds of millions of dollars of aid - if we stop sending now millions of starving people could die. $†$

[9-point Likert scale responses: Very Strongly Disagree to Very Strongly Agree]

7.

America should send more troops to Afghanistan in order to defeat the terrorists. *

[9-point Likert scale responses: Very Strongly Disagree to Very Strongly Agree]

8.

I support the current war in Afghanistan. *

[9-point Likert scale responses: Very Strongly Disagree to Very Strongly Agree]

9.

America should send more aid to famine-stricken countries in Africa because it could save lives. $t$ [9-point Likert scale responses: Very Strongly Disagree to Very Strongly Agree]

10.

The best years for the United States are yet to come.

[9-point Likert scale responses: Very Strongly Disagree to Very Strongly Agree]

11.

The United States is not the great country that it once was.

[9-point Likert scale responses: Very Strongly Disagree to Very Strongly Agree]

12.

It would be incredibly wasteful for America to leave Afghanistan now before the mission is complete considering we have lost so many of our armed forces there already. ${ }^{*}$

[9-point Likert scale responses: Very Strongly Disagree to Very Strongly Agree]

13.

I am against America sending more money to African countries stricken by famine and hunger. $t$

[9-point Likert scale responses: Very Strongly Disagree to Very Strongly Agree] 
14.

The United States is the greatest country on Earth. ${ }^{\otimes}$

[9-point Likert scale responses: Very Strongly Disagree to Very Strongly Agree]

15.

I am against the current war in Afghanistan. *

[9-point Likert scale responses: Very Strongly Disagree to Very Strongly Agree]

16.

I support what America has done in sending hunger assistance to African countries in famine. $\dagger$

[9-point Likert scale responses: Very Strongly Disagree to Very Strongly Agree]

17.

America should gradually begin to stop sending aid to African countries stricken by famine and hunger. $t$

[9-point Likert scale responses: Very Strongly Disagree to Very Strongly Agree]

18.

America should hasten to remove troops from Afghanistan. *

[9-point Likert scale responses: Very Strongly Disagree to Very Strongly Agree]

19.

I am paying attention to the questions in this survey.

[9-point Likert scale responses: Very Strongly Disagree to Very Strongly Agree]

20.

It seems the violence in Afghanistan is now an Afghani problem, and there is little else U.S. troops can do to help the situation. *

[9-point Likert scale responses: Very Strongly Disagree to Very Strongly Agree] 
22.

Are you now or have you previously served in the Armed Forces, in a combat environment? $\$$ [2 responses available: Yes or $\mathrm{No}]$

23.

Have you lost a family member, loved-one, or very close friend in the war in Afghanistan? \$ [2 responses available: Yes or No]

24.

Have you lost a family member, spouse or very close friend in the "War on Terror," or in the terrorists attacks of September 11, 2001? \$

[2 responses available: Yes or No]

25.

Have you ever donated to or volunteered in a hunger or famine-related aid effort?

[2 responses available: Yes or No]

26.

Are you an international student from the horn of Africa? $\$$

[2 responses available: Yes or No]

27.

I identify with the following political ideology (ideologies*):

* Please select all that apply

[Available responses: Conservative; Independent; Liberal; Libertarian; Moderate; Tea Party; None of the above]

${ }^{\otimes}$ Distracter item

\&xclusionary screening item

* DV-related item: Afghanistan conflict

t DV-related item: Famine Aid

Exploratory Demographic 


\section{APPENDIX F \\ INFORMED CONSENT NOTIFICATION (ONLINE STUDY)}

\section{OLD DOMINION UNIVERSITY Notification Document (Online)}

The purposes of this form are to give you information that may affect your decision whether to say YES or NO to participation in this research.

\section{PROJECT TITLE: "Project Reactions Online"}

DESCRIPTION: You are being asked to participate in a study how people form opinions, reactions, judgments, decisions. You will be asked to read information and from your computer screen, answer questions and respond to statements about this information. In the process of this study you may be asked questions about your perspective or stance on certain news events, situations or moral dilemmas. You may see some questions that are similar to others, or some questions may be encountered twice. This is a one session, hour-long study. Completion of this session may make you eligible for separate and different studies, later on, if you wish to participate in those. However this notification pertains only to this study, known as "Project Reactions Online."

EXCLUSIONARY CRITERIA: You must not have participated in a previous session of this study. You must be at least 18 years of age.

RISKS: The risks associated with this study include those associated with normal everyday use of computers.

BENEFITS: There is no cost or payment associated with your participation in this investigation. The researchers want your decision about participation in this study to be absolutely voluntary. You will receive no direct benefit from this research, other than this being a learning experience for how psychology studies are conducted.

As such, if you decide to participate in this study, you will receive a total of 1 Psychology department research credit for one hour of participation, which may be applied to course requirements or extra credit in certain Psychology courses. Equivalent credits may be obtained in other ways. You do not have to participate in this research study, or any Psychology department study, in order to obtain this credit.

CONFIDENTIALITY: You will be assigned a participant code and this number (not your name) will be used to organize all data and records collected. Your name will not be kept with or associated with the data collected, only your anonymous 5-digit SONA number. The SONA records that contain any identifying information are inaccessible to the researchers, and only accessible to authorized University staff and faculty. The results of this study may be used in reports, presentations, and publications; but the researchers will not identify you. Of course, records may be subpoenaed by court order or inspected by government bodies with oversight authority. 
WITHDRAWAL PRIVILEGE: It is OK for you to say NO. You may refuse to participate in or withdraw from this study at any time. If you do, there will be no penalty assigned to you whatsoever. PLEASE MAKE SURE YOU UNDERSTAND THIS COMPLETELY. If you ever feel uncomfortable or have any questions about your participation, please do not hesitate to contact the experimenter, Dr Ivan Ash, by email (iash@,odu.edu) or by phone at his office at (757) 683-4446. We have as our primary responsibility to ensure your health, safety and wellbeing and will do everything available to us to make sure your needs are given the most consideration. The researchers reserve the right to withdraw your participation in this study, at any time, if they observe potential problems with your continued participation.

COMPENSATION FOR ILLNESS AND INJURY: If you say YES, then your consent in this document does not waive any of your legal rights. However, in the event of injury arising from this study, neither Old Dominion University nor the researchers are able to give you any money, insurance coverage, free medical care, or any other compensation for such injury. In the event that you suffer injury as a result of participation in any research project please contact Old Dominion University Office of Research, at (757) 683-3460.

VOLUNTARY CONSENT: When you hit "NEXT" below and proceed to the following pages, you are saying several things. You are saying that you have read this form or have had it read to you, that you are satisfied that you understand this form, the research study, and its risks and benefits. If you have any questions later on, then the researchers should be able to answer them: Martin Smith-Rodden, Graduate researcher, at msmitrodd100@odu.edu, or (757) 393-7903. Also you can contact Dr. Ivan K. Ash, principal investigator at the ODU Human Cognition Lab, at iash@odu.edu or (757) 683-4446.

If at any time you feel pressured to participate, or if you have any questions about your rights or this form, then you should call the Old Dominion University Office of Research, at $757-683-3460$.

And most importantly, when you hit the "NEXT" button and advance to the next page, you are indicating to the researcher, YES, that you are a volunteer and agree to participate in this study. Upon request, the researcher can give you a copy of this form for your records, or you may print it out now. 


\section{APPENDIX G \\ FINAL SURVEY PAGE AND ONLINE DEBRIEFING}

\section{Congratulations...}

You finished the survey.

We appreciate your time and attention to this procedure.

The experiments you participate in can serve as educational opportunities, which allow you to learn a little about how psychologists study the nature of behavior, beliefs, emotions, and cognition. The information, responses and data gathered from the survey will inform forthcoming work, future research and experimentation that address how people form opinions on important matters currently in the news.

Since you have participated in this online study, you may be interested to know that a 1credit on-site study (Project Reactions 1.0) may be available to you. Please consult your SONA listings in the next few days (after your credit is posted), if you are interested in volunteering to participate in the on-site part of this research.

Since this is ongoing research, we would ask that you refrain from discussing specifics of this study with other classmates, or anyone that may be taking a psychology class this semester. This will help us prevent contamination or influencing of future subjects, and insure that this research -- as well as your time -- is all worthwhile. 


\section{APPENDIX H}

\section{RECRUITMENT TO THE PILOT STUDIES}

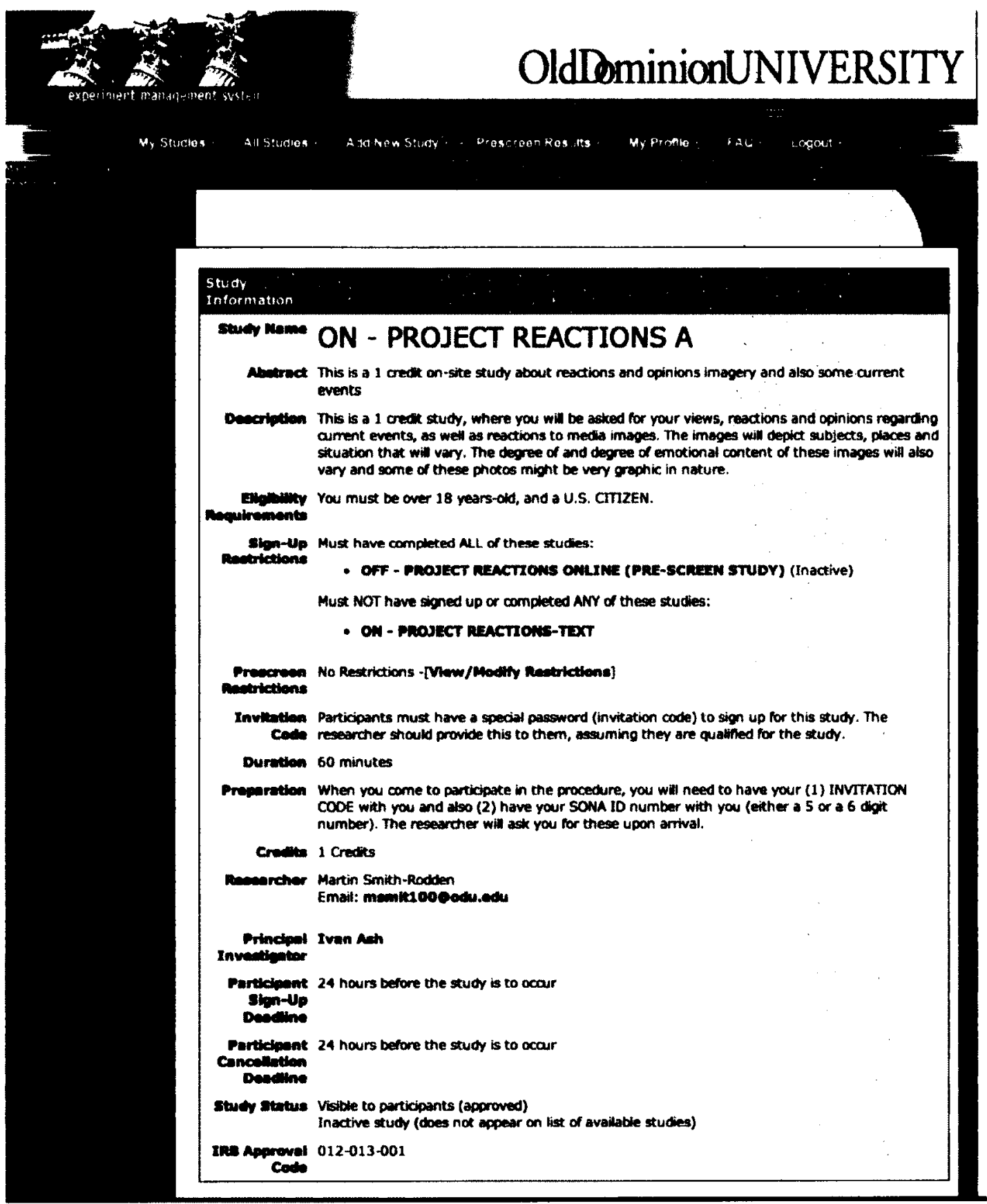




\section{APPENDIX I \\ TRAINING VIDEO FOR PILOT TESTING}

Runtime: 5:49 / produced by the author. To view, go to LINK:

https://vimeo.com/46508378

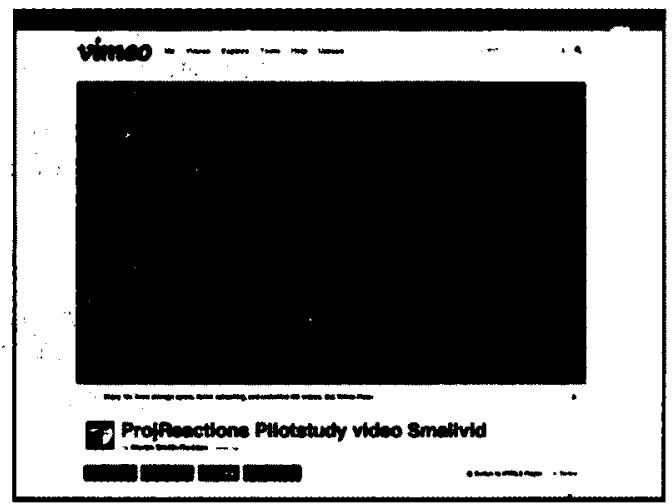

Figure 11. Framegrab from training video.

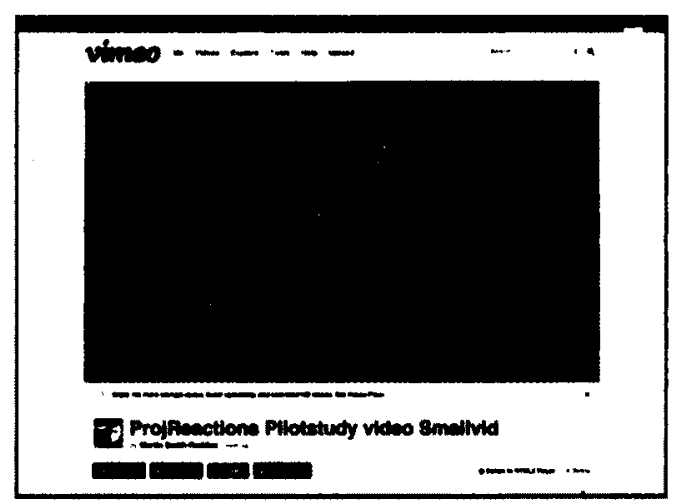

Figure I2. Framegrab from training video.

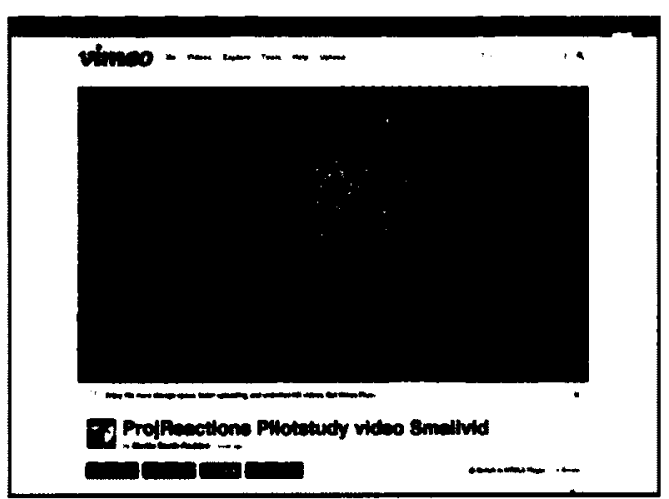

Figure 13. Framegrab from training video. 


\section{APPENDIX J}

\section{STIMULI SET FOR THE PILOT STUDY: AFGHANISTAN IMAGES}

Injured soldiers from the Afghanistan War. Sources: The Associated Press and The Virginian-Pilot.

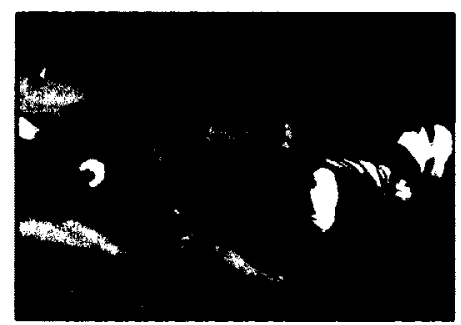

Figıre Jl. Disabled war vets. (AP).

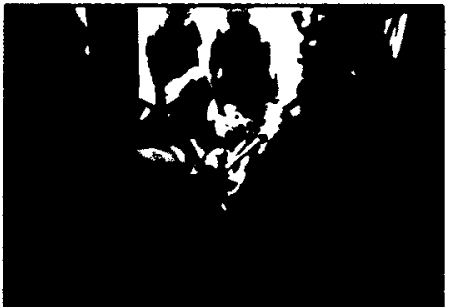

Figune J2. Seriously injured soldiers. (AP).

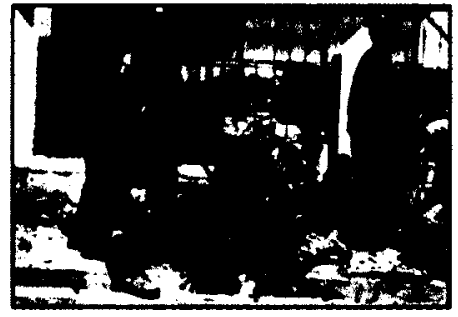

Figıne J4. Seriously injured soldiers in suucide bombing aftermath. (AP).

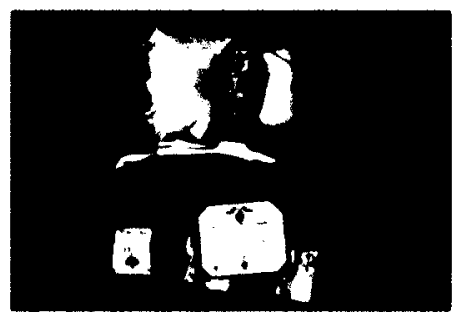

Figure J6. Seriously injured soldier with Purple Heart. (The Virginian-Pilot).

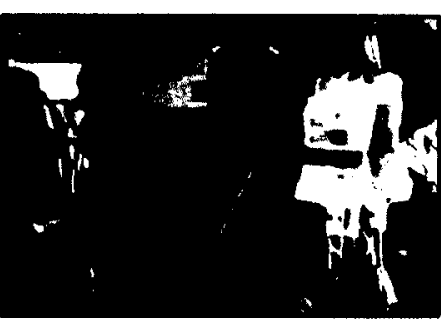

Figure J3. Lightly injured soldier in helicopter. (AP).

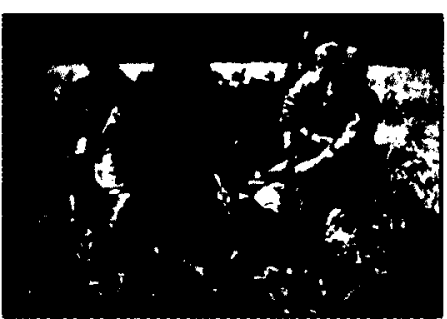

Figure J5. Injured soldiers. (AP).

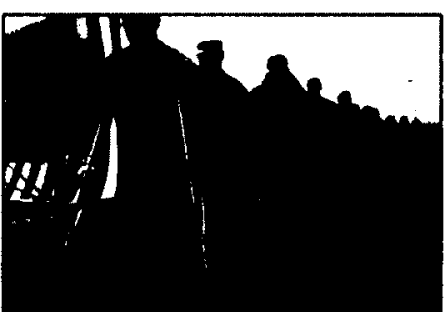

Figure J7. Disabled war vets. (AP). 


\section{APPENDIX K}

\section{OLD DOMINION UNIVERSITY AGREEMENT TO PARTICPATE}

\section{OLD DOMINION UNIVERSITY Notification Document}

The purposes of this form are to give you information that may affect your decision whether to say YES or NO to participation in this research.

PROJECT TITLE(s): This is for the PROJECT REACTIONS series (this includes "Project Reactions TEXT, Text-Plus, A, B, C or D"

DESCRIPTION: You are being asked to participate in a study how people form opinions, reactions, judgments, decisions. You will be asked to read information and from your computer screen, answer questions and respond to statements about this information. In the process of this study you may be asked questions about your perspective or stance on certain news events, situations or moral dilemmas. You may see some questions that are similar to others, or some questions may be encountered twice. This is a one session, hourlong study. Completion of this session may make you eligible for separate and different studies, later on, if you wish to participate in those.

EXCLUSIONARY CRITERIA: You may be excluded from participation if you have been involved in certain earlier versions of this study. You must be at least 18 years of age, and a United States citizen for this study.

RISKS: The risks associated with this study include those associated with normal everyday use of computers. The study may include written materials, images, or a combination of both. The nature of some of these written and visual materials should be noted: It is possible that you may find some of the written materials and images emotionally disturbing. The written materials and images may depict serious life-and-death dilemmas, which some people may emotionally struggle with. Some of the more vivid and disturbing images may depict people in a condition of life-and-death desperation, peril, misery, grave or serious injuries, starvation, and dying, or death.

BENEFITS: There is no cost or payment associated with your participation in this investigation. The researchers want your decision about participation in this study to be absolutely voluntary. You will receive no direct benefit from this research, other than this being a learning experience for how psychology studies are conducted. As such, if you decide to participate in this study, you will receive a total of one (1) Psychology department research credit for up to one hour of participation, which may be applied to course requirements or extra credit in certain Psychology courses. Equivalent credits may be obtained in other ways. You do not have to participate in this research study, or any Psychology department study, in order to obtain credit.

CONFIDENTIALITY: You will be assigned a participant code and this number (not your name) will be used to organize all data and records collected. Your name will not be kept with or associated with the data collected, only your anonymous SONA number (either a 5 or a 6 digit number). The SONA records that contain any identifying information are inaccessible to the researchers, and only accessible to authorized University staff and faculty. The results of this study may be used in reports, presentations, and publications; 
but the researchers will not identify you. Of course, records may be subpoenaed by court order or inspected by government bodies with oversight authority.

WITHDRAWAL PRIVILEGE: It is OK for you to say NO. You may refuse to participate in or withdraw from this study at any time. If you do, there will be no penalty assigned to you whatsoever. PLEASE MAKE SURE YOU UNDERSTAND THIS COMPLETELY. If you ever feel uncomfortable or have any questions about your participation, please do not hesitate to contact the experimenter, Dr Ivan Ash, by email (iash@odu.edu) or by phone at his office at (757) 683-4446. We have as our primary responsibility to ensure your health, safety and wellbeing and will do everything available to us to make sure your needs are given the most consideration. The researchers reserve the right to withdraw your participation in this study, at any time, if they observe potential problems with your continued participation.

COMPENSATION FOR ILLNESS AND INJURY: If you say YES, then your consent in this document does not waive any of your legal rights. However, in the event of injury arising from this study, neither Old Dominion University nor the researchers are able to give you any money, insurance coverage, free medical care, or any other compensation for such injury. In the event that you suffer injury as a result of participation in any research project please contact Old Dominion University Office of Research, at (757) 683-3460.

VOLUNTARY CONSENT: When you sign this document and proceed to the following procedure, you are saying several things. You are saying that you have read this form or have had it read to you, that you are satisfied that you understand this form, the research study, and its risks and benefits. If you have any questions later on, then the researchers should be able to answer them: Martin Smith-Rodden, Graduate researcher, at msmitrodd100@odu.edu, or (757) 393-7903. Also you can contact Dr. Ivan K. Ash, principal investigator at the ODU Human Cognition Lab, at iash@odu.edu or (757) 683-4446. If at any time you feel pressured to participate, or if you have any questions about your rights or this form, then you should call the Old Dominion University Office of Research, at 757-6833460.

And most importantly, when you sign this document, you are indicating to the researcher, $Y E S$, that you are a volunteer and agree to participate in this study. Upon request, the researcher can give you a copy of this form for your records.

Date

Signature of Participant

\section{INVESTIGATOR'S STATEMENT}

I certify that I have explained to this subject the nature and purpose of this research, including benefits, risks, costs, and any experimental procedures. I have described the rights and protections afforded to human subjects and have done nothing to pressure, coerce, or falsely entice this subject into participating. I am aware of my obligations under state and federal laws, and promise compliance. I have answered the subject's questions and have encouraged him/her to ask additional questions at any time during the course of this study. I have witnessed the above signature(s) on this consent form.

\section{Date}

Signature of Experimenter 


\section{APPENDIX L}

\section{STUDY RECRUITMENT FOR TEXT PILOT}

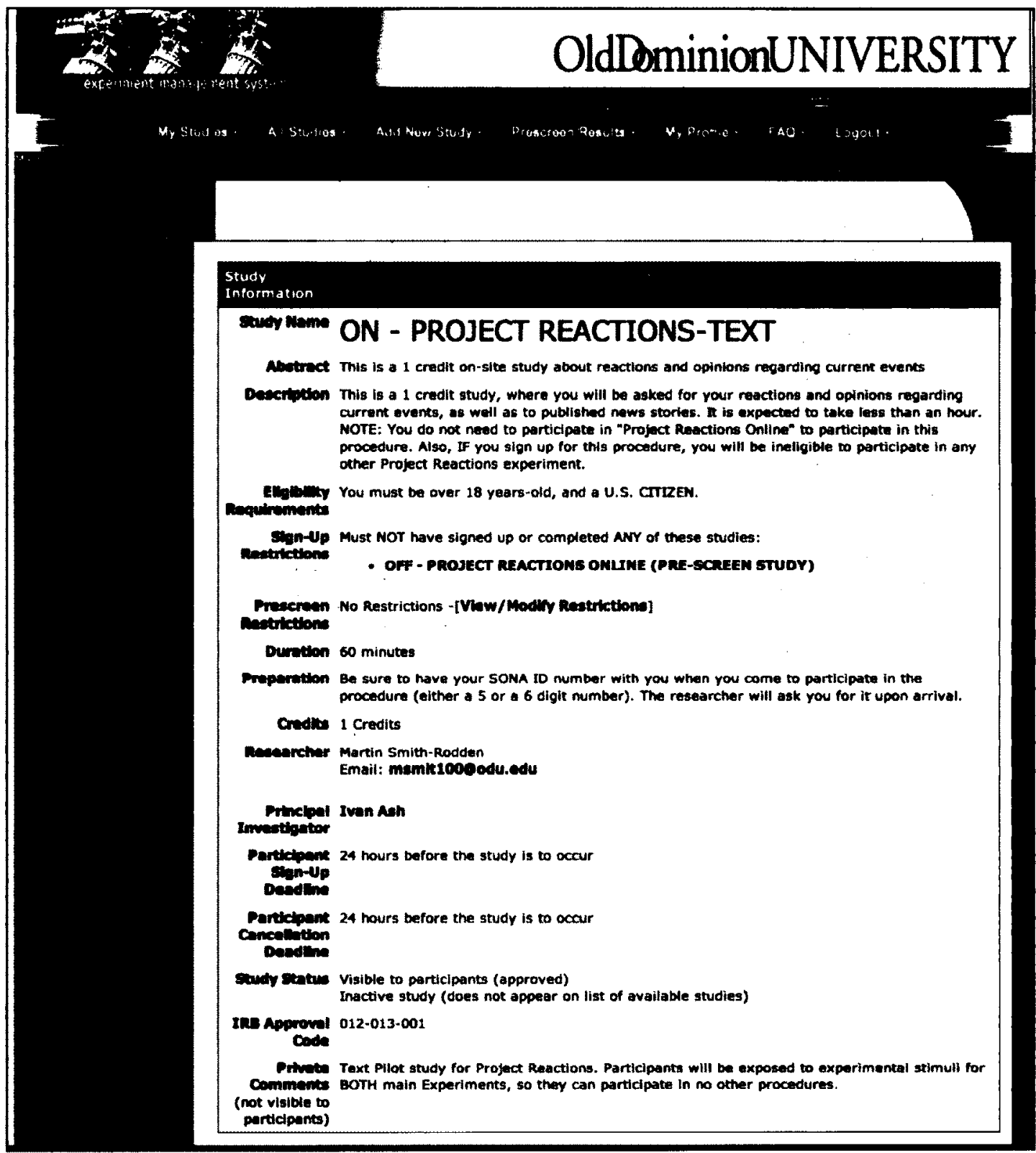




\section{APPENDIX M}

\section{AFGHANISTAN TEXT}

\section{IN AFGHANISTAN: AMERICANS FACE DIFFICULT CHOICES}

Roughly eleven years after the terrorist attacks of September 11, 2001, the war effort in Afghanistan has claimed the lives of thousands of United States servicemen and women. Recent incidents and setbacks in 2012 have brought the war to the forefront of political discussions, as Americans move into the Fall election. *

Reactions to the war from around the country vary about whether the US military in Afghanistan should stay or go.

“...We don't want to cut and run and just leave Afghanistan entirely on its own, because of the risk then is that we end up back where we started and with the risk that Afghanistan once again becomes a breeding ground for terrorism, and that is absolutely not in our interest," said Britain's US ambassador, Sir Peter Westmacott.

"...It's time to reassess why we are in Afghanistan, what we can hope to accomplish, and what our next move should be. ...At this point, we no longer have any valid interest in maintaining tens of thousands of soldiers in the country." Mitchell Bard, blogger for Huffington Post.

Regardless of which side of the debate people are on, there is little doubt that the issue of the Afghanistan War is a major issue on people's minds this year. Either way, the choices about what our military presence will be in that country will have consequences that will be felt for years to come. *

(232 words)

Sources:

* Written by the researcher.

Morning Edition, National Public Radio Transcript, March 14, 2012 (NPR, 2012)

$\therefore$ Mitchell Bard, Huffington Post Blog, March 14, 2012 (Bard, 2012) 


\section{APPENDIX N}

\section{PRACTICE STORY TEXT}

\section{THE GOOD AND BAD OF "NO CHILD LEFT BEHIND" (Rhodebeck, 2012)}

Although No Child Left Behind set goals through 2014, School District Superintendent Jeff Schuler said nobody anticipated the federal law would reach that year without some revision or adjustment.

Now that the deadline is mere years away, he said, schools and school districts are facing "an unrealistic target with very punitive outcomes or consequences."

NCLB calls for all public schoolchildren to be proficient in reading and math by 2014. Potential consequences for missing the benchmarks leading up to that goal include replacing teachers, implementing new curriculum and allowing students to attend other district schools.

Local educators don't deny there are good aspects of the law. They said it forced schools to stop looking at averages in education and to also consider scores of certain subgroups, such as low-income students and those with special needs.

The law also raises expectations year after year, indicating that just because schools are doing well doesn't mean that can't get better, said Erika Schlichter, director of educational services for grades 6-12 at the School District.

But NCLB also assumes students should learn at the same rate when, in fact, they don't, said Pam Turriff, a president of a local Education Association. Students have varying abilities, background knowledge., home experiences and, she said, readiness to learn. "Teachers believe all children can learn, but children don't come to school like widgets," Turriff said.

While educators seem to crave a new federal education law to replace NCLB, they don't go into as much detail about what the new law should do. They simply maintain that the current law is problematic. If Schuler had input in the next federal education law he said he would want it to focus on student growth overtime and to have multiple measures of achievement. 'I don't think testing only in reading and math really adequately measures the overall development of students;' he said. 
APPENDIX 0

\section{STUDY RECRUITMENT FOR EXPERIMENT 1}

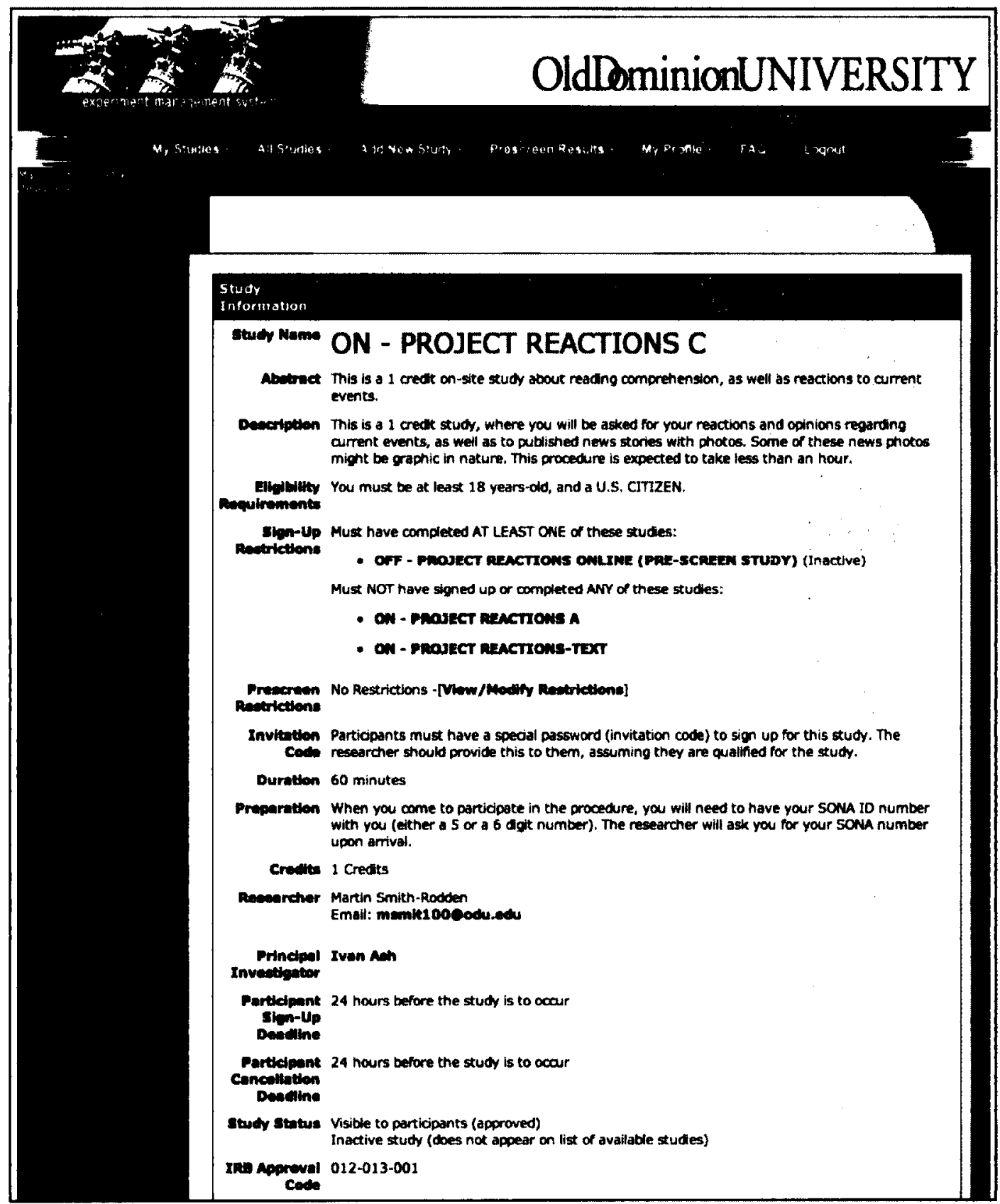




\section{APPENDIX P}

\section{VIDEO BRIEFING}

Training video for Experiments 1 and 2 (length: 6:31/ produced by the author).

To view, go to LINK: https://vimeo.com/46508379

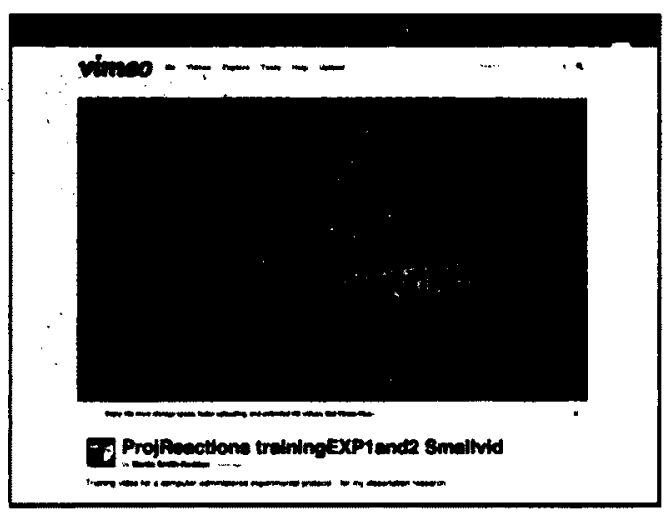

Figure P1. Framegrab from training video.

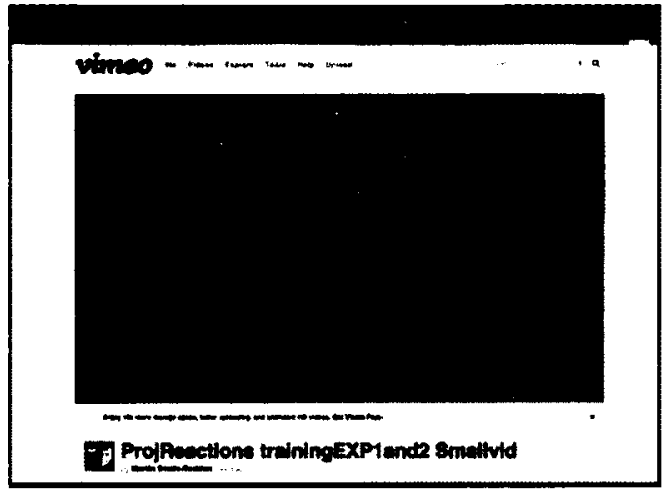

Figure P2. Framegrab from training video.

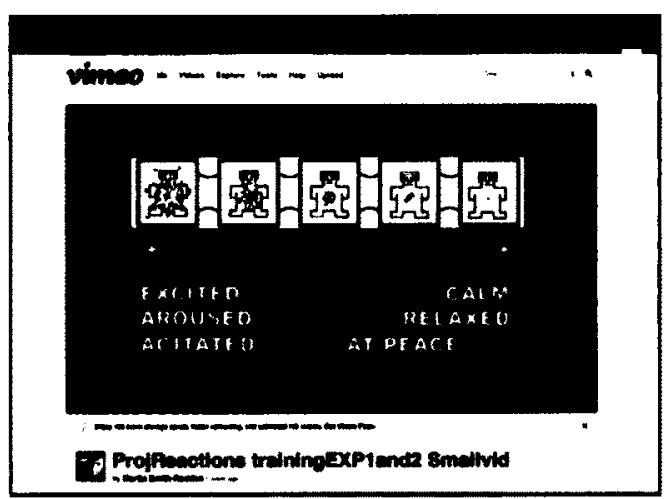

Figure P3. Framegrab from training video. 


\section{APPENDIX Q}

\section{GENERAL MILITARISTIC ATTITUDES}

Inventory items for Militaristic versus Pacifist orientation.

It is entirely appropriate to engage in preemptive attacks on countries (e.g., Iran, North Korea, etc.) that may pose a threat to the United States, even if there's no evidence they are planning to attack us right now. (Weise, et al, 2008)

The only chance we have to stop international terrorism is if the United States follows a strict and uncompromising approach to this problem, using military intervention. (Weise, et al, 2008)

The best way for the United States to address the problem of terrorism involves increasing U.S. military presence in troubled areas around the world (e.g., Middle East). (Weise, et al, 2008)

If the U.S. wants peace, it must set a peaceful example. (Vail et al, 2010) ${ }^{\star}$

If our leaders advocate violent solutions, they can only expect more violence in return. (Vail et al, 2010) ${ }^{\star}$

Fewer people will suffer if the United States aggressively pursued peaceful diplomacy instead of aggressively using its military. (Vail et al, 2010) 


\section{APPENDIX R}

\section{OLD DOMINION UNIVERSITY AGREEMENT TO PARTICPATE}

\section{OLD DOMINION UNIVERSITY Notification Document}

The purposes of this form are to give you information that may affect your decision whether to say YES or NO to participation in this research.

PROJECT TITLE(s): This is for the PROJECT REACTIONS series (this includes "Project Reactions TEXT, Text-Plus, A, B, C or D"

DESCRIPTION: You are being asked to participate in a study how people form opinions, reactions, judgments, decisions. You will be asked to read information and from your computer screen, answer questions and respond to statements about this information. In the process of this study you may be asked questions about your perspective or stance on certain news events, situations or moral dilemmas. You may see some questions that are similar to others, or some questions may be encountered twice. This is a one session, hourlong study. Completion of this session may make you eligible for separate and different studies, later on, if you wish to participate in those.

EXCLUSIONARY CRITERIA: You may be excluded from participation if you have been involved in certain earlier versions of this study. You must be at least 18 years of age, and a United States citizen for this study.

RISKS: The risks associated with this study include those associated with normal everyday use of computers. The study may include written materials, images, or a combination of both. The nature of some of these written and visual materials should be noted: It is possible that you may find some of the written materials and images emotionally disturbing. The written materials and images may depict serious life-and-death dilemmas, which some people may emotionally struggle with. Some of the more vivid and disturbing images may depict people in a condition of life-and-death desperation, peril, misery, grave or serious injuries, starvation, and dying, or death.

BENEFITS: There is no cost or payment associated with your participation in this investigation. The researchers want your decision about participation in this study to be absolutely voluntary. You will receive no direct benefit from this research, other than this being a learning experience for how psychology studies are conducted. As such, if you decide to participate in this study, you will receive a total of one (1) Psychology department research credit for up to one hour of participation, which may be applied to course requirements or extra credit in certain Psychology courses. Equivalent credits may be obtained in other ways. You do not have to participate in this research study, or any Psychology department study, in order to obtain credit.

CONFIDENTIALITY: You will be assigned a participant code and this number (not your name) will be used to organize all data and records collected. Your name will not be kept with or associated with the data collected, only your anonymous SONA number (either a 5 or a 6 digit number). The SONA records that contain any identifying information are inaccessible to the researchers, and only accessible to authorized University staff and faculty. The results of this study may be used in reports, presentations, and publications; 
but the researchers will not identify you. Of course, records may be subpoenaed by court order or inspected by government bodies with oversight authority.

WITHDRAWAL PRIVILEGE: It is OK for you to say NO. You may refuse to participate in or withdraw from this study at any time. If you do, there will be no penalty assigned to you whatsoever. PLEASE MAKE SURE YOU UNDERSTAND THIS COMPLETELY. If you ever feel uncomfortable or have any questions about your participation, please do not hesitate to contact the experimenter, Dr Ivan Ash, by email (iash@odu.edu) or by phone at his office at (757) 683-4446. We have as our primary responsibility to ensure your health, safety and wellbeing and will do everything available to us to make sure your needs are given the most consideration. The researchers reserve the right to withdraw your participation in this study, at any time, if they observe potential problems with your continued participation.

COMPENSATION FOR ILLNESS AND INJURY: If you Say YES, then your consent in this document does not waive any of your legal rights. However, in the event of injury arising from this study, neither Old Dominion University nor the researchers are able to give you any money, insurance coverage, free medical care, or any other compensation for such injury. In the event that you suffer injury as a result of participation in any research project please contact Old Dominion University Office of Research, at (757) 683-3460.

VOLUNTARY CONSENT: When you sign this document and proceed to the following procedure, you are saying several things. You are saying that you have read this form or have had it read to you, that you are șatisfied that you understand this form, the research study, and its risks and benefits. If you have any questions later on, then the researchers should be able to answer them: Martin Smith-Rodden, Graduate researcher, at msmitrodd100@odu.edu, or (757) 393-7903. Also you can contact Dr. Ivan K. Ash, principal investigator at the ODU Human Cognition Lab, at iash@odu.edu or (757) 683-4446. If at any time you feel pressured to participate, or if you have any questions about your rights or this form, then you should call the Old Dominion University Office of Research, at 757-6833460 .

And most importantly, when you sign this document, you are indicating to the researcher, $Y E S$, that you are a volunteer and agree to participate in this study. Upon request, the researcher can give you a copy of this form for your records.
Date
Signature of Participant

\section{INVESTIGATOR'S STATEMENT}

I certify that I have explained to this subject the nature and purpose of this research, including benefits, risks, costs, and any experimental procedures. I have described the rights and protections afforded to human subjects and have done nothing to pressure, coerce, or falsely entice this subject into participating. I am aware of my obligations under state and federal laws, and promise compliance. I have answered the subject's questions and have encouraged him/her to ask additional questions at any time during the course of this study. I have witnessed the above signature(s) on this consent form. 


\section{APPENDIX S}

\section{DEBRIEFING (FOR PROJECT REACTIONS C \& D)}

The experiments you participate can serve as educational opportunities. They allow you to learn a little about how psychologists study the nature of behavior, beliefs, emotions, and cognition.

This research examines how people use verbal and visual news material in printed, and/or multimedia form in their decision-making and judgment formation - or what media psychologists call "media effects." Certain theories predict that people make judgments and decisions about certain news topics based on almost a visceral emotional reaction to the topic. These emotions - what psychologists call "affect" - are incorporated in to decisionmaking strategies called heuristics, or the simple mental shortcuts that help guide us during our often-complex daily decisions. So, the decision strategy called the affect heuristic describes a strategy in which we make these "gut-level" evaluations about the general "goodness" or "badness" of something, rapidly and automatically, during a decision. Ultimately these responses guide us in an "approach" or "withdrawal" response, either toward or away from the subject of the decision. Our research focuses on how the affect heuristic may guide us in our responses to news stories and especially news images.

The materials and topics we used in our research were stories and images U.S. support of African famine assistance and also about the U.S. military presence in Afghanistan. All materials were specially selected stories, photos, which have come out of popular media sources. These include Internet news sources, wire service organizations (for example: The Associated Press), or from the local newspaper here in Norfolk. In these experiments, the images were manipulated according to their degree of emotional arousal. Some of you were exposed to images that were highly emotionally arousing (or "graphic"), some to low-arousal images, and some of you saw no images at all (that is, you only saw a "text-only" version of the story). We are simply examining how people, on the average, respond to these different presentations of news images, holding the text constant. This helps us understand how exposure to emotionally-arousing images may impact people's opinions and judgments about a certain topic or story.

Your participation and responses to this material is invaluable to us in this important research, and we appreciate your time and participation. As you can see, it is very important that participants do not know about the content of the stories or the nature of the experiment before they arrive at the study. That is why we asked you not to discuss the experiment with anyone in the university participant pool. We ask that you continue to refrain from discussing this study with anyone who may be in any psychology classes this semester. This will help ensure that the data we collect in this study are uncontaminated and that everyone's time spent participating in this experiment was worthwhile.

If you have any questions or concerns about this study feel free to contact Martin Smith-Rodden, graduate researcher, at msmit100@odu.edu, or 757-393-7903, or you can contact Ivan K. Ash, Ph.D., the principle investigator of ODU's Human Cognition Lab, at iash@odu.edu or 757-683-4446.

Again, thank you for your participation today! 


\section{APPENDIX T}

\section{RECRUITMENT TO THE EXPERIMENT 2 PILOT STUDY}

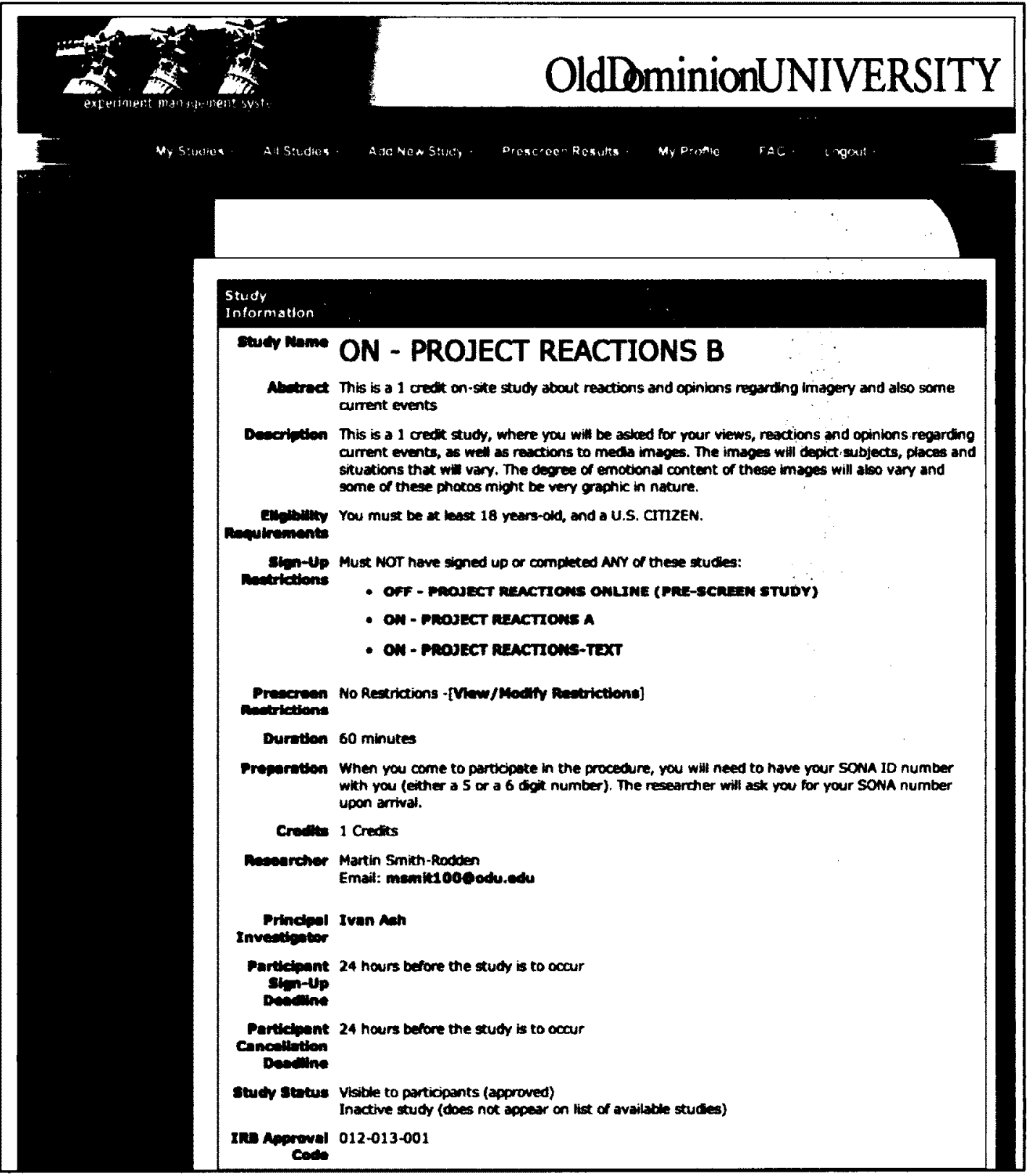




\section{APPENDIX U}

\section{STIMULI SET FOR THE FAMINE IMAGE PILOT STUDY}

Pictures of refugees and children suffering from starvation from African Famine in late 2011. Sources: The Associated Press

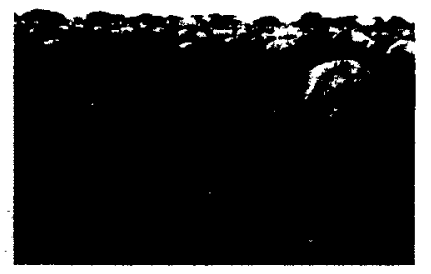

Figure U1. Image of tents in a Somalia refugee camp during famine in late 2011. (AP Photo)

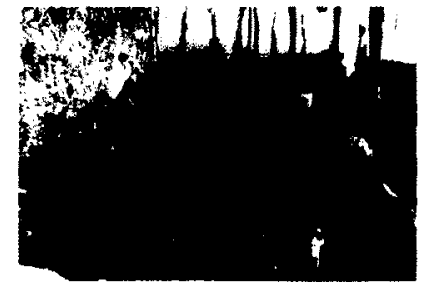

Figure U2. Image of people gathered within a shelter in a Somalia refugee camp during famine in late 2011. (AP Photo)

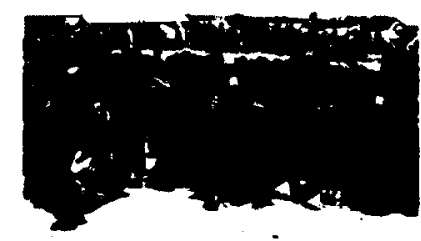

Figure U4. Image of hundreds of people gathered and sitting outside in a Somalia refugee camp during famine in late 2011. (AP Photo)

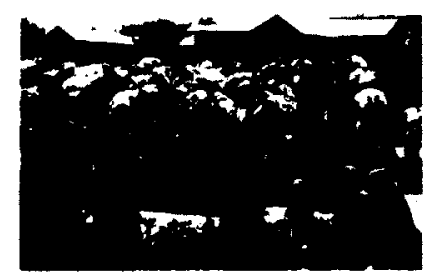

Figure U6. Image of hundreds of people gathered outside in food lines in a Somalia refugee camp during famine in late 2011. (AP Photo)

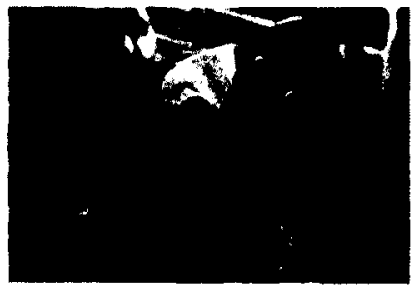

Figure U3. Image of an emaceated and crying baby held in a clinic at a Somalia refugee camp during famine in late 2011. (AP Photo)

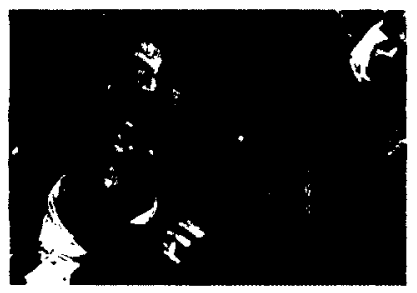

Figure US. Image of an emaceated and starving baby held in a clinic at a Somalia refugee camp during famine in late 2011. (AP Photo)

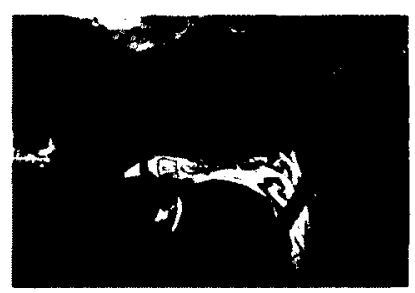

Figure U7. Image of an emaceated and starving baby staring into the camera in a clinic at a Somalia refugee camp during famine in late 2011. (AP Photo) 


\section{APPENDIX V}

\section{FAMINE RELIEF: AMERICANS FACE DIFFICULT CHOICES}

According to a report issued from two international aid organizations, thousands of people needlessly died from famine in East Africa last year, because the rich nations, such as the United States, failed to act on early warnings. Meanwhile, monitoring agencies have issued early-warnings of a new impending hunger crisis in West Africa, due to low rainfall for this year.

"We can no longer allow this grotesque situation to continue; where the world knows an emergency is coming but ignores it..." said Justin Forsyth, head of Save the Children, the second agency that issued the report.

"What nobody wants to do is throw money into a faraway black hole - nor should they feel obligated to do so..." said online commenter Mikhail Mikhailstan, in a post to a New York Times story about the report.

"No one deserves to starve to death," responded a commenter named "Tara" from Brooklyn.

With another impending famine, agencies say that unless countries like the U.S. react faster and more decisively, history could repeat itself. After last year's contentious election, the economy is still on the minds of many Americans, who are increasingly intolerant of spending. Whether or not the public will support famine aid to Africa is anyone's guess.

(203 words) 


\section{APPENDIX W}

\section{RECRUITMENT TO EXPERIMENT 2}

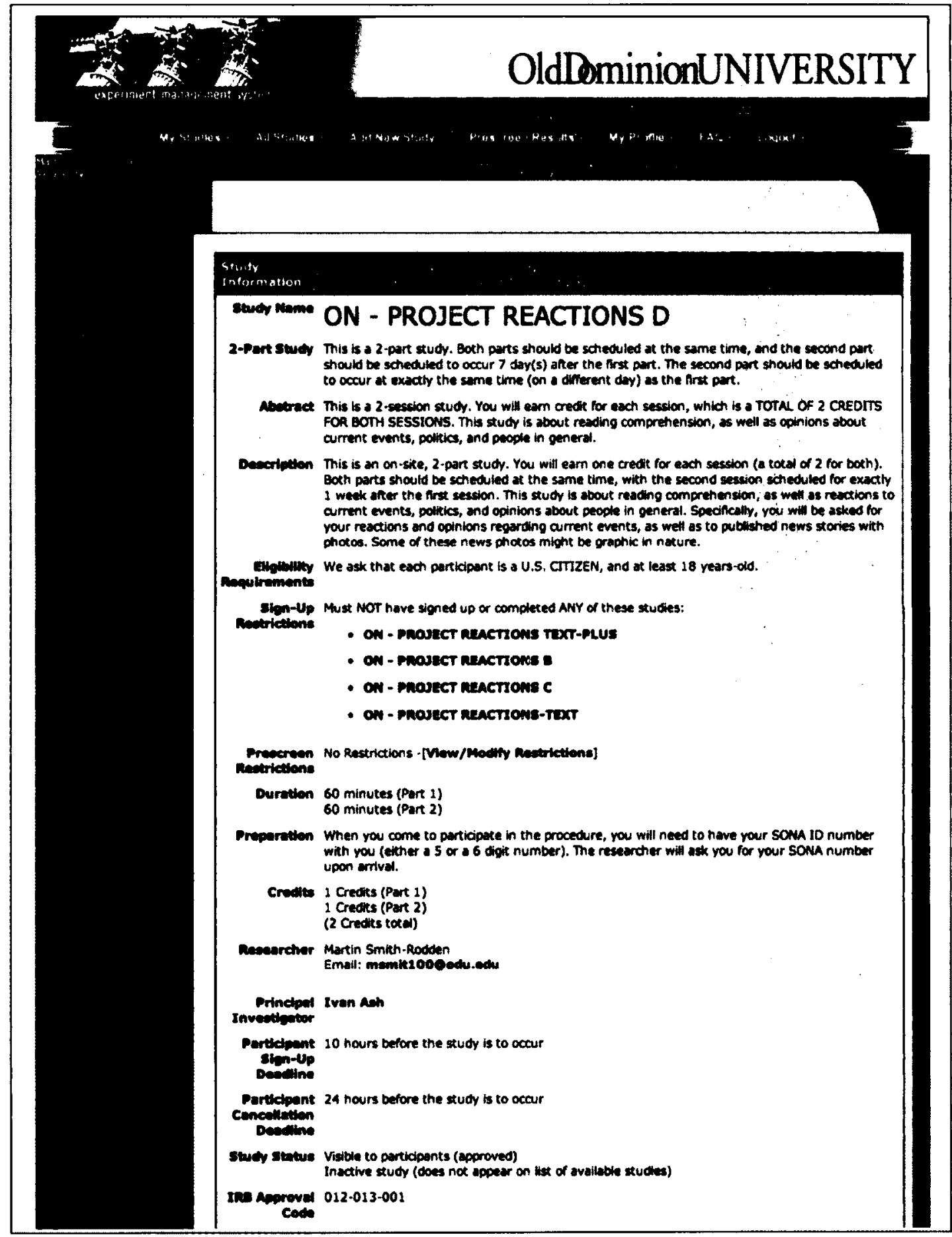




\section{APPENDIX X}

\section{SCREEN INTERFACES FOR EXPERIMENT 2 PRE-SCREENING}

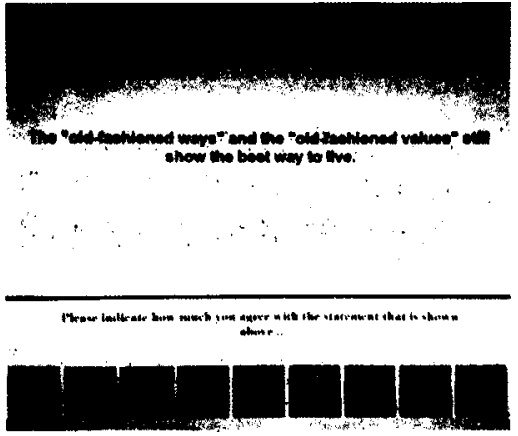

Figure X1: Example of a 9pt Likert item.

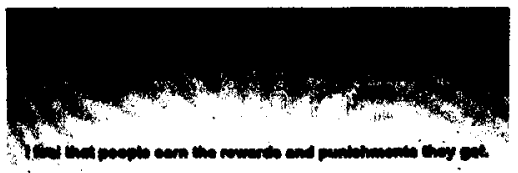

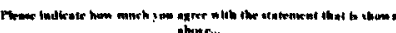

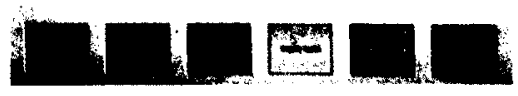

Figure X3: Example of a 6pt Likert item.

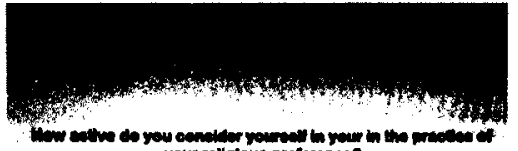

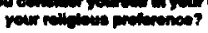

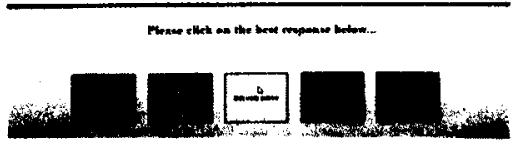

Figure X2: Example of multiple choice answer buttons.

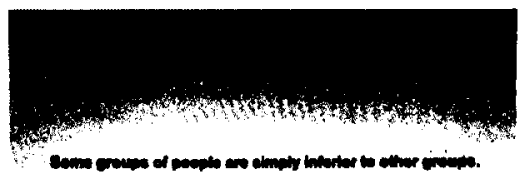

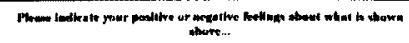

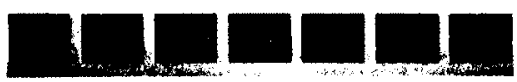

Figure X4: Example of 7pt Likert item.

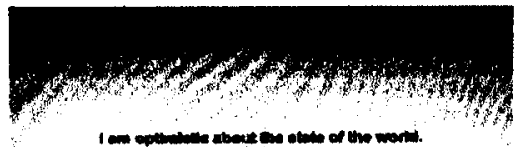

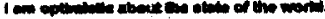

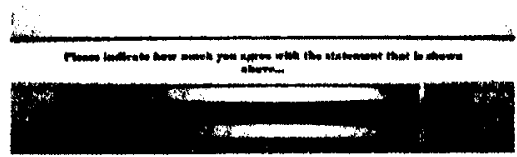

Figure XS: Example of item with an $81 \mathrm{pt}$ Likert response bar. 


\section{APPENDIX Y}

\section{TRAINING VIDEO FOR PRESCREENING PROCEDURE}

Running time: 4:47. To view, go to LINK: https://vimeo.com/56515326

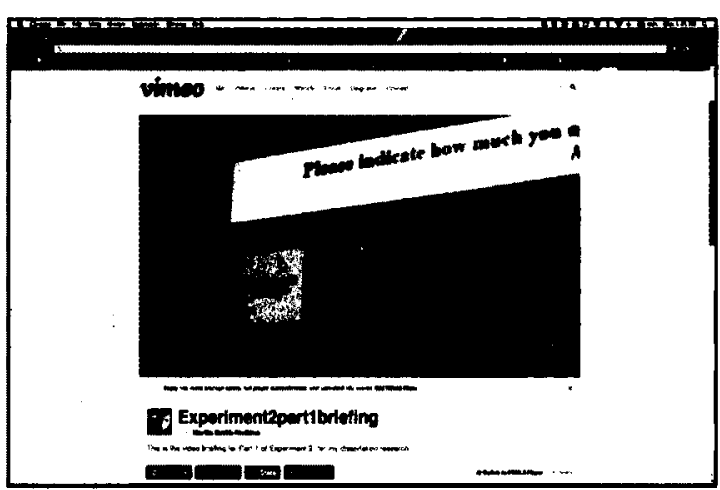

Figure Yl. Framegrab from training video.

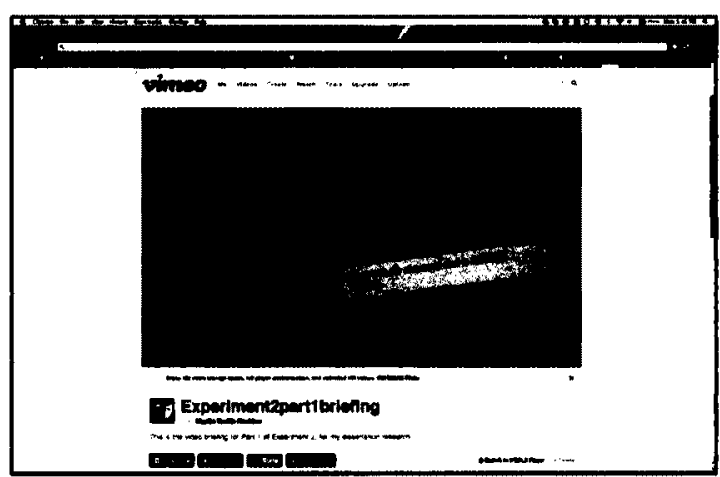

Figure Y2. Framegrab from training video.

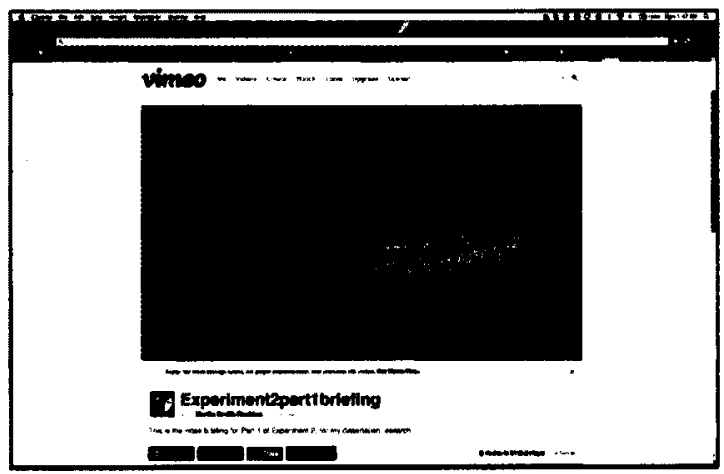

Figure Y3. Framegrab from training video. 


\section{APPENDIX Z}

\section{ATTITUDES TOWARD CHARITABLE ORGANIZATIONS (ACO, WEBB, ET AL., 2000)}

1. The money given to charities goes for good causes.

2. Much of the money donated to charity is wasted. *

3. My image of charitable organizations is positive.

4. Charitable organizations have been quite successful in helping the needy.

5. Charity organizations perform a useful function for society.

* Reverse scored 
APPENDIX AA

ATTITUDES TOWARD HELPING OTHERS

(AHO, WEBB, ET AL., 2000)

1. Helping troubled people with their problems is very important to me.

2. People should be willing to help others who are less fortunate.

3. People should be more charitable toward others in society.

4. People in need should receive support from others. 


\section{VITA}

\section{CURRICULUM VITAE}

Martin Daniel Smith-Rodden

1731 Barron Street

Portsmouth, VA. 23704

\section{EDUCATION BACKGROUND}

Virginia Wesleyan College

Degree: Bachelor of Arts, cum laude,

May 2003

Major: Social Sciences/Sociology concentration

Old Dominion University

Degree: Masters of Science Degree, Psychology

May 2010

Current program: Applied Experimental Psychology Program (Ph.D)

Anticipated date of degree completion: December 2013

Old Dominion University

Department of Psychology

Mills Godwin Building

Norfolk, VA 23529-026

\section{RESEARCH INTERESTS}

Social Cognition, Decision Making, Judgments of Trust and Distrust, The Hindsight Bias effect, Biasing and Influence Factors resulting from Exposure to Media Imagery, Social Stigma, Implicit Cognition.

\section{THESIS}

Smith-Rodden, M. \& Ash, I. K. Trust judgments and the hindsight bias effect. Old Dominion University (Defended, December 2009, M.S. in May 2010).

\section{PUBLICATIONS}

Smith-Rodden, M. \& Ash, I. K. (2012) Investigating the psychological effects of news imagery: A case for evidence-based decision making and practices. Visual Communications Quarterly, 19:1, 20-32 